Florida International University FIU Digital Commons

FIU Electronic Theses and Dissertations

University Graduate School

3-26-2007

\title{
Analysis and properties of carotenoids in vivo and in vitro
}

Yisi Cao

Florida International University

DOI: $10.25148 /$ etd.FI14052562

Follow this and additional works at: https://digitalcommons.fiu.edu/etd

Cart of the Chemistry Commons

\section{Recommended Citation}

Cao, Yisi, "Analysis and properties of carotenoids in vivo and in vitro" (2007). FIU Electronic Theses and Dissertations. 2033.

https://digitalcommons.fiu.edu/etd/2033

This work is brought to you for free and open access by the University Graduate School at FIU Digital Commons. It has been accepted for inclusion in FIU Electronic Theses and Dissertations by an authorized administrator of FIU Digital Commons. For more information, please contact dcc@fiu.edu. 
FLORIDA INTERNATIONAL UNIVERSITY

Miami, Florida

ANALYSIS AND PROPERTIES OF CAROTENOIDS

IN VIVO AND IN VITRO

A thesis submitted in partial fulfillment of the

requirements for the degree of

MASTER OF SCIENCE

in

CHEMISTRY

by

Yisi Cao

2007 
To: Interim Dean Mark Szuchman

College of Arts and Sciences

This thesis, written by Yisi Cao, and entitled Analysis and Properties of Carotenoids in vivo and in vitro, having been approved in respect to style and intellectual content, is referred to you for judgment.

We have read this thesis and recommend that it be approved.

Yong Cai

Kenneth G. Furton

John T. Landrum, Major Professor

Date of Defense: March 26, 2007

The thesis of Yisi Cao is approved.

Interim Dean Mark Szuchman

College of Arts and Sciences

Dean George Walker University Graduate School

Florida International University, 2007 


\section{DEDICATION}

I would like to dedicate this thesis to my parents for their constant love, understanding and support of my education and for being a source of encouragement to me in all aspects of my life. 


\section{ACKNOWLEDGMENTS}

I am grateful to Dr. Martha Neuringer from the Oregon National Primate Research Center for the project and providing the retina samples for the study. I would also like to extend my sincere thanks to Dr. Richard A. Bone, Ms. Francesca AlvarezCalderon, and the rest of the research team of the Department of Chemistry and Biochemistry for their help and encouragement. I am also grateful to Dr. Xiaotang Wang for the NMR analysis, and Dr. Paulette Johnson for her statistical assistance.

I wish to express my sincere gratitude to the members of my committee: Dr. Yong Cai, Dr. Kenneth G. Furton, and Dr. John T. Landrum for their support, patience, and direction. Their love and concern for my academic pursuits and my general wellbeing has been most appreciated.

Finally, I would like to extend my heartfelt appreciation to my major professor, Dr. John T. Landrum, for his invaluable contributions and encouragement in helping me attain my goal. Thanks for your confidence in my research ability and for the great learning experience. 


\author{
ABSTRACT OF THE THESIS \\ ANALYSIS AND PROPERTIES OF \\ CAROTENOIDS IN VIVO AND IN VITRO \\ by \\ Yisi Cao \\ Florida International University, 2007 \\ Miami, Florida \\ Professor John T. Landrum, Major Professor
}

The purpose of this study was to develop a deeper understanding of the nature of carotenoid metabolism in the human and primate retina. We have sought to do this from two perspectives (1) through preparation and study of a carotenoid diketone that is a candidate metabolic product and (2) through measurement of the carotenoid distribution in the retinas of neonatal macaques.

In this thesis we report the synthesis, purification, and characterization of the product using HPLC, UV/Vis, MS, ${ }^{1} \mathrm{H}-\mathrm{NMR}$. The data obtained are all consistent with the proposed $\beta, \beta$-carotene-3,3'-dione.

There has been no thorough study of the development of the macular pigment during the earliest stages of life immediately following birth. In this study 30 macaque retinas ranging from 148 days of gestation to 15 years in age were analyzed. The amounts of the carotenoids, lutein, R,R-zeaxanthin, and meso-zeaxanthin were determined using C18 reversed-phase column and chiral, normal-phase column HPLC. 
INTRODUCTION

1. Structure and Properties............................................................. 1

2. Biological Functions ................................................................... 7

II

THE INTERMEDIATE PRODUCT FORMED BY

REDUCTION OF RHODOXANTHIN ......................................... 16

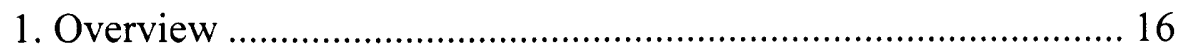

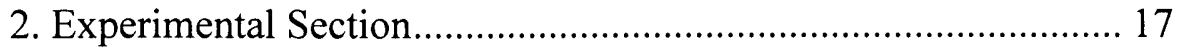

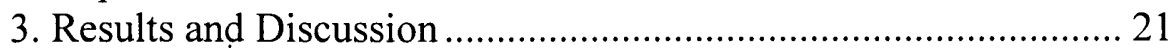

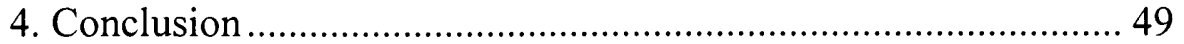

III MEASUREMENT OF THE CAROTENOIDS

STEREOISOMERS IN THE NON-HUMAN PRIMATE

RETINA, NEONATAL RETINA AS A FUNCTION OF

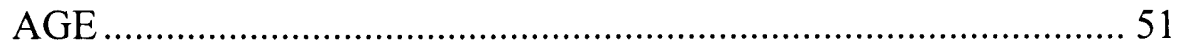

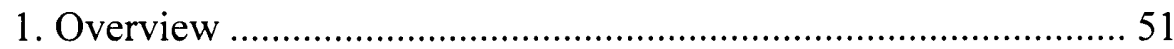

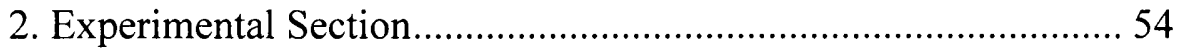

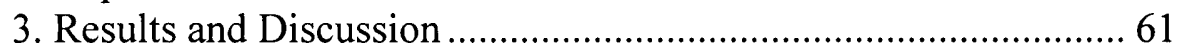

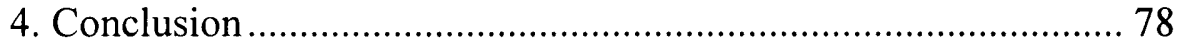

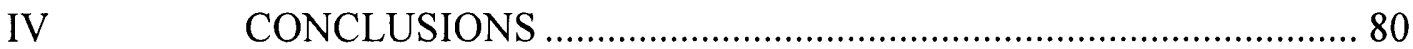

1. Identification of $\beta, \beta$-carotene-3,3'-dione ................................... 80

2. Changes in Carotenoid Stereoisomers in the Non -human Primate Retina with Age ............................................. 81

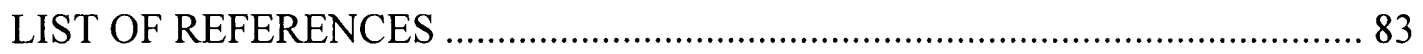




\section{LIST OF TABLES}

TABLE

PAGE

Table 1.1

The ratio of distribution of lutein and zeaxanthin in human retina varies with distance from the center of the retina.

Table 1.2 The amounts of carotenoids found in the macular in the first decade of life.

Table 2.1

Experimental ${ }^{1} \mathrm{H}-\mathrm{NMR}$ data and literature values for zeaxanthin

Table 2.2 Experimental $400 \mathrm{~Hz}{ }^{1} \mathrm{H}-\mathrm{NMR}$ data and literature data of rhodoxanthin

Table 2.3 Experimental ${ }^{1}$ H-NMR data of intermediate reduction of Rhodoxanthin.

Table 2.4 Experimental ${ }^{1} \mathrm{H}-\mathrm{NMR}$ data and literature data of oxo -lutein.

Table 2.5

Chemical shifts, integration, and assignments of different hydrogens in the intermediate reduction of rhodoxanthin

Table 3.1 Resolution of zeaxanthin stereoisomers as a function of the solvent composition.

Table 3.2 Concentration of lutein (L), zeaxanthin (Z), 3R,3'R -zeaxanthin (RRZ), meso-zeaxanthin (RSZ) and 3S,3'S -zeaxanthin (SSZ) in the inner, medial and outer regions from 26 monkey.

Table 3.3.1 Mean $( \pm \mathrm{SD})$ carotenoid concentrations in retina sections,

Table 3.3.2 Mean $( \pm \mathrm{SD})$ carotenoid concentrations in retina sections, $4 \mathrm{~mm}$ and $8 \mathrm{~mm}$....

Table 3.3.3 Mean $( \pm \mathrm{SD})$ carotenoid concentrations in retina sections, $2 \mathrm{~mm}$ and $8 \mathrm{~mm}$.

Table 3.4

Mean $( \pm$ SD) between carotenoid concentrations at new born and adult retinas. 


\section{LIST OF FIGURES}

FIGURE

Figure 1.1

The structure of lycopene 2

Figure 1.2

The structure of $\beta, \beta$-Carotene

2

Figure 1.3 The general scheme process the end-group cyclizations of Carotenoids.

Figure 1.4

The structure of zeaxanthin, 3,3'-dihydroxy- $\beta, \beta$

-carotene, processes the same end-group ring type 3

Figure 1.5

The structure of 3,3 '-dihydroxy- $\beta, \varepsilon$-carotene, processes

2 different end group ring types

Figure 1.6

These chemical structures show 3 zeaxanthin

stereoisomers

Figure 1.7 These chemical structures show 8 lutein stereoisomers in nature

Figure 1.8 The structures of several carotenoid commonly found in the biological systems. 8

Figure 1.9

The chemical structure of oxo-lutein. 13

Figure 1.10

The chemical structure of oxo-zeaxanthin.

Figure 1.11 Possible reactions leading to oxidation products of lutein and zeaxanthin...

Figure 1.12 The tautomeric relationship between $\beta$ - and $\varepsilon$-ring structures.

Figure 2.1 Possible structure of intermediate formed during the reduction of rhodoxanthin . 16

Figure 2.2 Procedure for the synthesis of zeaxanthin stereoisomers 23

Figure 2.3 Lutein and zeaxanthin detected using HPLC System 1. Lutein retention time $=11.75 \mathrm{~min}$, zeaxanthin retention time $=12.90 \mathrm{~min}$. 
Figure 2.4 UV/Visible spectrum of zeaxanthin in EtOH.

$\lambda_{\max }=452 \mathrm{~nm}, \mathrm{III} / \mathrm{II}=28 \%$.

Figure 2.5

The APCI ${ }^{+}$mass spectrum of zeaxanthin showing the principle ion $[\mathrm{M}+\mathrm{H}]+=569 \mathrm{~m} / \mathrm{z}$, and the fragment produced by loss of $\mathrm{H}_{2} \mathrm{O}[\mathrm{M}+\mathrm{H}-18]=551 \mathrm{~m} / \mathrm{z}$.

Figure 2.6

The ${ }^{1} \mathrm{H}-\mathrm{NMR}$ of zeaxanthin obtained in $\mathrm{CDCl}_{3}$

Figure 2.7

The chemical structure of ionone ring on zeaxanthin

Figure 2.8

Partial synthesis of rhodoxanthin involves the loss of 6 electrons...

Figure 2.9

The product mixture resulting from reaction of zeaxanthin and $\mathrm{MnO}_{2}$ detected with HPLC system 1

Figure 2.10

TLC showing separation between rhodoxanthin and the rest of the reaction by-products

Figure 2.11

Purified rhodoxanthin from TLC

Figure 2.12

$\mathrm{UV} /$ Visible spectrum of Rhodoxanthin in EtOH, $\lambda_{\max }=490 \mathrm{~nm}$

Figure $2.13 \quad \mathrm{The} \mathrm{APCI}^{+}$mass spectrum of rhodoxanthin. $[\mathrm{M}+\mathrm{H}]^{+}=563 \mathrm{~m} / \mathrm{z}$ 33

Figure 2.14

${ }^{\prime} \mathrm{H}-\mathrm{NMR}$ of rhodoxanthin obtained in $\mathrm{CDCl}_{3}, 400 \mathrm{MHz}$ 34

Figure 2.15

IR spectrum of rhodoxanthin 35

Figure 2.16

Oxidation reaction of zeaxanthin and the structures of all-trans rhodoxanthin and its 6,6'-di-cis, 6 -cis isomers 36

Figure 2.17 The possible candidates for the reduction product formed by the reaction of rhodoxanthin with $\mathrm{Zn} / \mathrm{HOAc}$

Figure 2.18

HPLC of product mixture formed by reduction of rhodoxanthin with $\mathrm{Zn} / \mathrm{HOAc}$

Figure 2.19 Purified compound 1 from reduction of rhodoxanthin with $\mathrm{Zn} / \mathrm{HOAc}$ (system 2) 
Figure 2.20 UV/Visible spectrum of compound $1 . \lambda_{\max }=450 \mathrm{~nm}$.

$\mathrm{III} / \mathrm{II}=50 \%$

Figure 2.21 The $\mathrm{APCI}^{+}$mass spectrum of the reduction of

rhodoxanthin

Figure 2.22 ${ }^{1} \mathrm{H}-\mathrm{NMR}$ of the compound 1 obtained in $\mathrm{CDCl}_{3}$, $400 \mathrm{MHz}$

Figure 2.23

IR of the compound 1

Figure 2.24

${ }^{1} \mathrm{H}-\mathrm{NMR}$ of oxo-lutein ( $\varepsilon$-ring) obtained in $\mathrm{CDCl}_{3}$, $400 \mathrm{MHz}$ 46

Figure 2.25

The chemical structure of $\beta$-ring and $\varepsilon$-ring 48

Figure 2.26

The elucidated structure of compound 1 50

Figure 3.1

The chemical structure of zeaxanthin, $A,(\beta, \beta$-carotene

$-3,3^{\prime}$ '-diol) and lutein, $B,(\beta, \varepsilon$-carotene-3,3'-diol) are shown above

Figure 3.2

The three stereoisomers of zeaxanthin $3 R, 3^{\prime} R-\beta, \beta-$ carotene-3,3'-diol, 3S,3'S- $\beta, \beta$-carotene-3,3'-diol, and $3 \mathrm{R}, 3$ 'S- $\beta, \beta$-carotene-3,3'-diol 53

Figure 3.3

A view of a retina showing the sectioning. The retina was sectioned using punches that were 2,4 , and $8 \mathrm{~mm}$ in diameter......

Figure 3.4 The chemical structure of monopropyl lutein, 3-hydroxy -3 '-propoxy $\beta, \varepsilon$-carotene 56

Figure 3.5

The chromatogram showing the separation of a sample which also contained a small amount of lutein. 58

Figure 3.6

Calculation of the resolution of peaks in the chiral column chromatography 60

Figure 3.7

An example chromatogram showing the carotenoids from a primate retina using a reversed-phase chromatography. Peak 1, retinal; Peak 2, lutein; Peak 3, zeaxanthin; Peak 4, oxo-lutein; Peak 5, cis isomer; IS, internal standard, mono-propyl lutein and its internal standard. 
Figure 3.8 Lutein and zeaxanthin standards in reversed-phase chromatogram

Figure 3.9 HPLC chromatograms, obtained with a chiral normal -phase column of macular zeaxanthin A from analysis of single neonate retina. and $\mathrm{B}$ from anaiysis of a single adult primate retina. In order of elution, the peaks are (3S,3'S)-zeaxanthin, meso-zeaxanthin, zeaxanthin, and lutein 64

Figure 3.10

HPLC chromatograms obtained with a reversed-phase column of carotenoids. These were obtained from the three different regions of a single primate retina. In order of elution, the carotenoids are lutein, zeaxanthin, and internal standard.

Figure 3.1! HPLC chromatograms obtained with a chirai, norma! -phase column of macular zeaxanthin. These were obtained from the three different regions of a single primate retina, A) inner, B) medial, and C) outer retinal sections

Figure 3.12 The ratio of meso-zeaxanthin to lutein (vertical) and zeaxanthin to lutein (horizontal) for different sections of retina tissue.

Figure 3.13 Effect of age on the amounts of for L, RSZ, and RRZ in neonate primate retinas. 75

Figure 3.14 Effect of age on the $\mathrm{Z} / \mathrm{L}$. and RSZ/L, ratio in neonate retinas 76

Figure 3.15 Effect of age on the total mass of xanthophylls in new born and adult primate retinas

Figure 3.16

Effect of age on the total mass of the zeaxanthin/lutein ratio between new born and adult primate retinas 


\section{Chapter I INTRODUCTION}

Carotenoids are one class natural pigments and are widely found in many fruits, vegetables, and flowers, ${ }^{1,2}$ including oranges, pineapples, carrots, tomatoes, sunflowers, and orchids. Many animals also have carotenoids in their skin, feathers, serum, fatty tissue, or retinas. Examples of animals that are noted for their carotenoid coloration include birds, insects, fish, and crustaceans. Although carotenoids are most often associated with higher plants and animals, they are also commonly found in microorganisms, such as algae and bacteria. Somewhat more than 600 different carotenoids have been isolated from nature sources. Each year new carotenoids are identified. ${ }^{3,4}$ Carotenoids can be synthesized in nature only by higher plants, algae, and microorganisms. Although animals are incapable of synthesizing carotenoids, they obtain carotenoids in their diet. About 50 different carotenoids are known to be absorbed from the diet and metabolized by humans. ${ }^{5}$

\section{Structure and Properties}

Carotenoids are defined by their chemical structures. The majority of carotenoids are comprised from a 40-carbon isoprenoid structure, which can be considered the skeleton of the molecule. Lycopene which is formed biosynthetically from phytoene is the precursor to virtually all of the common $\mathrm{C}_{40}$ carotenoids, Figure 1.1. The $\mathrm{C}_{9}$ endgroups of carotenoids may have several different structures. The end-groups may be acyclic $\mathrm{C}_{9}$ alkenes, e.g. lycopene. Also it can be terminated by the cyclic end-groups containing $\mathrm{C}_{5}$ or $\mathrm{C}_{6}$ rings and these may be elaborated with oxygen-containing functional groups. End-groups of carotenoids are typically 6 -membered rings. $\beta$-carotene, shown below, Figure 1.2, is generally considered representative of the carotenoid family 
possessing $\mathrm{C}_{6}$ end-group rings. $\beta$-carotene was $2 \beta$-rings but carotenoids with $\varepsilon$ - and $\gamma$ ring structures are also known, see Figure 1.3. These different kinds of end-group cyclization are now known to be carried out by different enzymes. Both lycopene $\beta$ cyclase and lycopene $\varepsilon$-cyclase are important examples, see Figure $1.3{ }^{6}$ But there is no report of biochemical studies on the formation of the (6S)- $\gamma$ end group. ${ }^{6}$ The oxygencontaining carotenoids can be alcohols, aldehydes, or ketones. Lycopene, $\beta$-carotene, and the xanthophylls, zeaxanthin and lutein, are the most abundant and characteristic carotenoids found in animals because of their high concentrations in common dietary plants. ${ }^{7,8,9}$

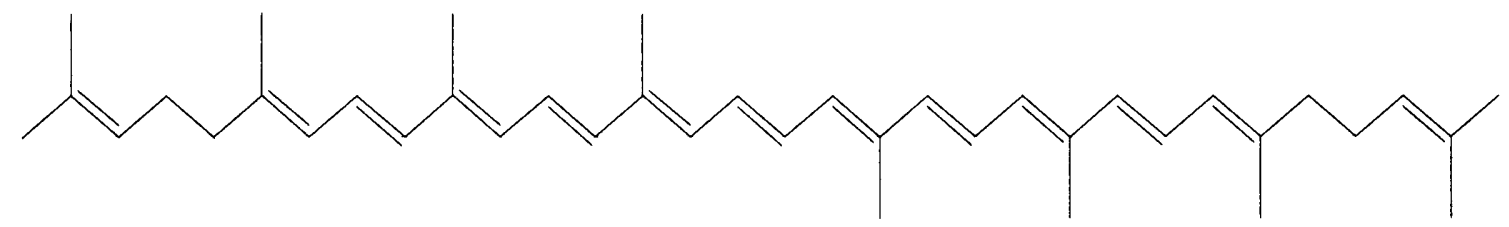

Figure 1.1 The structure of lycopene

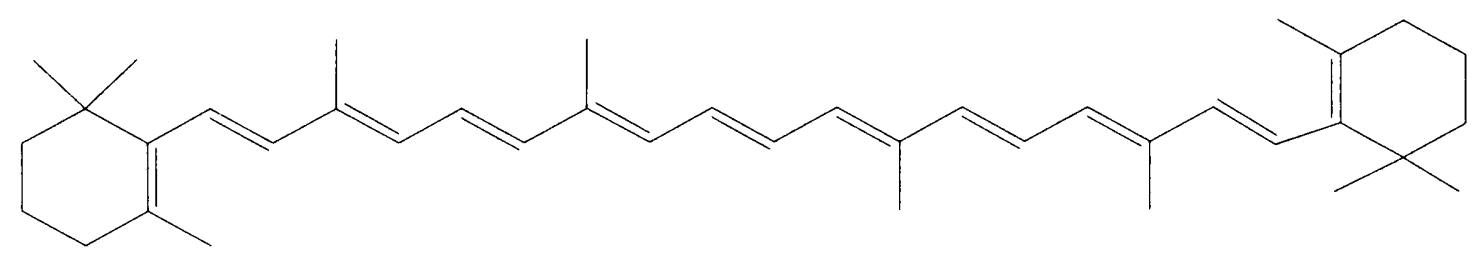

Figure 1.2 The structure of $\beta, \beta-$ Carotene 
$\mathrm{H}^{+}$

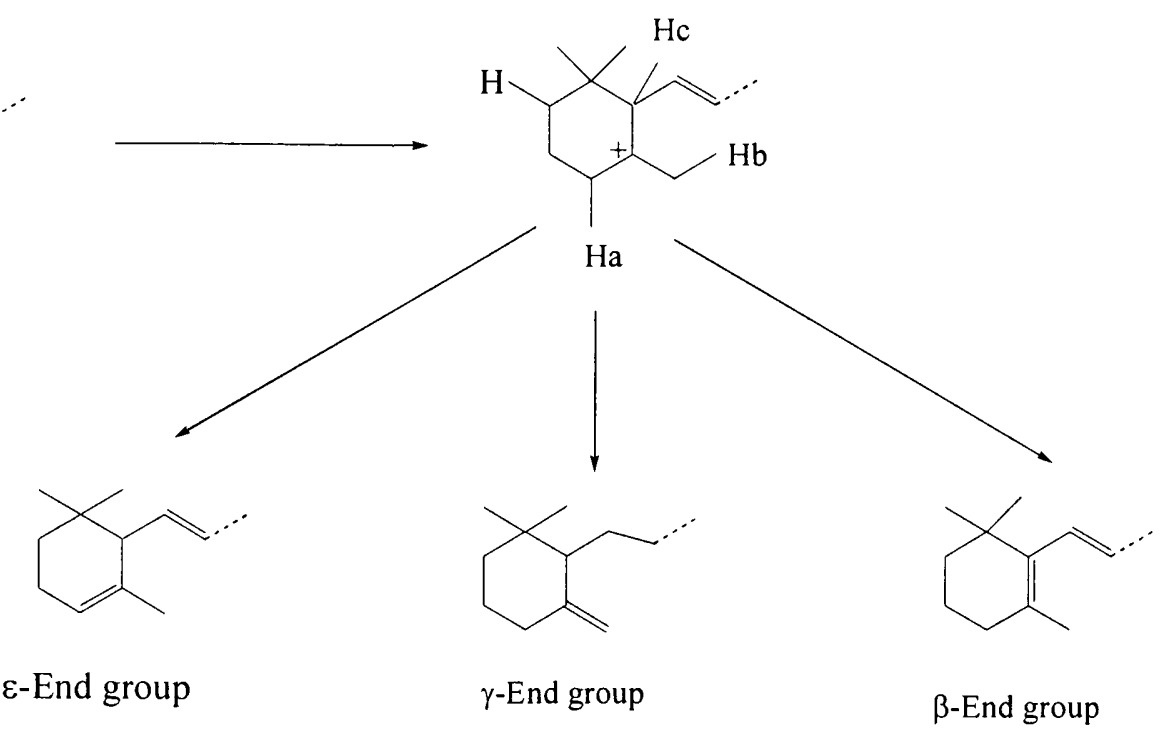

Figure 1.3 The general scheme process the end-group cyclizations of carotenoids

The hydrocarbon carotenoids are known as carotenes, while carotenes which contain one or more polar functional groups are named xanthophylls. Lutein and zeaxanthin, the major yellow pigments in higher plants, are the most common xanthophylls found in nature. Lutein and zeaxanthin are central to the body of research to be described here. Their structures are seen in Figures 1.4 and 1.5. Lutein is a micronutrient, and is found in many fruits and vegetables in our diet. Zeaxanthin is a yellow pigment and is widespread in nature. It occurs in maize, algae, and bacteria. ${ }^{4}$ Both of them are abundant carotenoids found in the animals.

$\mathrm{HO}$<smiles>CC1=C(/C=C/C(C)=C/C=C/C(C)=C/C=C/C=C(C)/C=C/C=C/C2C(C)C[C@@H](O)C[C@]2(C)I)C(C)(C)C[C@@H](O)C1</smiles>

Figure 1.4 The structure of zeaxanthin, 3,3'-dihydroxy- $\beta, \beta$-carotene, processes the same end-group ring type 
$\mathrm{HO}$

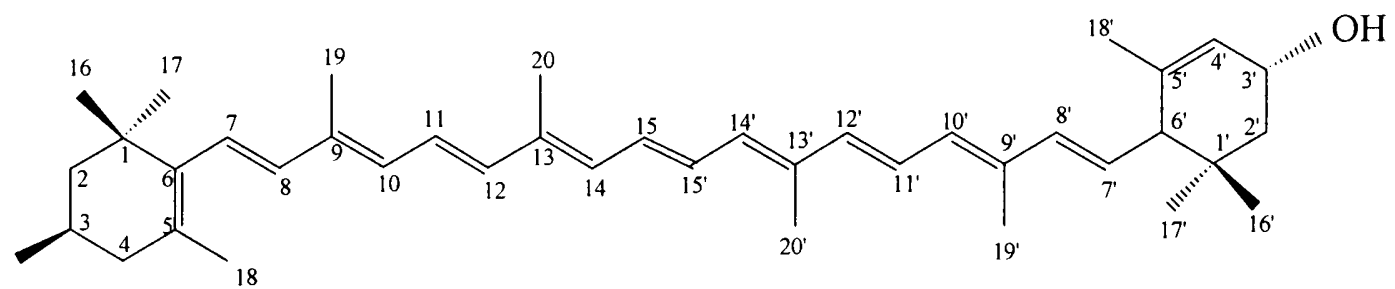

Figure 1.5 The structure of lutein, 3,3'-dihydroxy- $\beta, \varepsilon$-carotene, processes 2 different endgroup ring types

Lutein and zeaxanthin are dihydroxy-carotenoids which possess 2 ionone rings that are substituted at the 3- and 3'- carbons. Lutein and zeaxanthin are constitutional isomers and the only difference is based on the position of the double bond in one of the ionone rings. Zeaxanthin has $\beta, \beta$ end-groups while lutein has one $\beta$-ring and one $\varepsilon$-ring. The 3- and 3'-carbons of the ionone rings are stereocenters and both lutein and zeaxanthin exist in multiple stereoisomeric forms.

In zeaxanthin, Figure 1.5 , the ionone rings are both $\beta$ rings. The $\beta$-ionone ring double bond is placed between the $\mathrm{C} 5$ and $\mathrm{C} 6$ carbons. The ionone ring systems are substituted by hydroxyl groups at 3- and 3'- carbons. Zeaxanthin possesses two stereocenters and consequently three stereoisomers exist; all three occur in nature. ${ }^{11}$ They are 3R,3'R- $\beta, \beta$-carotene-3,3'-diol (RRZ), 3R,3'S- $\beta, \beta$-carotene-3,3'-diol (RSZ), and 3S,3'S- $\beta, \beta$-carotene-3,3'-diol (SSZ), see Figure 1.6. The configuration of RRZ is found in most common animals and higher plants. ${ }^{10}$ In the retina, RRS and RSZ are present in nearly equal amounts. SSZ is also present, but at very low levels. ${ }^{12}$ 


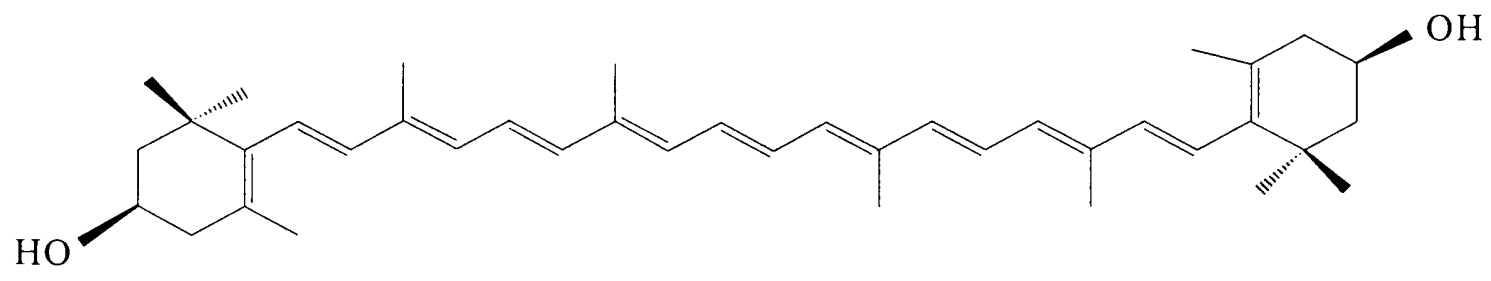

(3R, 3'R)- $\beta, \beta$-carotene-3,3'-diol

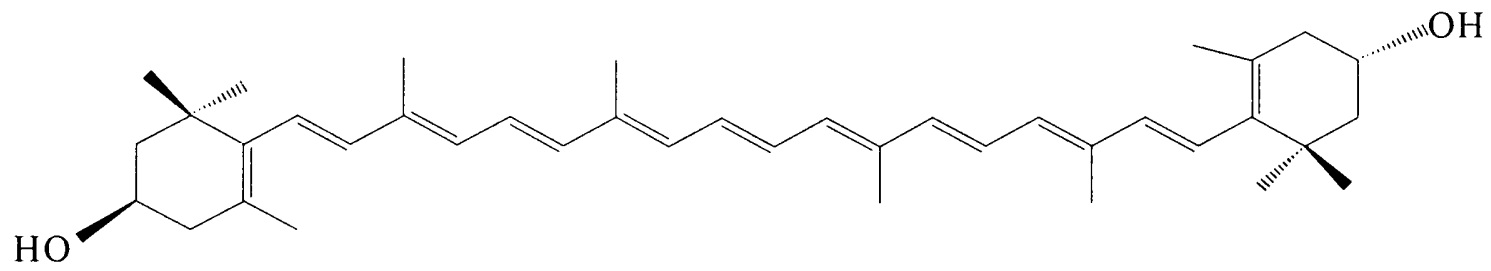

(3R,3'S)- $\beta, \beta$-carotene-3,3'-diol

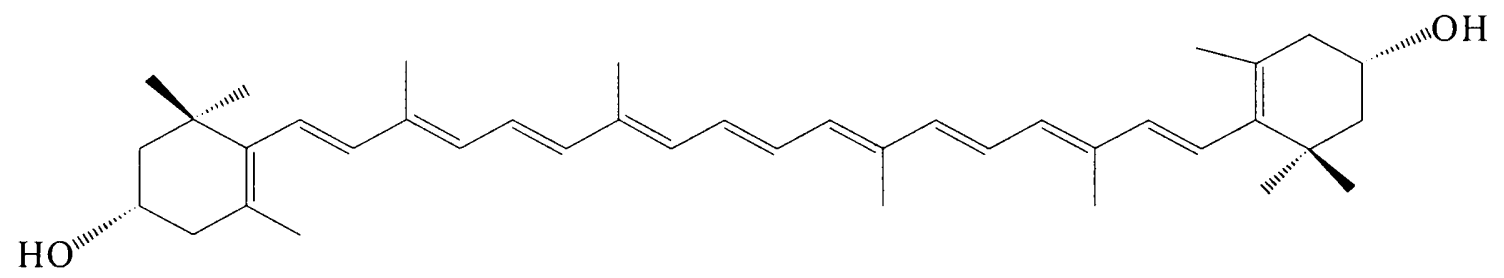

(3S, 3'S)- $\beta, \beta$-carotene-3,3'-diol

Figure 1.6 These chemical structures show 3 zeaxanthin stereoisomers

Lutein, see Figure 1.5 , has a $\beta$-ionone ring and an $\varepsilon$-ionone ring. The presence of the hydroxyl groups on the 3-and 3'- carbons in lutein gives similar physical properties to zeaxanthin. The double bond from $\varepsilon$-ionone ring is placed on $\mathrm{C} 4$ and $\mathrm{C} 5$ and the 3'hydroxyl group is allylic. ${ }^{13}$ Lutein has three stereocenters and it is capable of forming 8 isomers, see Figure $1.7 .{ }^{14}$ However, only a single lutein stereoisomer, (3R,3'R,6'R)- $\beta, \varepsilon-$ carotene-3,3'-diol (1), is present in most higher plants. Lactucaxanthin and epilutein are present in a few species but are not major dietary carotenoids. ${ }^{14}$ 
<smiles>CC1=C[C@H](O)CC(C)(C)[C@H]1/C=C/C(C)=C/C=C/C(C)=C/C=C/C=C(C)/C=C/C=C(C)/C=C/[C@H]1C(C)=C[C@H](O)CC1(C)C</smiles>

(3R, $\left.3^{\prime} \mathrm{R}, 6^{\prime} \mathrm{R}\right)$ Lutein (1)

(3R, $3^{\prime} R, 6^{\prime} R$ )-3, $3^{\prime}$-dihydroxy- $\beta, \varepsilon$-carotene

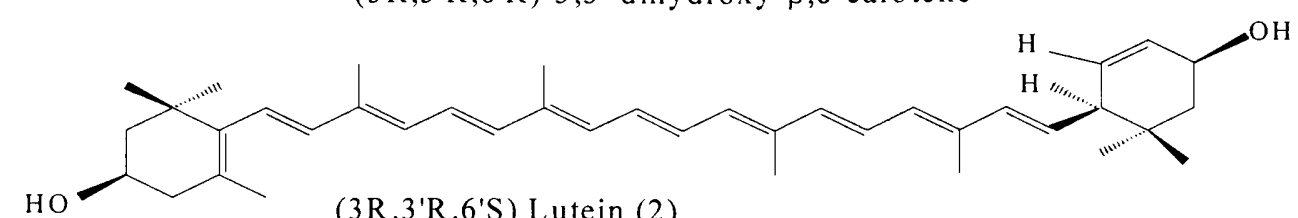

(3R, 3'R,6'S) Lutein (2)

(3R, 3'R,6'S)-3,3'-dihy droxy- $\beta, \varepsilon$-carotene

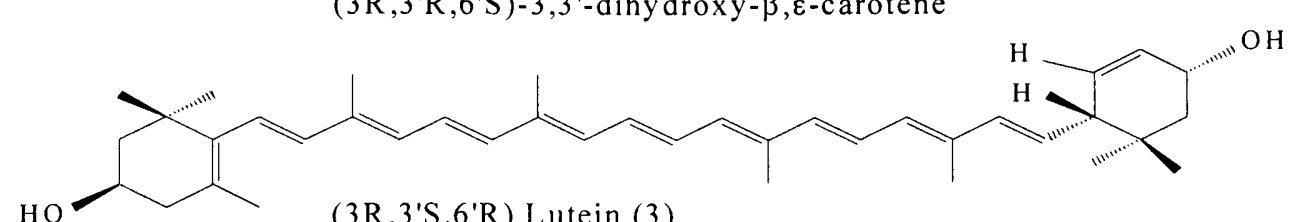

(3R, 3'S, 6'R)-3,3'-dihydroxy- $\beta, \varepsilon$-carotene

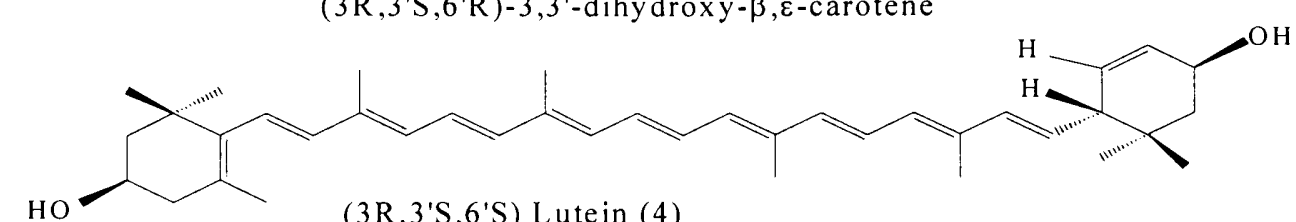

(3R, 3'S, 6'S) Lutein (4)

(3R,3'S,6'S)-3,3'-dihydroxy- $\beta, \varepsilon$-carotene

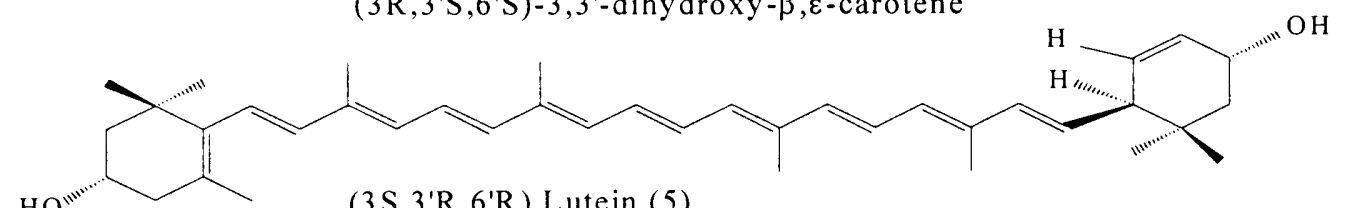

(3 $S, 3^{\prime} R, 6^{\prime} R$ ) Lutein (5)

(3S, 3'R, 6'R)-3, $3^{\prime}$-dihydroxy- $\beta, \varepsilon$-carotene

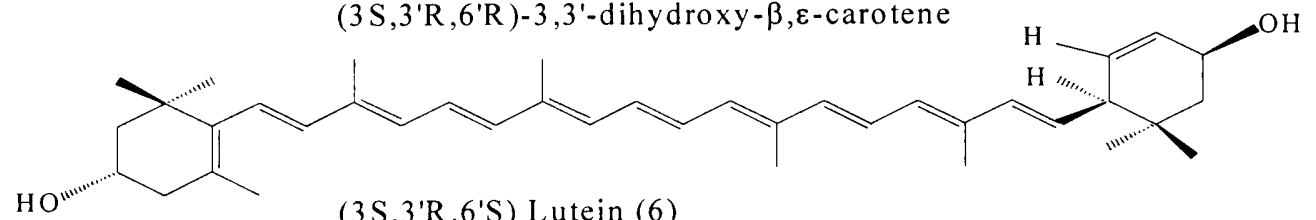

(3S, 3'R,6'S) Lutein (6)

(3S, $\left.3^{\prime} R, 6^{\prime} S\right)-3,3^{\prime}$-dihydroxy- $\beta, \varepsilon$-carotene<smiles>CC1=C[C@H](O)CC(C)(C)[C@]1(C)/C=C/C(C)=C/C=C/C(C)=C/C=C/C=C(C)/C=C/C=C(C)/C=C/C1=C(C)C[C@@H](O)CC1(C)C</smiles>

(3S, 3'S, 6'R) Lutein (7)

(3S, 3'S, 6'R)-3,3'-dihydroxy- $\beta, \varepsilon$-carotene

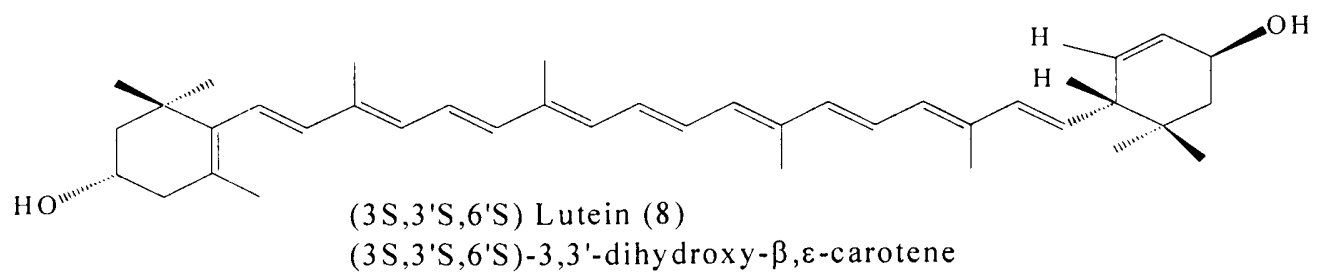

Figure 1.7 These chemical structures show 8 lutein stereoisomers in nature 


\section{Biological Functions}

The role of carotenoids in photosynthesis has been extensively studied. In photosynthetic systems, carotenoids are well known for their light-harvesting and photoprotection roles in natural system. ${ }^{15}$ One function of carotenoids is to prevent the formation of singlet oxygen and hence protect the organism from this photo-oxidation reaction. The other function of carotenoids is to act as accessory light-harvesting pigments where they function by transferring their excitation energy to bacteriochlorophyll through singlet energy transfer. It has been demonstrated that natural all-trans (E) carotenoids are involved in this process. In plants and algae, carotenoids serve as antioxidants that can be able to protect against photosensitized oxidation by quenching the excitation energy of the chlorophyll triplet state and singlet oxygen. ${ }^{16}$

Recently, interest has focused on the role of antioxidant nutrients such as vitamins $\mathrm{A}, \mathrm{C}$, and $\mathrm{E}$ and the carotenoids in the protection against oxidative processes in biological systems. ${ }^{17}$ A comparison of dietary carotenoids has revealed that only select groups of carotenoids are found in vivo. Among those most abundantly found in blood are lutein and zeaxanthin. The other carotenoids include, lycopene (1), $\alpha$-carotene (2), $\beta$ carotene (3), and other common xanthophylls including, lactucaxanthin (4), $\beta$ cryptoxanthin (5). Identified metabolites in human blood include oxo-lutein (6), epilutein (7), and . $\varepsilon, \varepsilon$-carotene-3,3'-dione (8), Figure $8 .{ }^{18,19,20}$ 
<smiles>CC(C)=CCC/C(C)=C/C=C/C(C)=C/C=C/C(C)=C/C=C/C=C(C)/C=C/C=C(C)/C=C/C=C(\C)CCC=C(C)C</smiles>

Lycopene (1)

$2,6,10,14,19,23,27,31$-octam ethyldotriaconta-

$2,6,8,10,12,14,16,18,20,22,24,26,30$-tridecaene<smiles>CC1=C(/C=C/C(C)=C/C=C/C(C)=C/C=C/C=C(C)/C=C/C=C(C)/C=C/C2=C(C)CCCC2(C)C)C(C)(C)CCC1</smiles>

$\beta$-carotene (2)<smiles>CC1=CCCC(C)(C)C1/C=C/C(C)=C/C=C/C(C)=C/C=C/C=C(C)/C=C/C=C(C)/C=C/C1=C(C)CCCC1(C)C</smiles>

$\alpha$-carotene (3)<smiles>CC1=CC(O)CC(C)(C)C1/C=C/C(C)=C/C=C/C(C)=C/C=C/C=C(C)/C=C/C=C(C)/C=C/C1C(C)=C[C@H](O)CC1(C)C</smiles>

Lactucaxanthin (4)

$\varepsilon, \varepsilon$-carotene-3,3'-diol<smiles>CC1=CC(=O)CC(C)(C)C1=C/C=C(C)/C=C/C=C(C)/C=C/C=C/C(C)=C/C=C/C(C)=C/C=C1\C(C)=CC(=O)CC1(C)C</smiles>

$\beta$-cryptoxanthin (5)

Didehydro-4,5'-retro- $\beta, \beta$-carotene-3,3'-dione<smiles>CC1=CC(=O)CC(C)(C)C1/C=C/C(C)=C/C=C/C(C)=C/C=C/C=C(C)/C=C/C=C(C)/C=C/C1=C(C)CC(O)CC1(C)C</smiles>

Oxo-lutein (6)

3 -hydroxy- $\beta, \varepsilon$-carotene-3'-one<smiles>CC1=CC(O)CC(C)(C)C1/C=C/C(C)=C/C=C/C(C)=C/C=C/C=C(C)/C=C/C=C(C)/C=C/C1=C(C)C[C@@H](O)CC1(C)C</smiles>
$\mathrm{HO}$

Epilutein (7)

(3R, 3'S,6'R) Lutein

$\mathrm{O}$<smiles>[R9]OC(=O)C(C=CC(C)=CC=CC1C(C)=CC(=C)CC1(C)C)=CC=CC=C(C)C=CC=C(C)C=CC1C(C)=CC(=O)CC1(C)C</smiles>

$\varepsilon, \varepsilon$-carotene-3,3'-dione $(8)$

Figure 1.8 The structures of several carotenoid commonly found in the biological systems 
Several studies have demonstrated that carotenoids act as antioxidants and may have significant biological functions and activities in animals and humans. For example, Bone and Landrum established that the macular pigment may play a protective role in the eye. ${ }^{21}$ The main components in the human macular pigment are lutein and zeaxanthin. ${ }^{21}$ The most important function of these carotenoids is to protect the central retina against damaging photochemical reactions owing to the absorption of blue light. Because of the short wavelength of blue light, it can induce the formation of reactive free radicals, triplet excited states, superoxide, and singlet oxygen within the retina. ${ }^{22,23}$ The absorption of blue light by the macular pigment can reduce the potential for light damage to the retina.

It is hypothesized that light-promoted damage to the retina is one of several possible factors contributing to the development of age-related macular degeneration (AMD), ${ }^{24,25}$ The disease results in degeneration of the macula, leading to the loss of central vision. As the increasing population ages, the prevalence of AMD is increasing. ${ }^{26,27}$ Strategies for prevention or delay of the onset of AMD need to be studied. Such strategies may support methods to reduce the prevalence of visual impairment and blindness among the older people.

Bone and Landrum demonstrated that lutein and zeaxanthin were the two major constituents of macular pigment in the retina. ${ }^{28}$ In 1988, Bone and Landrum investigated the distribution of zeaxanthin and lutein throughout the human retina. ${ }^{21}$ They studied the distribution of lutein and zeaxanthin from the center of the retina out to the periphery by cutting the retina into concentric rings. They demonstrated that zeaxanthin is the dominant component from the center of fovea out to $2.5 \mathrm{~mm}$, while lutein is the principal component in the peripheral retina. The ratio of lutein to zeaxanthin is shown in Table 
1.1. ${ }^{29}$ They also investigated the relationship between age and the distribution of zeaxanthin and lutein in human retina. They studied 87 donors between the ages of 0 and 95, no dependence on age was observed in the quantity of either pigment. ${ }^{21}$ For approximately $90 \%$ of the samples, zeaxanthin was dominant in the central retinas. For the remaining $10 \%$ of the samples from fetus to 2 years, lutein was the major component. The dependence on age of the xanthophyll concentration is studied in first decade samples, see Table 1.2. ${ }^{21}$ In 1991, Handelman et. al. measured the amounts of zeaxanthin and lutein in the central retinas of monkeys. ${ }^{31}$ In 1993, Bone, Landrum investigated the zeaxanthin and lutein stereoisomers in human plasma and the retina via the formation of dibenzoate derivatives. The carotenoids in retinas reveal that a unique non-dietary carotenoid, R,S-zeaxanthin, is present only in the macular pigment. ${ }^{30}$ This is mesozeaxanthin. They found only (3R,3'R)-zeaxanthin in the human blood. However, in the human retina, they found two zeaxanthin stereoisomers, (3R,3'R)- and (3R,3'S)zeaxanthin. Because no (3R,3'S)-zeaxanthin exists in human blood and it is known that humans are unable to synthesize the carotenoids, it was proposed that a chemical conversion was occurring in human eyes. The ratio of (3R,3'S)-zeaxanthin to lutein is greater in the macula relative to the periphery of the retina. ${ }^{30,32}$ Recently, Johnson, Neuringer et. al. investigated the source of meso-zeaxanthin in the monkey retina. ${ }^{32}$ Monkeys were separated into 3 groups. The first group was fed a semipurified diet containing all essential nutrients but no xanthophylls. The second group was supplemented with pure lutein and the third group with pure zeaxanthin. At the completion, carotenoids in serum, adipose tissue, and retina (central $4 \mathrm{~mm}, 8 \mathrm{~mm}$ annulus, and the peripheral retina) were determined. Monkeys fed xanthophyll-free diets had no 
lutein or zeaxanthin in serum or tissues. After lutein or zeaxanthin supplementation, serum and adipose tissue concentrations significantly increased in the supplemented groups. Both lutein and 3R,3'S-zeaxanthin were present in retinas of monkeys supplemented with lutein, with RSZ present only in the macula (central $4 \mathrm{~mm}$ ). RSZ or meso-zeaxanthin, was not present in the diet. All-trans zeaxanthin, but no RSZ, accumulated in retinas of monkeys supplemented with zeaxanthin. Their study demonstrated that lutein is the precursor of RSZ, a major component of macular pigment. The conversion of lutein to its isomer zeaxanthin in the eye is believed to take place in the central macula. ${ }^{32}$

TABLE 1.1 The ratio of distribution of lutein and zeaxanthin in human retina varies with distance from the center of the retina

\begin{tabular}{c|c}
\hline The distribution from fovea $(\mathrm{mm})$ & Ratio of lutein/zeaxanthin \\
\hline $0-0.75$ & 0.5 \\
$0.75-1.6$ & 0.73 \\
$1.6-2.5$ & 1.04 \\
$2.5-5.8$ & 1.85 \\
$5.8-8.7$ & 2.24 \\
$8.7-12.2$ & 2.22 \\
\hline
\end{tabular}

Based on previous work, it is known that the carotenoids that compose the macular pigment in the human retina increase in amount during the first few years of life and that the proportion of zeaxanthin also increases in the central retina during this time. As the age increases, more lutein $(\mathrm{L})$ must be converted to meso-zeaxanthin (RSZ). ${ }^{21}$ 
TABLE 1.2 The amounts of carotenoids found in the macular in the first decade of life

\begin{tabular}{ccc}
\hline Age (years) & Lutein + zeaxanthin (ng) & Lutein/zeaxanthin (mass ratio) \\
\hline 0 & 7 & 1.59 \\
0.4 & 4.5 & 1.25 \\
0.5 & 24.6 & 1.41 \\
0.8 & 4.8 & 1.67 \\
1.3 & 66.2 & 1.75 \\
1.6 & 41.5 & 1.24 \\
1.7 & 28.6 & 1.49 \\
3 & 25.1 & 0.67 \\
7 & 41 & 0.53 \\
9 & 27.6 & 0.87 \\
\hline
\end{tabular}

Oxidative metabolites also can be found in the retina. The amount of these oxidative carotenoids is approximately $20 \%$ of the total carotenoid concentration. The identity of these compounds has already been reported. ${ }^{21}$ These oxidized carotenoids are reported to be oxo-lutein, epilutein, and $\varepsilon, \varepsilon$-carotene-3,3'-dione. If the main function of carotenoids is to protect the biological system from the oxidative processes, then the presence of oxidation by-products of these carotenoids in the body may provide an idea of which processes may occur. The presence of oxo-lutein, meso-zeaxanthin, and epilutein, which are not commonly found among the dietary carotenoids suggest that some biochemical processes may result the metabolism of these compounds.

A possible mechanism for the formation of RSZ has been suggested involving oxidation of lutein to produce oxo-lutein followed by synthetic reduction to produce RSZ. Oxo-lutein, see Figure 1.9, contains an $\varepsilon$-ring in which the carbonyl is conjugated with the double bond. This compound may be reduced in vivo to produce RSZ. Another possible intermediate may be the oxo-zeaxanthin, 3-hydroxy- $\beta, \beta$-carotene-3'-one. Oxo- 
zeaxanthin, see Figure 1.10, might also be expected to form from the oxidation of zeaxanthin. This compound has not previously been described. In fact, there is reason to believe, based on a general knowledge of carbonyl chemistry that the $\beta, \gamma$-carbonyl structure of oxo-zeaxanthin should readily tautomerize to the $\alpha, \beta$-carbonyl structure oxolutein, see Figures 1.11 and 1.12.

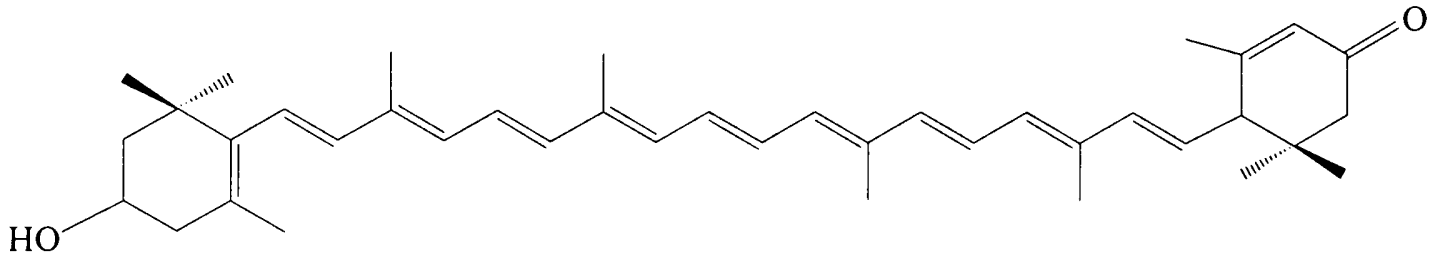

Figure 1.9 The chemical structure of oxo-lutein

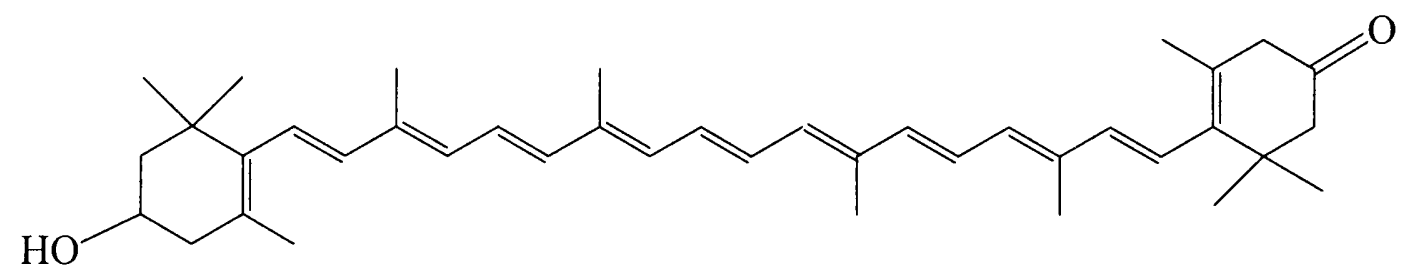

Figure 1.10 The chemical structure of oxo-zeaxanthin

During the reduction of rhodoxanthin to produce racemic zeaxanthin, an intermediate compound is produced that has at least moderate stability. It has been suggested this compound is a diketone having the $\beta, \beta$-ring structure where the doublebond at the 3 and 3 ' carbons have a $\beta, \gamma$-position relative to the carbonyl. Part of the work described here has been to characterize this intermediate and to understand the stability of carotenoids having this structure. This work will shed light on the possible reaction pathway by which meso-zeaxanthin is formed. 
<smiles>CCC=CC1C(C)=CC(O)CC1(C)C</smiles>

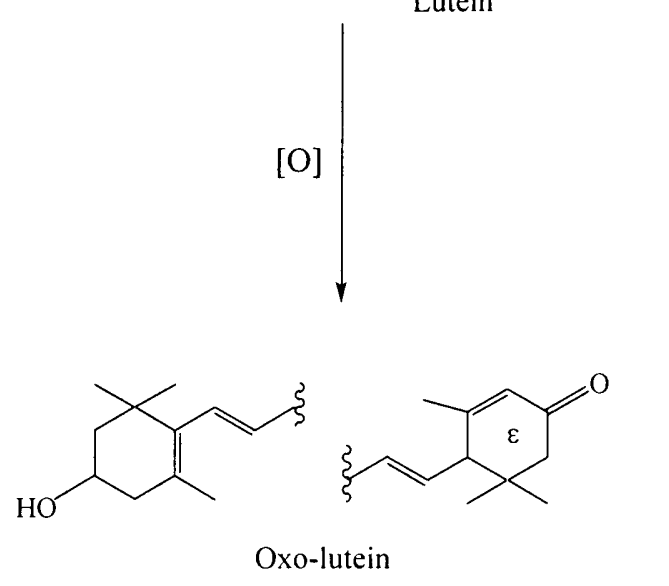

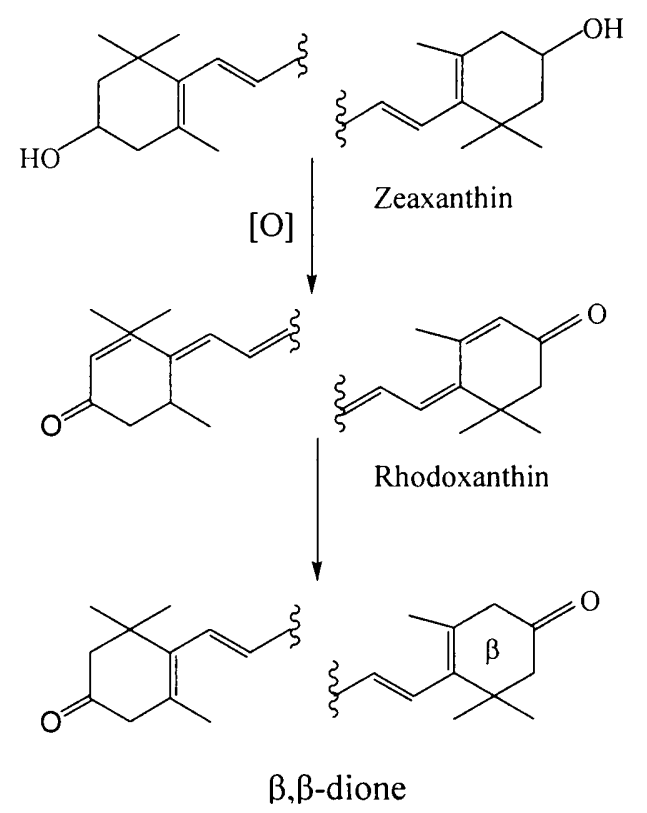

Figure 1.11 Possible reactions leading to oxidation products of lutein and zeaxanthin<smiles>[Y]C=CC1(C)C(C)C(=O)CC(C)(C)C1C</smiles>
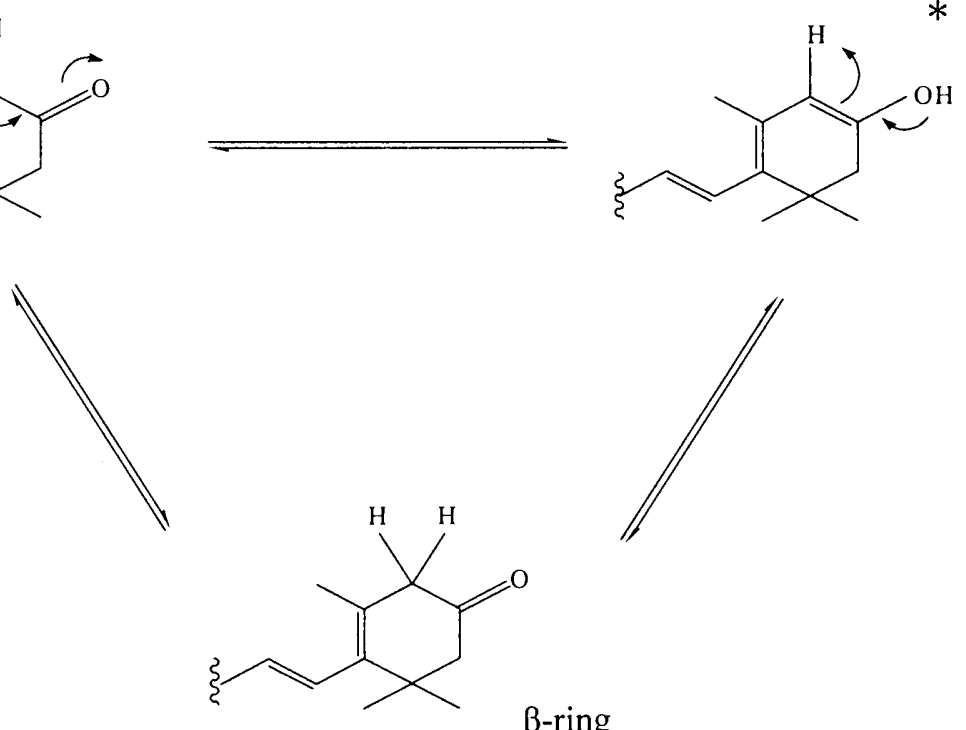

$\beta$-ring

Figure 1.12 The tautomeric relationship between $\beta$ - and $\varepsilon$-ring structures

This thesis considers two aspects of the problem of understanding the nature of the macular pigment. The first part described in Chapter II will be the elucidation of the structure of $\beta, \beta$-carotene-dione. The second part of this thesis, Chapter III, involves measurement of the carotenoid distribution in the retinas of neonatal macaques. The 
development and metabolism of the macular pigment in primate and human retinas still remains an incompletely understood process and these studies will contribute new information and serve as a basis for unraveling this physiological problem. 


\section{CHAPTER II THE INTERMEDIATE PRODUCT FORMED BY REDUCTION OF RHODOXANTHIN}

\section{Overview}

The 3,3'- $\beta, \beta$-carotene-diones were discussed in Chapter I. These compounds are hypothesized to be metabolites of zeaxanthin in biological systems. Reduction of rhodoxanthin results in the formation of the zeaxanthin stereoisomers, see Figure 2.1. During this reduction xanthophyll compounds are formed whose structures have not been unambiguously assigned. 3,3'- $\beta, \beta$-carotene-dione is a suggested intermediate formed during the 2 step reduction of rhodoxanthin to produce the zeaxanthin stereoisomers. To isolate the intermediate of this reduction, two reactions are carried out. $\mathrm{MnO}_{2}$ is employed to oxidize R,R-zeaxanthin forming rhodoxanthin, which is subsequently reduced by $\mathrm{Zn} / \mathrm{HOAc}$ to form an intermediate compound, see Figure 2.1. This intermediate is thought to be $3,3^{\prime}-\beta, \beta$-carotene-dione, compound 1 , but the possibility that it is $3,3^{\prime}-\beta, \beta-$ carotene-dione, compound 2 has not been ruled out.

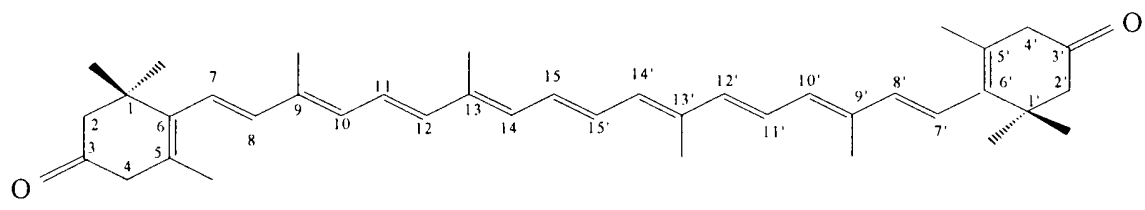

Compound 1, $\beta, \beta$-carotene-3,3'-dione

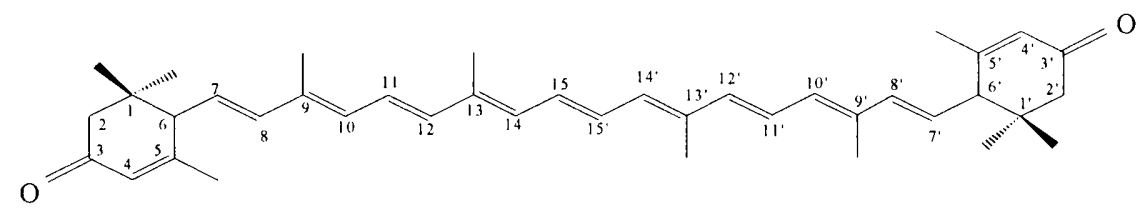

Compound $2, \varepsilon, \varepsilon$-caroten-3,3'-dione

Figure 2.1 Possible structure of intermediate formed during the reduction of rhodoxanthin 
Characterization of this intermediate product of rhodoxanthin has remained incomplete. The reduction chemistry of rhodoxanthin remains an unresolved question, the following is our work on this problem. Both analytical and spectroscopic methods, such as, IR, UV/Vis, MS, NMR, and HPLC, are employed to identify the structure of this intermediate.

\section{Experimental Section}

\subsection{Oxidation of Zeaxanthin with $\mathrm{MnO}_{2}$}

Methods similar to Entschel et al. ${ }^{33} 1959$ were used to perform the zeaxanthin oxidation reaction. All of the procedures were done in the dim light and all the containers were wrapped with aluminum foil to avoid degradation and isomerization of carotenoids.

$10 \mathrm{mg}$ zeaxanthin were dissolved in $30 \mathrm{ml}$ of dry distilled acetone to produce a saturated solution. This solution was passed through a column of $\mathrm{MnO}_{2}$ having the dimension $35 \times 5 \mathrm{~mm}$ at a flow rate of 1 minute. The reactant was characterized by a color change from yellow/orange to cherry red. The solvent was removed by rotary evaporator and the product further dried under a nitrogen stream. The product was purified by preparative thin layer chromatography (Whatman PLK 5 Silica gel $150 \AA$ Plate, $20 \times 20 \mathrm{~cm}, 1000 \mu \mathrm{m}$ ). The sample was applied to the plate as an acetone solution. After drying, the plate was eluted with a solvent mixture containing $75 \%$ hexane and $25 \%$ acetone. Rhodoxanthin product was obtained by scraping the rhodoxanthin band from the plate dissolving in $\mathrm{CH}_{2} \mathrm{Cl}_{2}$ followed by filtration. The solvent was removed by rotary evaporator and the pure rhodoxanthin was further dried under a nitrogen stream. Samples were stored for further use at $-80^{\circ} \mathrm{C}$. UV/Vis of rhodoxanthin in $\mathrm{EtOH}, \lambda_{\max }=$ 490nm, see Figure 2.12. Mass spectrum of rhodoxanthin can be seen in Figure 2.13. IR 
spectrum of rhodoxanthin can be seen in Figure 2.15. ${ }^{1} \mathrm{H}$ NMR of rhodoxanthin can be seen in Figure 2.14.

2.2 Reduction of Rhodoxanthin with $\mathrm{Zn} / \mathrm{HOAc}$

Rhodoxanthin was reduced by active granular zinc. Zinc was stirred with $\mathrm{HCl}-$ ethyl ether solution for couple of minutes until zinc looked shiny. The HCl-ethyl ether solution was prepared by gently shaking with concentrated $\mathrm{HCl}$ in a separatory funnel. (Caution: Gas build-up can cause spraying of concentrated $\mathrm{HCl}$ if gas is not carefully vented.) The ether solution was poured off and leaving the dry active zinc. The activated zinc was washed with ethyl ether 3 times. Ethyl ether was evaporated and the dried active zinc was used immediately for reduction reaction.

$6 \mathrm{mg}$ of purified rhodoxanthin was dissolved in $20 \mathrm{ml} \mathrm{CH}_{2} \mathrm{Cl}_{2}$ and $1 \mathrm{ml} \mathrm{HOAc}$. $3.5 \mathrm{~g}$ of active zinc was added to the solution. The solution was stirred for $20-30 \mathrm{~min}$ until it turned lemon yellow. At this time, the stirring bar was removed from the flask. The reaction was quenched by addition of $1000 \mathrm{ml}$ saturated $\mathrm{NaHCO}_{3}$ solution. The resulting mixture was extracted with $\mathrm{CH}_{2} \mathrm{Cl}_{2}$ and cold deionized water. This extraction procedure was repeated three times. The organic layer containing the carotenoid fraction was dried over magnesium sulfate for 5 minutes followed by gravity filtration to remove $\mathrm{MgSO}_{4}$. The solvent was removed by rotary evaporation and further dried under a steam of nitrogen in preparation for separation by preparatory reversed-phase HPLC. UV/Vis of the intermediate product of rhodoxanthin in $\mathrm{EtOH}, \lambda_{\max }=450 \mathrm{~nm}$, see Figure 2.20. Mass spectrum of the intermediate can be seen in Figure 2.21. IR spectrum of the intermediate can be seen in Figure 2.23. ${ }^{1} \mathrm{H}$ NMR of intermediate can be seen in Figure 2.22. 


\subsection{Instrumental Analysis for Product Characterization}

\subsubsection{UV/Visible Spectroscopy (UV/Vis)}

All carotenoids samples were dissolved in ethanol and pipetted into a UV cell $(1 \mathrm{~cm})$. The UV/Visible spectra of reactant were obtained prior to reaction in order to compare results. All spectra were obtained by scanning from $600-300 \mathrm{~nm}^{34}$

\subsubsection{Chromatography}

\subsubsection{Reversed-Phase HPLC}

HPLC analysis was performed on a system composed of Waters 2690 Separations Module and Model 996 photodiode array detector. The column used for separation products was a Phenomenex Ultracarb $3 \mu \mathrm{m}$ ODS $(250 \times 4.6 \mathrm{~mm})$ with a manual injection loop volume of $50 \mu \mathrm{l}$, and a flow rate of $1 \mathrm{ml} / \mathrm{min}$. (System 1)

The separation was performed on a system composed of a LDC/Milton Roy spectromonitor detector coupled to a LDC multiple solvent delivery system. The column used for separation was a Phenomenex Ultracarb $3 \mu \mathrm{m}$ ODS $(250 \times 21.20 \mathrm{~mm})$ with an injection loop volume of $500 \mu \mathrm{L}$, and a flow rate of $5 \mathrm{ml} / \mathrm{min}$. (System 2)

System 1 analysis was performed monitoring at $452 \mathrm{~nm}$ for zeaxanthin, $450 \mathrm{~nm}$ for the intermediate compound and $490 \mathrm{~nm}$ for rhodoxanthin. ${ }^{34}$ System 2 analysis was used to purify the reduced rhodoxanthin. ${ }^{34}$ Both systems used an isocratic solvent composition of $85 \%$ acetonitrile, $15 \%$ methanol, with $1 \mathrm{ml}$ triethlamine per liter of mobile phase added to inhibit degradation of the carotenoids on the column and improve separation. ${ }^{35}$

\subsubsection{Thin Layer Chromatography}

TLC was done using Analtech sheets, Alumina GF $250 \mu \mathrm{m}$. The solvent used to develop the plates was composed of $75 \%$ hexanes and $25 \%$ acetone for rhodoxanthin and 
$98 \%$ dichloromethane and $2 \%$ methanol for the reduced rhodoxanthin intermediate. ${ }^{29}$ The samples to be analyzed were dissolved in the above solvent and applied with a spotter made from a capillary tube by drawing in a flame.

\subsubsection{Preparative Thin layer Chromatography}

Preparative TLC was employed to purify rhodoxanthin. This was done using Whatman PLK 5 Silica gel $150 \AA$ Plate $(20 \times 20 \mathrm{~cm}, 1000 \mu \mathrm{m})$. The solvent used to develop the plates consisted of $75 \%$ hexanes, $25 \%$ acetone. Samples (rhodoxanthin and its by-products) to be separated were dissolved in acetone in order to both minimize sample volume and maximize evaporation rate of the solvent during plate preparation. The TLC plates were spotted with a Pasteur pipette, the tip was drawn out in a flame to produce a narrow capillary. After application, the solvent was allowed to evaporate while keeping the plate in the dark for about 10 min. Plates were developed in a glass chamber one time. The bright-red band was scraped from the plate, collected, and dissolved in methylene chloride. The solution was filtered through filter paper and the solvent was removed by rotary evaporation and the sample was further dried under a flow of nitrogen. The resulting compound was stored in round bottom flask at $-80^{\circ} \mathrm{C}$.

\subsubsection{Mass Spectrometry Analysis}

Mass spectra were obtained on a Finnigan Navigator aQa Mass Spectrometer equipped for APCI (atmospheric pressure chemical ionization). The positive-ion APCI mode was selected. The column used for separation was a Phenomenex Ultracarb $3 \mu \mathrm{l}$ ODS $(150 \times 4.6 \mathrm{~mm})$ with a flow rate of $1 \mathrm{ml} / \mathrm{min}$. Samples to be studied were dissolved in ethanol. Samples were injected into the system by the autosampler, the mobile phase was $85 \%$ acetonitrile and $15 \%$ methanol. NOTE: $\mathrm{Et}_{3} \mathrm{~N}$ must not be used during $\mathrm{MS}$ 
detection because it will contaminate the instrument and suppress ionization. The temperature in the chamber was set to $300^{\circ} \mathrm{C}$. The voltage applied to the needle was set at $5 \mathrm{mV}$. Purified zeaxanthin, rhodoxanthin, and the reduced rhodoxanthin intermediate were run separately. The mass spectra were recorded between 500-600 m/z. Background (solvent blank) was subtracted in order to obtain a clean spectrum.

d) NMR Analysis

NMR spectra were obtained for zeaxanthin, rhodoxanthin and the reduction product formed from rhodoxanthin, respectively. NMR data was obtained using a BrukerElectospin $400 \mathrm{MHz}$ Ultrashield NMR spectrometer. Samples were greater than $90 \%$ pure (HPLC) and were dried on a high vacuum pump for 30-45 min to remove all traces of the solvent. About $0.6 \mathrm{ml}$ of $\mathrm{CDCl}_{3}$ was used to dissolve the sample. Proton spectra were obtained using the standard parameters available in the software package. The number of scans used to obtain ${ }^{1} \mathrm{H}-\mathrm{NMR}$ was usually set to 32 or 1032 , depending on sample concentration.

e) Infrared Spectrometry (IR)

The IR system used was a MIDAC M2000 Series FTIR spectrometer. Samples were dissolved in dichloromethane and transferred carefully by a Pasteur pipette to the surface of $\mathrm{NaCl}$ plate to obtain an even coverage under nitrogen. The $\mathrm{NaCl}$ plate without sample was used as the blank.

\section{Results and Discussion}

In order to analyze the zeaxanthin stereoisomers in the tissues, see chapter III, we need to prepare the three zeaxanthin stereoisomers. The procedure is shown in Figure 2.2. This procedure involves formation and isolation of a intermediate product, compound 1, 
that has been previously described as $3,3^{\prime}-\beta, \beta$-carotene dione. The evidence for this assigned structure is solely the formation of the zeaxanthin isomers which result from a subsequent $\mathrm{NaBH}_{4}$ reduction of this compound, see Figure 2.2. We describe the purification and characterization of compound 1 below.

\subsection{Zeaxanthin}

Zeaxanthin will be the first compound to be discussed in this section. It is the starting material for our studies and because of the extremely close similarity of these compounds it is imperative that we characterize all products by careful comparison to this starting material. It is discussed in order to establish the basis by which the other compounds have been examined. In this manner it will be easier for the reader to understand the concepts and criteria used to assign the identity of the compounds studied.

\subsubsection{Results}

\subsubsection{HPLC analysis}

Because of the similar structures of the lutein and zeaxanthin, their chromatographic retention times are very close. The HPLC chromatogram of a lutein and zeaxanthin mixture is shown in Figure 2.3. The retention time of lutein is $11.75 \mathrm{~min}$ while the retention time of zeaxanthin is $12.90 \mathrm{~min}$.

\subsubsection{UV/Vis analysis}

$\mathrm{UV} / \mathrm{V}$ is spectrum of zeaxanthin in EtOH is shown in Figure 2.4. The $\lambda_{\max }$ is $452 \mathrm{~nm}$. The two bands at either side of the main absorption band are observed at 424 and $478 \mathrm{~nm}$, respectively. The ratio of the vibrational bands (III/II) was calculated to be $28 \%$. 


\subsubsection{MS analysis}

MS analysis of carotenoids was done using $\mathrm{APCI}^{+}$. This is a soft ionization method and generally gives quasi-molecular ions. In the case of zeaxanthin, mass spectra produce a higher intensity 569 parent ion and this is the principle ion of the mass spectrum and the 551 peak.
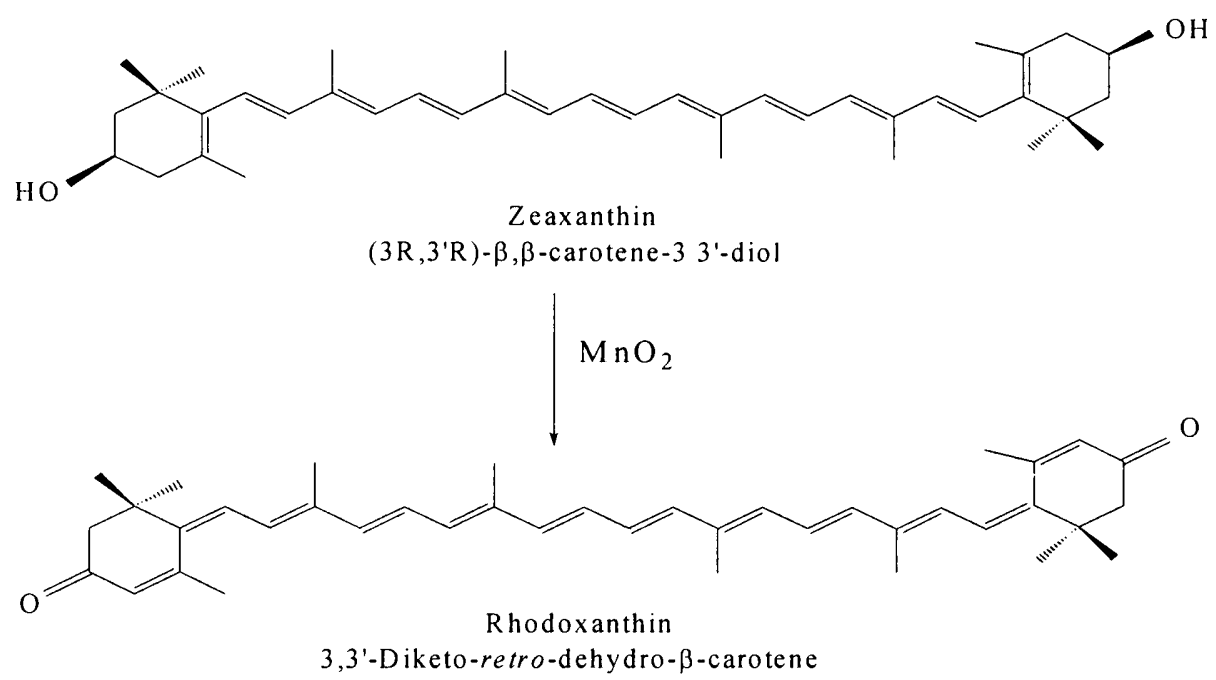

3,3'-Diketo-retro-dehydro- $\beta$-carotene

(Compound 1 or com pound 2 )



Figure 2.2 Procedure for the synthesis of zeaxanthin stereoisomers 


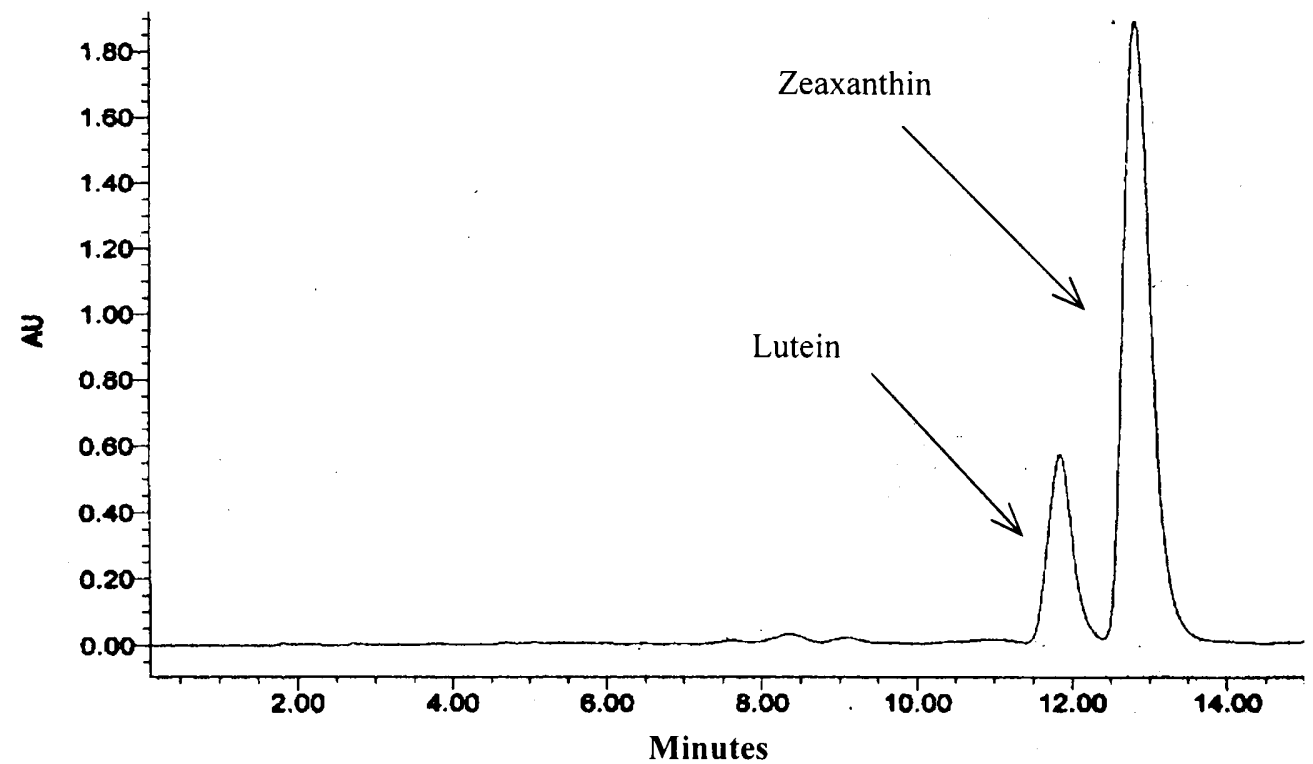

Figure 2.3 Lutein and zeaxanthin detected using HPLC System 1. Lutein retention time $=11.75 \mathrm{~min}$, zeaxanthin retention time $=12.90 \mathrm{~min}$.

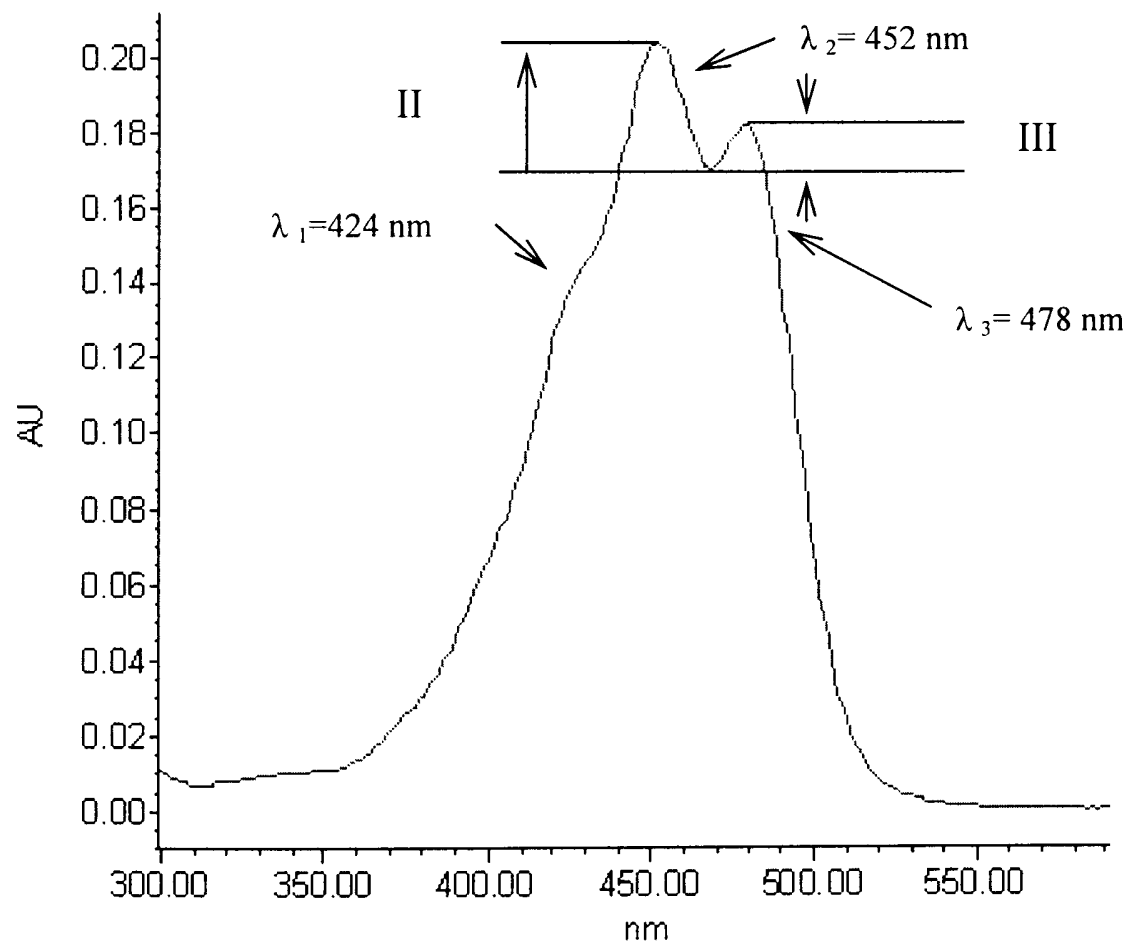

Figure 2.4 UV/Visible spectrum of zeaxanthin in EtOH. $\lambda_{\max }=452 \mathrm{~nm}$. $\mathrm{III} / \mathrm{II}=28 \%$ 


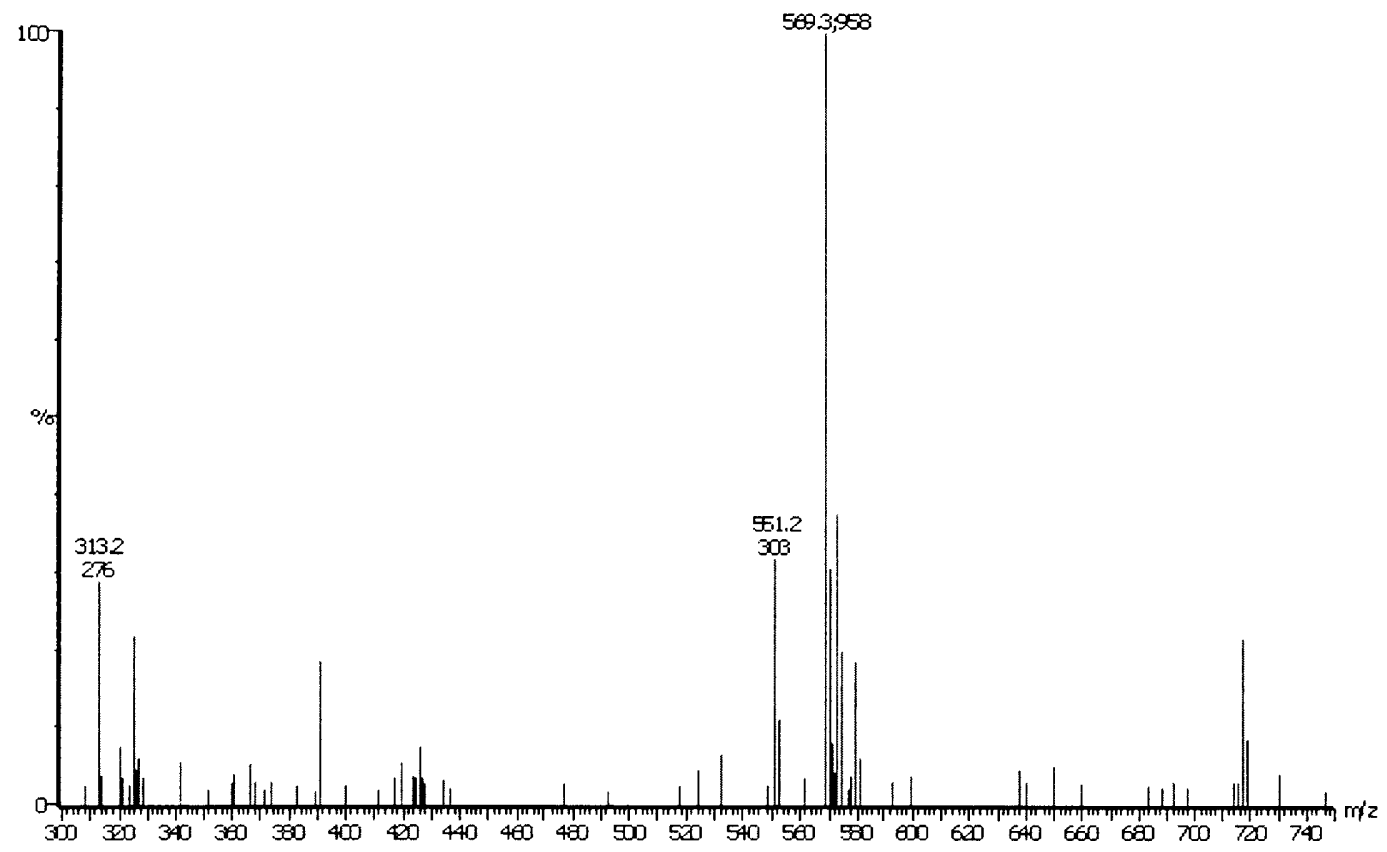

Figure 2.5 The APCI ${ }^{+}$mass spectrum of zeaxanthin showing the principle ion $[\mathrm{M}+\mathrm{H}]^{+}=569 \mathrm{~m} / \mathrm{z}$, and the fragment produced by loss of $\mathrm{H}_{2} \mathrm{O}[\mathrm{M}+\mathrm{H}-18]=551 \mathrm{~m} / \mathrm{z}$.

\subsubsection{NMR analysis}

Proton NMR spectra of carotenoids are extremely complicated, see Figure 2.6. These compounds have over 50 hydrogens atoms. This large number of protons together with the complex splitting patterns makes it very hard to unambiguously assign identities. Since the focus of this research is the oxidation of zeaxanthin hydroxyl group, the most important assignments will be unique the protons on the ionone rings. These are readily assigned. The structure of the $\beta$-ionone rings present in zeaxanthin is shown in Figure 2.7. The hydrogen atoms are numbered consistent with the common numbering system. Table 2.1 lists the observed resonance and literature values of peaks for the critical hydrogens. 


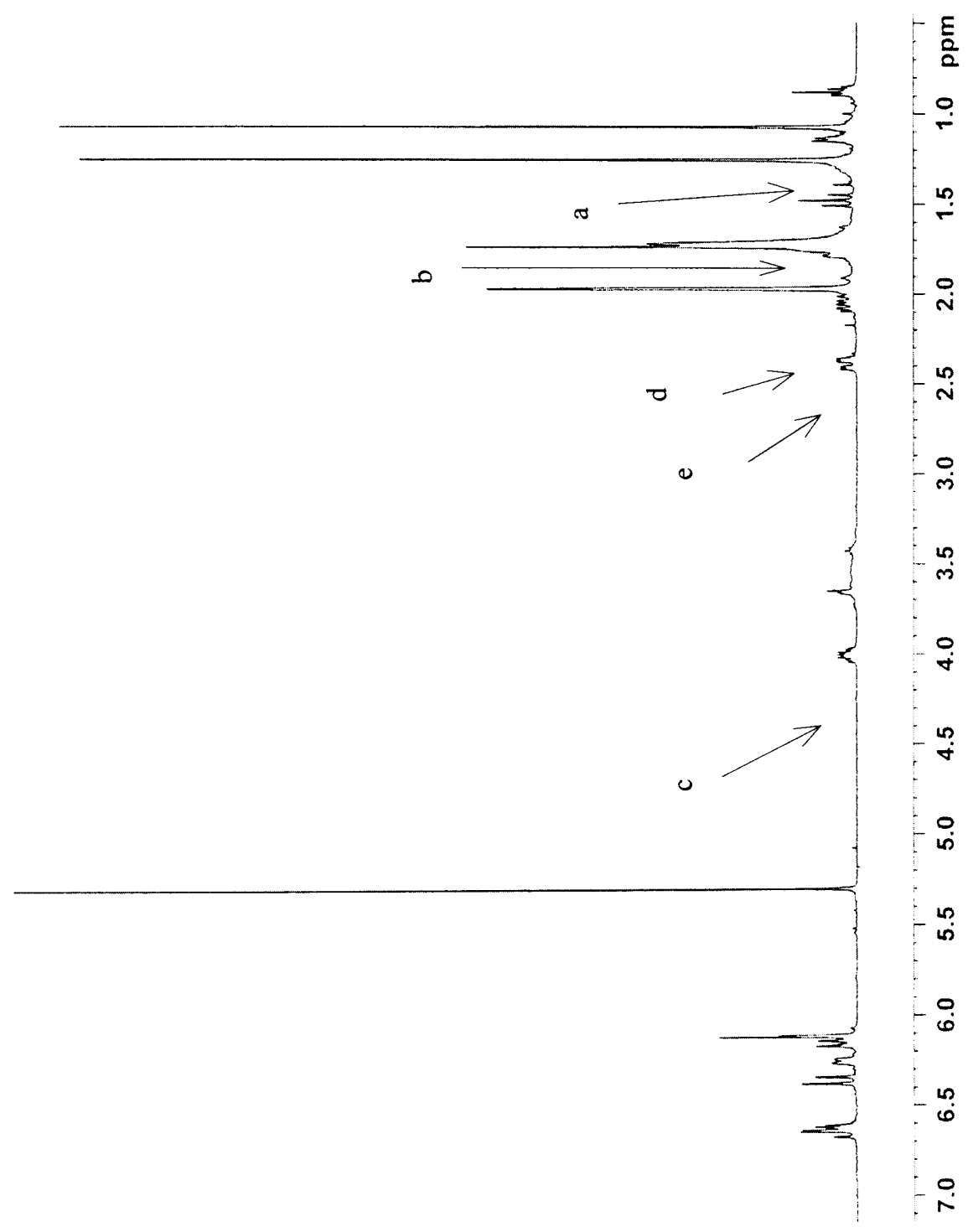

Figure 2.6 The ${ }^{1} \mathrm{H}$-NMR of zeaxanthin obtained in $\mathrm{CDCl}_{3}$ 


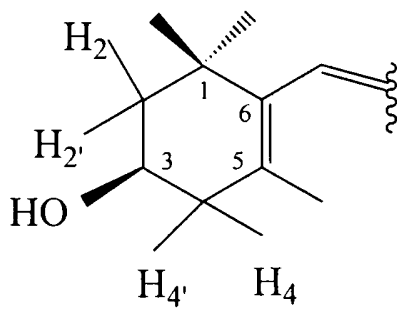

Figure 2.7 The chemical structure of ionone ring on zeaxanthin

TABLE 2.1 Experimental ${ }^{1} \mathrm{H}-\mathrm{NMR}$ data and literature values for zeaxanthin

\begin{tabular}{ccc}
\hline Protons $\delta(\mathrm{ppm})^{*}$ & $\begin{array}{c}\text { Experimental chemical } \\
\text { shift }(\mathrm{ppm})\end{array}$ & $\begin{array}{c}\text { Literatural chemical shift } \\
(\mathrm{ppm})\end{array}$ \\
\hline a H-C(2) & 1.48 & 1.48 \\
b H-C (2') & 1.74 & 1.77 \\
c H-C (3') & 4 & 4.01 \\
d H-C(4) & 2.05 & 2.04 \\
e H-C (4') & 2.39 & 2.39 \\
\hline
\end{tabular}

* a, b, c, d, e refer to the positions of hydrogens on the spectrum, see Figure 2.6

\subsubsection{Discussion}

The origin of the UV/Visible spectrum in carotenoids is the fully allowed $\pi \rightarrow \pi^{*}$ transition of the conjugated $\pi$ system. The longer the conjugated double-bond chain, the less the energy needed for the transition, and hence, the longer the wavelength at the maximum absorption. Because of characteristic vibrational modes in the carotenoid molecules, three bands are observed on the spectrum. The different intensity of each band provides the valuable information. III/II ratio is a useful one. This ratio is the height of the band of peak III absorbing at the longest wavelength, divided by peak II, the middle absorption band; (this is usually the principle $\lambda_{\max }$ ). For carotenoids possessing $2 \beta$ rings, the III/II ratio is about $30 \%$, for $\beta, \gamma$-carotenes, it is about $45 \%$, and carotenoids with $\varepsilon, \varepsilon$; $\gamma, \gamma ;$ or $\alpha, \alpha$ rings give III/II ratios of about $100 \%{ }^{36}$ 
The base peak is given by a fragment at $[\mathrm{M}+\mathrm{H}]^{+}$at $569 \mathrm{~m} / \mathrm{z}$. This corresponds to the molecular weight of the molecule, $568 \mathrm{~g} / \mathrm{mol}$. Mass spectrometry gave a $[\mathrm{M}+\mathrm{H}-18]^{+}$ at $551 \mathrm{~m} / \mathrm{z}$. This fragment is due to the loss of water, after the protonation of one of the alcohol groups.

Because zeaxanthin has a symmetric structure, the assignment of the peaks on NMR spectra is also symmetric. However, it is very difficult to assign the location of each proton in the carotenoid on ${ }^{1} \mathrm{H}-\mathrm{NMR}$ spectra. A broad peak around $4.00 \mathrm{ppm}$ was assigned to the axial proton at $\mathrm{C}\left(3,3^{\prime}\right)$. Peaks around 1 to $2 \mathrm{ppm}$ were assigned to the protons on saturated methyl carbons $\left[\mathrm{C}\left(2,2^{\prime}\right), \mathrm{C}\left(4,4^{\prime}\right), \mathrm{C}\left(16,16^{\prime}\right), \mathrm{C}\left(17,17^{\prime}\right), \mathrm{C}\left(18,18^{\prime}\right)\right.$, $\left.\mathrm{C}\left(20,20^{\prime}\right)\right]$. Those around $6 \mathrm{ppm}$ were contributed by the olefinic protons on the double carbon bonds [C(7,7'), $\left.\mathrm{C}\left(8,8^{\prime}\right), \mathrm{C}\left(10,10^{\prime}\right), \mathrm{C}\left(11.11^{\prime}\right), \mathrm{C}\left(12,12^{\prime}\right), \mathrm{C}\left(14,14^{\prime}\right), \mathrm{C}\left(15,15^{\prime}\right)\right]$. The peak at $7.28 \mathrm{ppm}$ was caused by the residual protons in the solvent $\left(\mathrm{CDCl}_{3}\right)$ and this value is identical to the data in the literature $(\delta=7.26 \mathrm{ppm}) .{ }^{38}$ Other data are also consistent with those in the literature. ${ }^{37}$

3.2 Oxidation of zeaxanthin with manganese (IV) oxide

The mechanism of retro rearrangement of double bonds for the biosynthesis of 4',5'-didehydro-4,5'-retro- $\beta, \beta$-carotene-3,3'-diol is still unknown. However, Williams et. al. ${ }^{39}$ proposed a possible mechanism for it and Britton ${ }^{40}$ also suggested a similar oxidation process in the biosynthesis of rhodoxanthin. So the possible process which might be involved in the oxidation reaction of zeaxanthin was proposed as shown in Figure 2.8. 


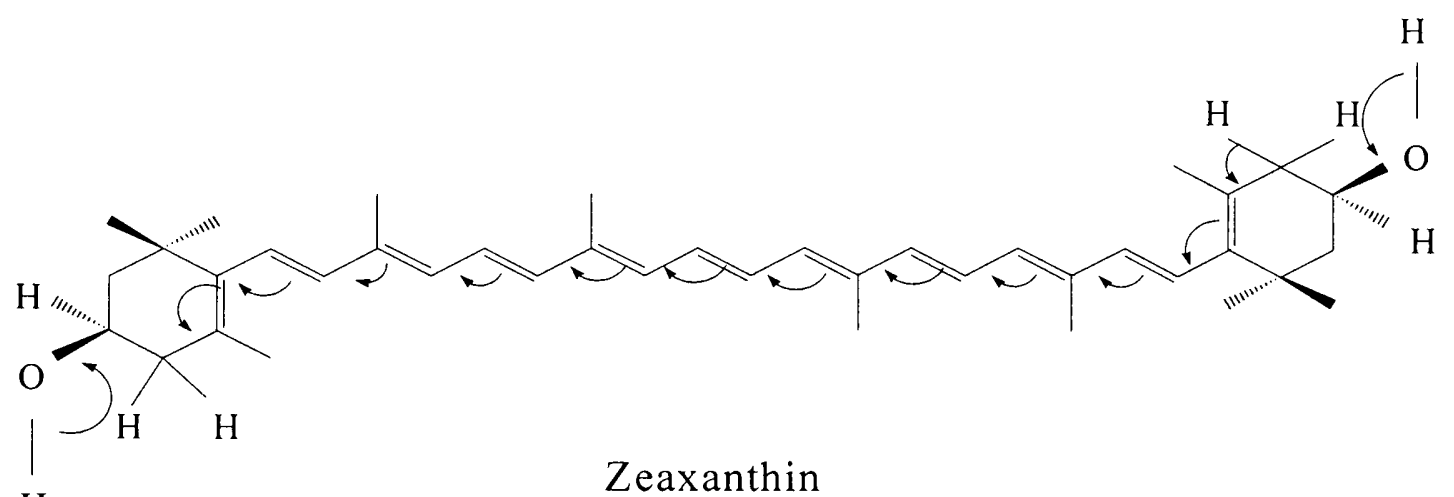

$\mathrm{H}$

Zeaxanthin

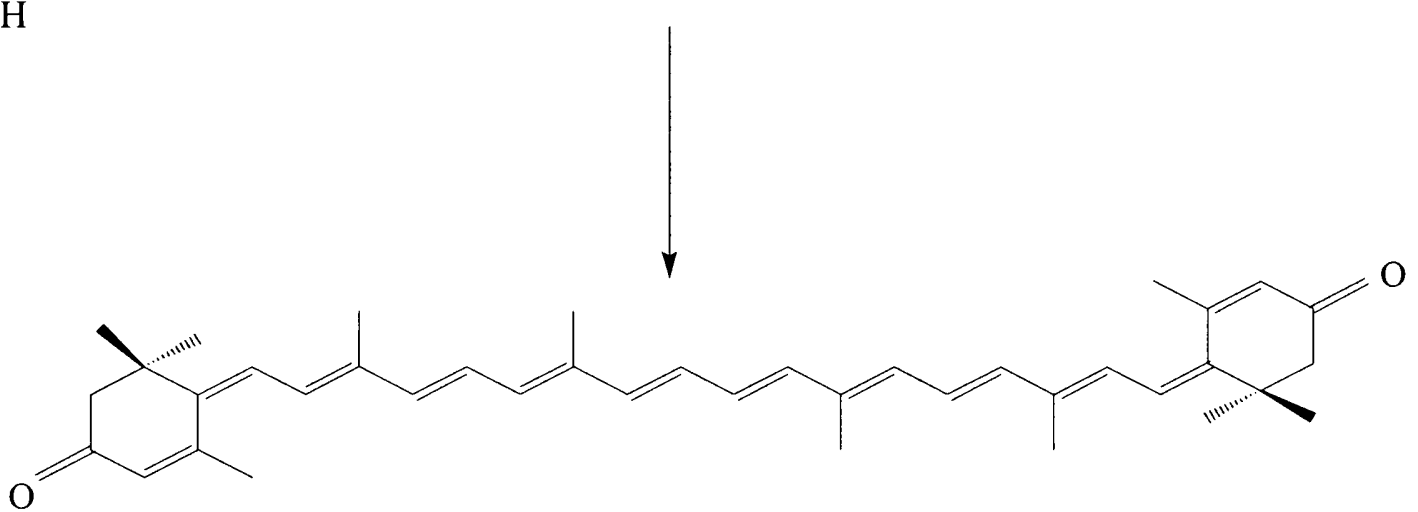

Rhodoxanthin

Figure 2.8 Partial synthesis of rhodoxanthin involves the loss of 6 electrons

Reaction of zeaxanthin with $\mathrm{MnO}_{2}$ proved to be an efficient way of synthesizing rhodoxanthin and it can produce several different products. A single compound is present in high yield, and the other compounds were observed in very low yields (5\% or less). The main compound, rhodoxanthin, was collected using preparative TLC, as described in Figure 2.10. Once the rhodoxanthin fraction was separated, it was stored under nitrogen in the dark at $-80^{\circ} \mathrm{C}$ for further analysis and reaction. 


\subsubsection{Results}

\subsubsection{HPLC analysis}

The chromatogram in Figure 2.9 shows the HPLC analysis (system I) of rhodoxanthin. The rhodoxanthin product was observed at a retention time of $9.75 \mathrm{~min}$ and $10.50 \mathrm{~min}$, respectively.

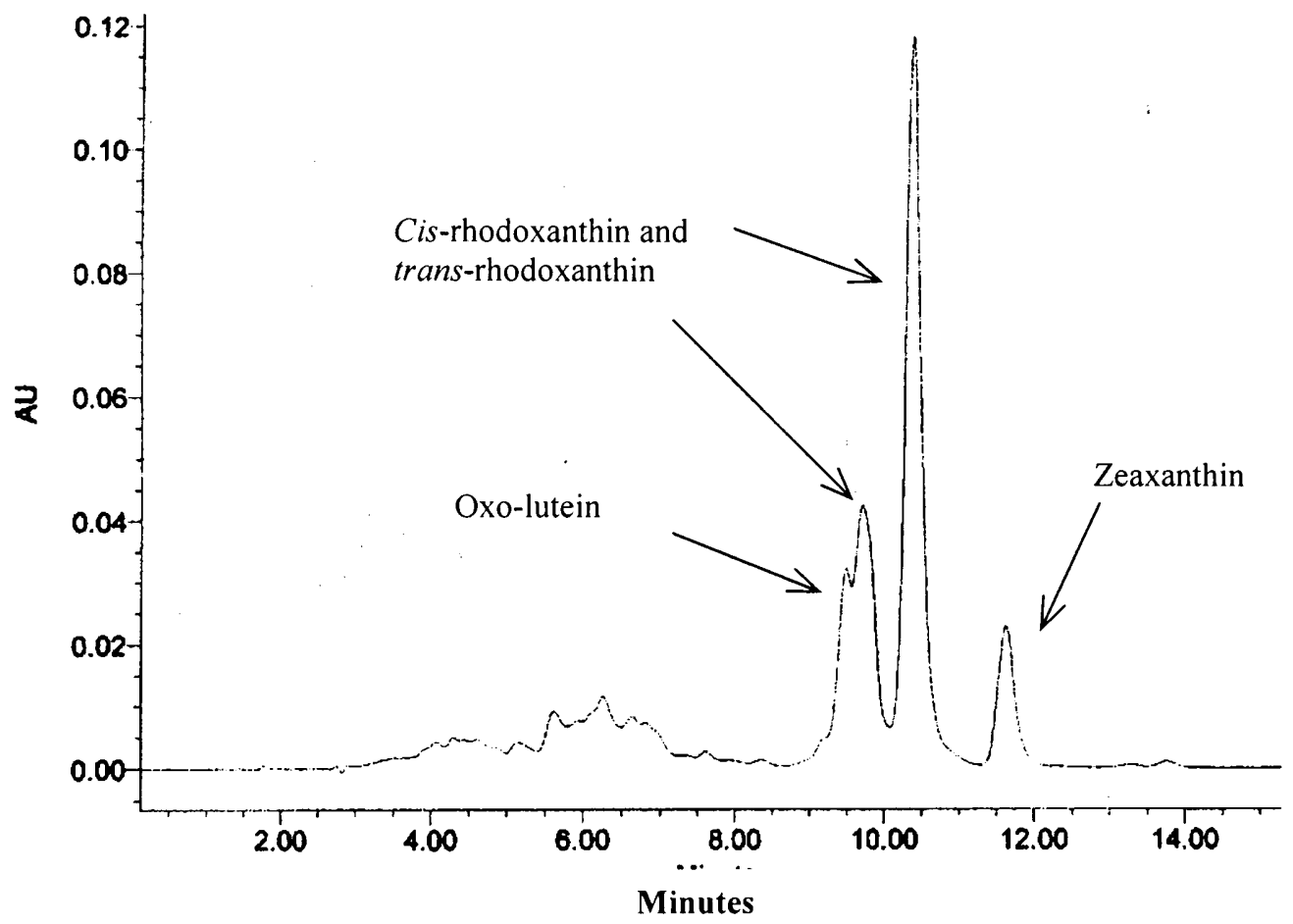

Figure 2.9 The product mixture resulting from reaction of zeaxanthin and $\mathrm{MnO}_{2}$ detected with HPLC system I

\subsubsection{Separation and Purification}

Separation and purification of this rhodoxanthin was done by preparative TLC. This was possible due to the large yield obtained from the reaction, which enabled the use of this chromatographic technique as opposed to HPLC. Figure 2.8 shows a developed plate. The purified rhodoxanthin is shown in Figure 2.10. 


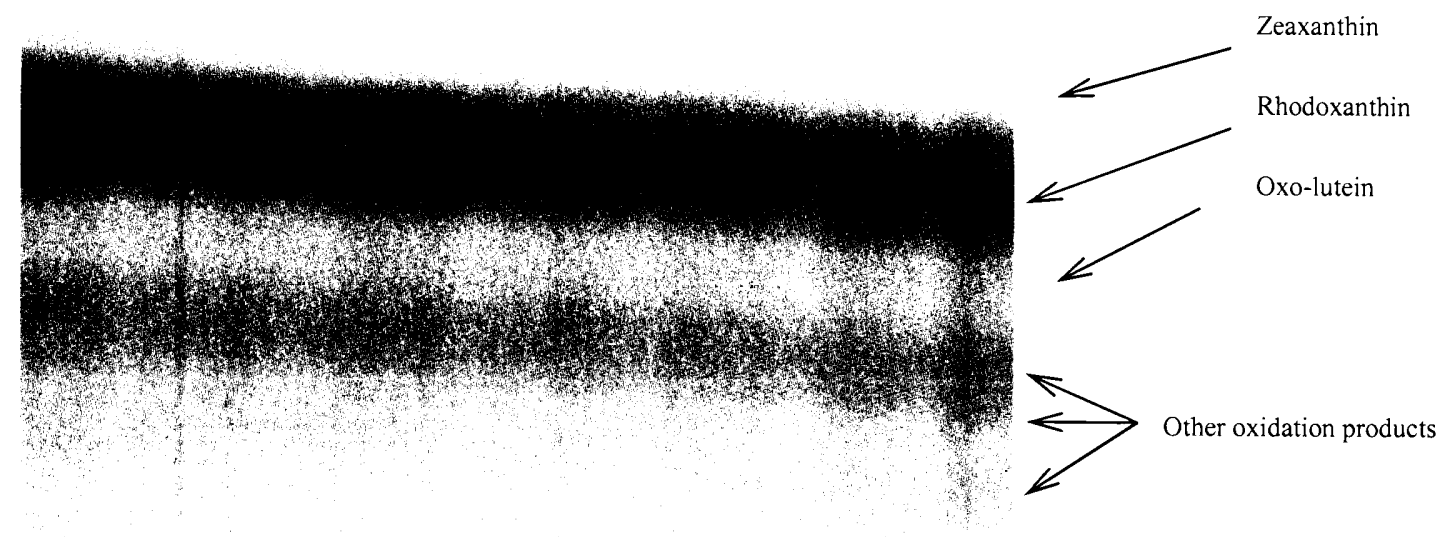

Figure 2.10 TLC showing separation between rhodoxanthin and the rest of the reaction by-products

HPLC analysis (system I) of rhodoxanthin gave a retention time of $6.2 \mathrm{~min}$. The compound analyzed by HPLC was obtained from collection on preparative TLC. This HPLC system proved to give a mixture of isomers of rhodoxanthin and enable the separation of relatively large amounts of compound.

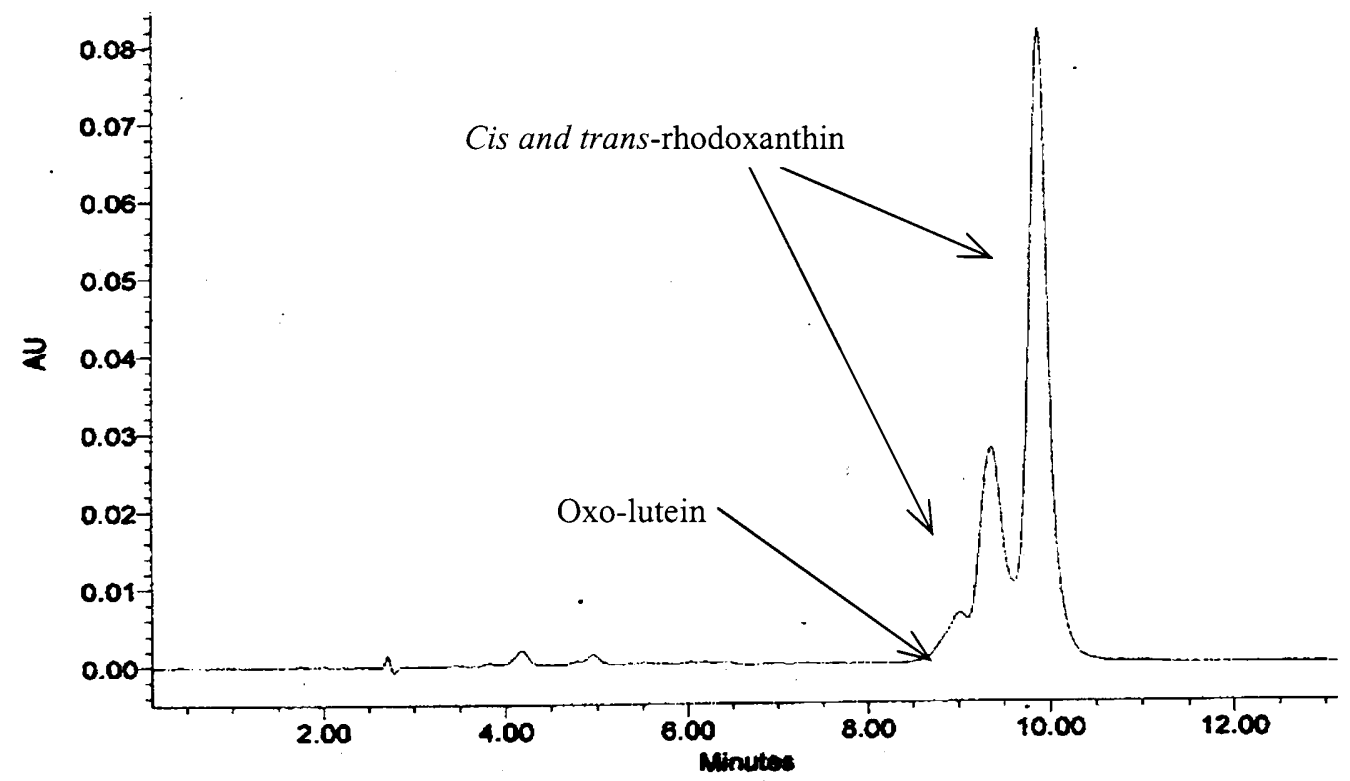

Figure 2.11 Purified rhodoxanthin from TLC 
3.2.1.3. UV/Visible analysis

UV/Visible analysis of rhodoxanthin shows $\lambda_{\max }$ of $490 \mathrm{~nm}$. It can be seen in Figure 2.12.

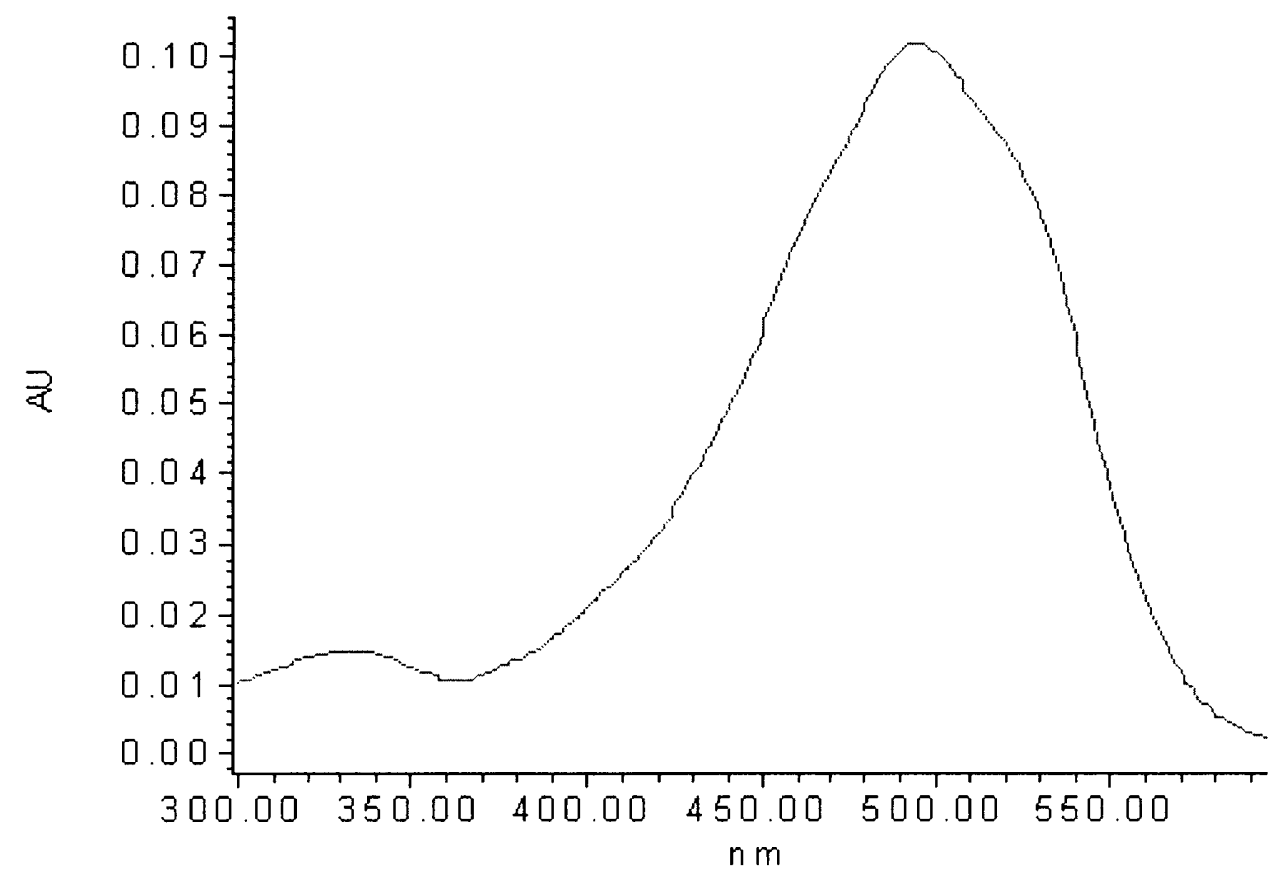

Figure $2.12 \mathrm{UV} /$ Visible spectrum of Rhodoxanthin in $\mathrm{EtOH}, \lambda_{\max }=490 \mathrm{~nm}$.

\subsubsection{MS analysis}

Mass spectrometry shows the presence a molecular ion $[\mathrm{M}+\mathrm{H}]^{+}=563 \mathrm{~m} / \mathrm{z}$, which is the base peak. This mass is consistent with the molecular weight $562 \mathrm{~g} / \mathrm{mol}$ of rhodoxanthin. It can be seen in Figure 2.13.

\subsubsection{NMR analysis}

The proton NMR as in the case of rhodoxanthin is hard to assign due to the large number of hydrogens in the structure and their coupling. The NMR spectrum can be seen in Figure 2.14. In the following table, a number of the peaks are tentatively assigned. 
Although these splitting patterns are extremely complex, these assignments allow us to unambiguously assign the structure of the ring.

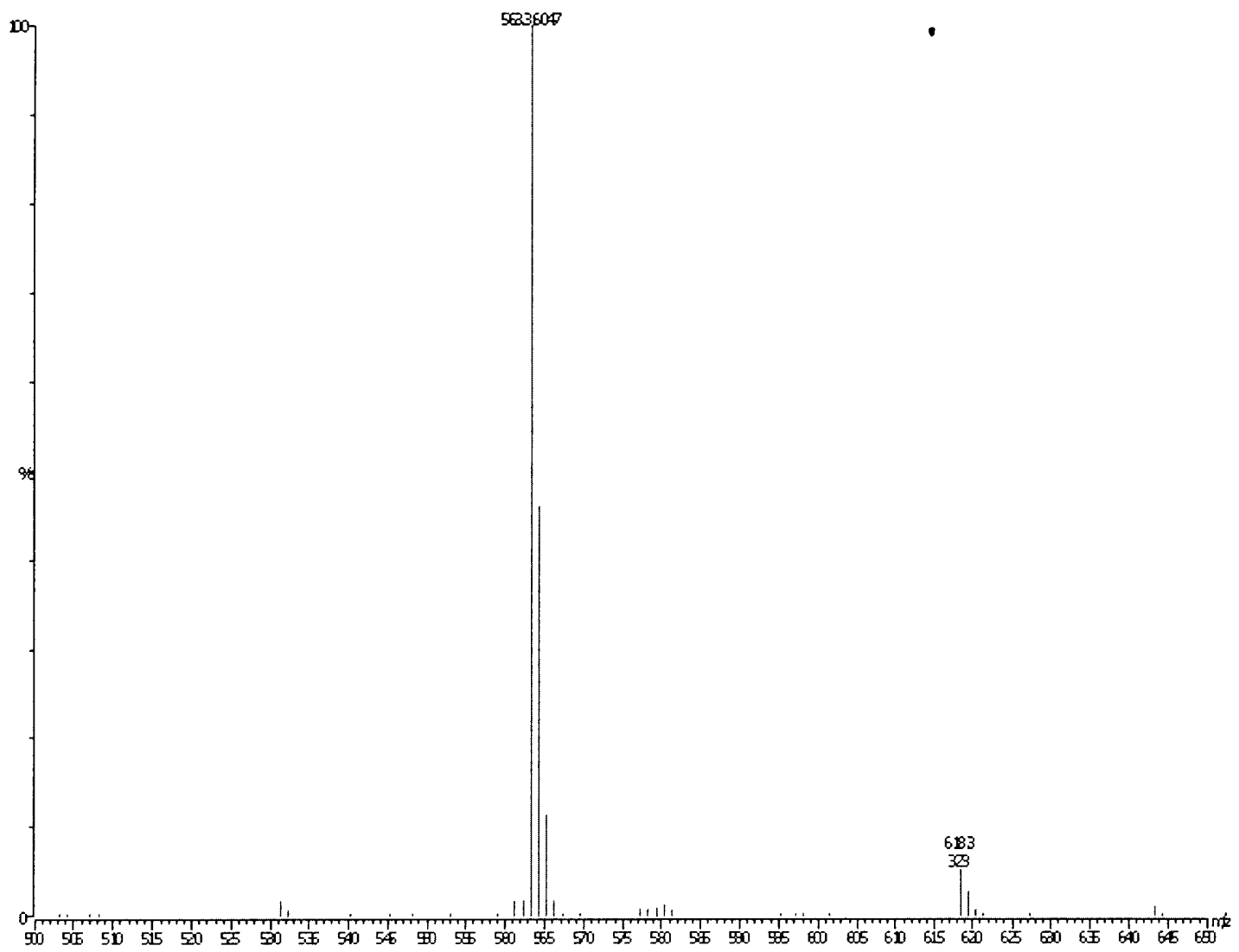

Figure $2.13 \mathrm{The} \mathrm{APCI}^{+}$mass spectrum of rhodoxanthin. $[\mathrm{M}+\mathrm{H}]^{+}=563 \mathrm{~m} / z$.

Table 2.2. Experimental $400 \mathrm{~Hz}{ }^{1} \mathrm{H}-\mathrm{NMR}$ data and literature data of rhodoxanthin

\begin{tabular}{l|l|l|l|l|l}
\hline \multirow{2}{*}{$\begin{array}{l}\text { Proton } \\
\delta(\mathrm{ppm})^{*}\end{array}$} & \multicolumn{3}{|l|}{ Experimental } & \multicolumn{3}{|l|}{ Literature at $400 \mathrm{MHz}$} \\
\cline { 2 - 6 } & $\begin{array}{l}\text { chemical } \\
\text { shift }\end{array}$ & integration & all-trans & 6 -cis & 6,6 '-di-cis \\
\hline a H-C (2) & 2.396 & 2 & 2.395 & $\sim 2.340$ & 2.341 \\
b H-C (2') & 2.396 & 2 & & $\sim 2.394$ & \\
c H-C (4) & 5.939 & 1 & 5.936 & $\sim 5.937$ & 5.94 \\
d H-C (4') & 5.939 & 1 & 5.937 & \\
\hline
\end{tabular}




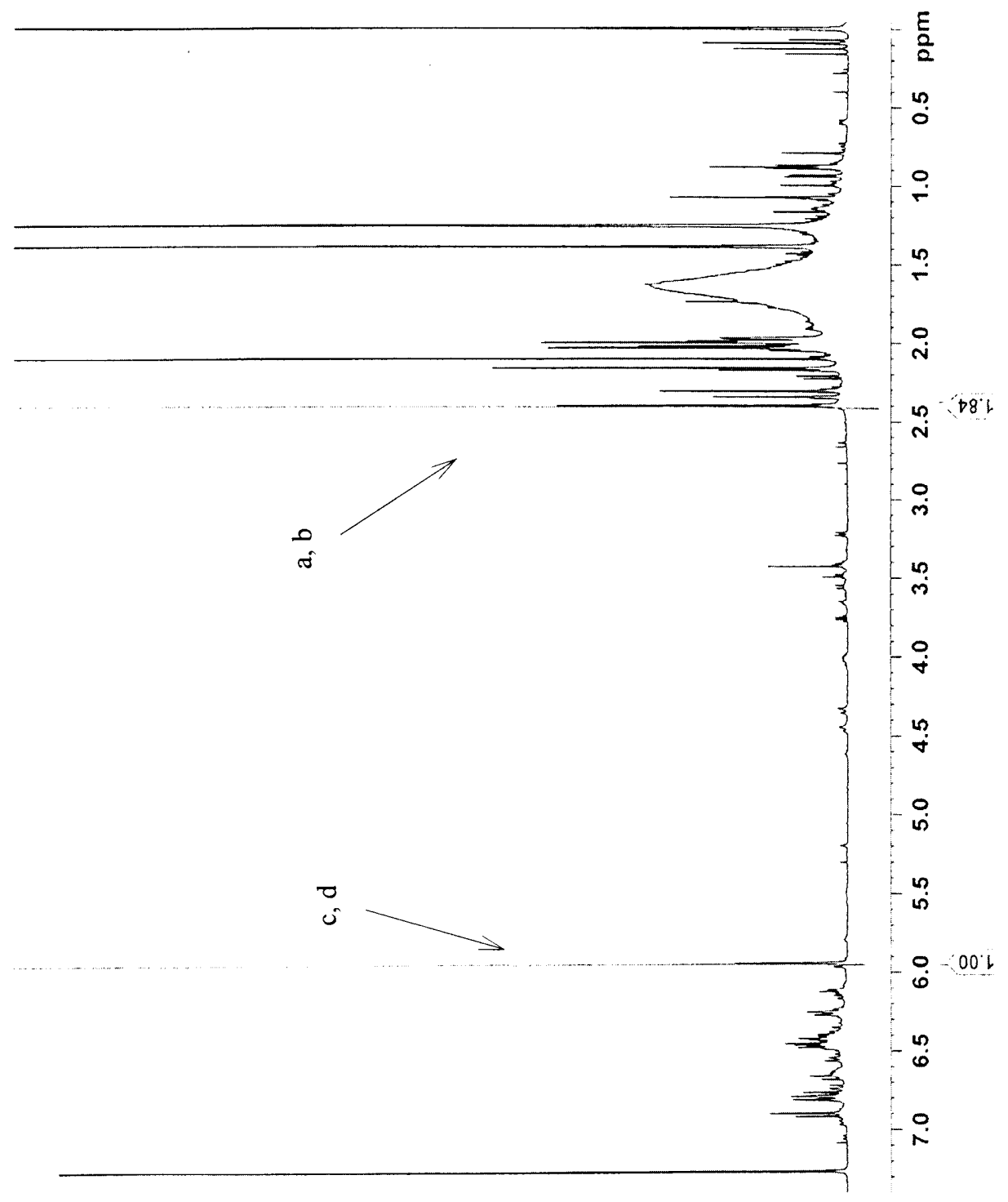

Figure $2.14{ }^{\mathrm{I}} \mathrm{H}$-NMR of rhodoxanthin obtained in $\mathrm{CDCl}_{3}, 400 \mathrm{MHz}$ 


\subsubsection{IR analysis}

As can be observed in Figure 2.15, a sharp and strong band is present at $1660 \mathrm{~cm}^{-1}$

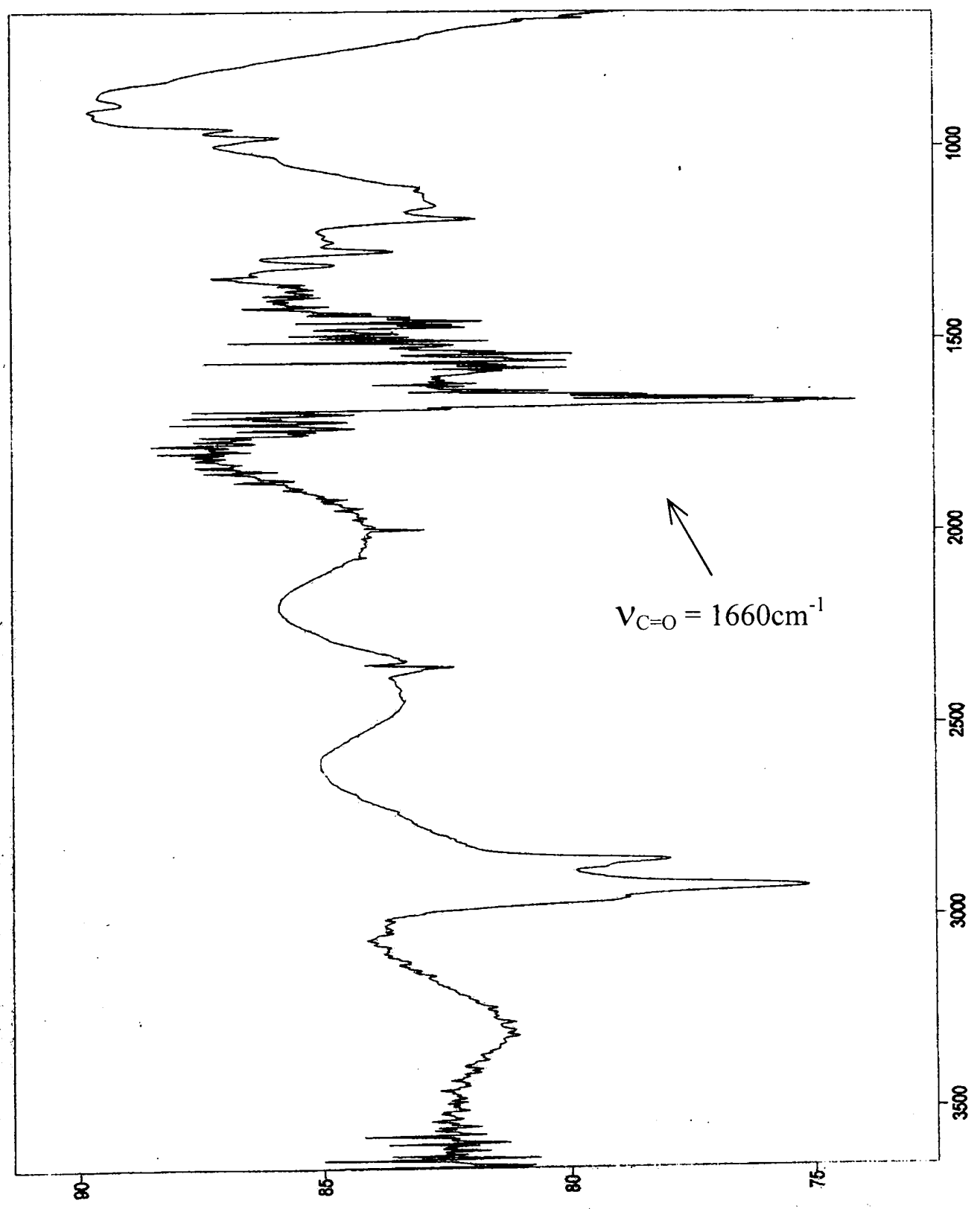

Figure 2.15 IR spectrum of rhodoxanthin 


\subsubsection{Discussion}

The chromatogram of purified rhodoxanthin can be seen in Figure 2.11. In addition of trace of cleavage products and oxo-lutein residue, there are 2 basic peaks. Both of them are rhodoxanthin because rhodoxanthin has 3 isomers in literature. ${ }^{36,40,41}$ It can be seen in Figure 2.16.
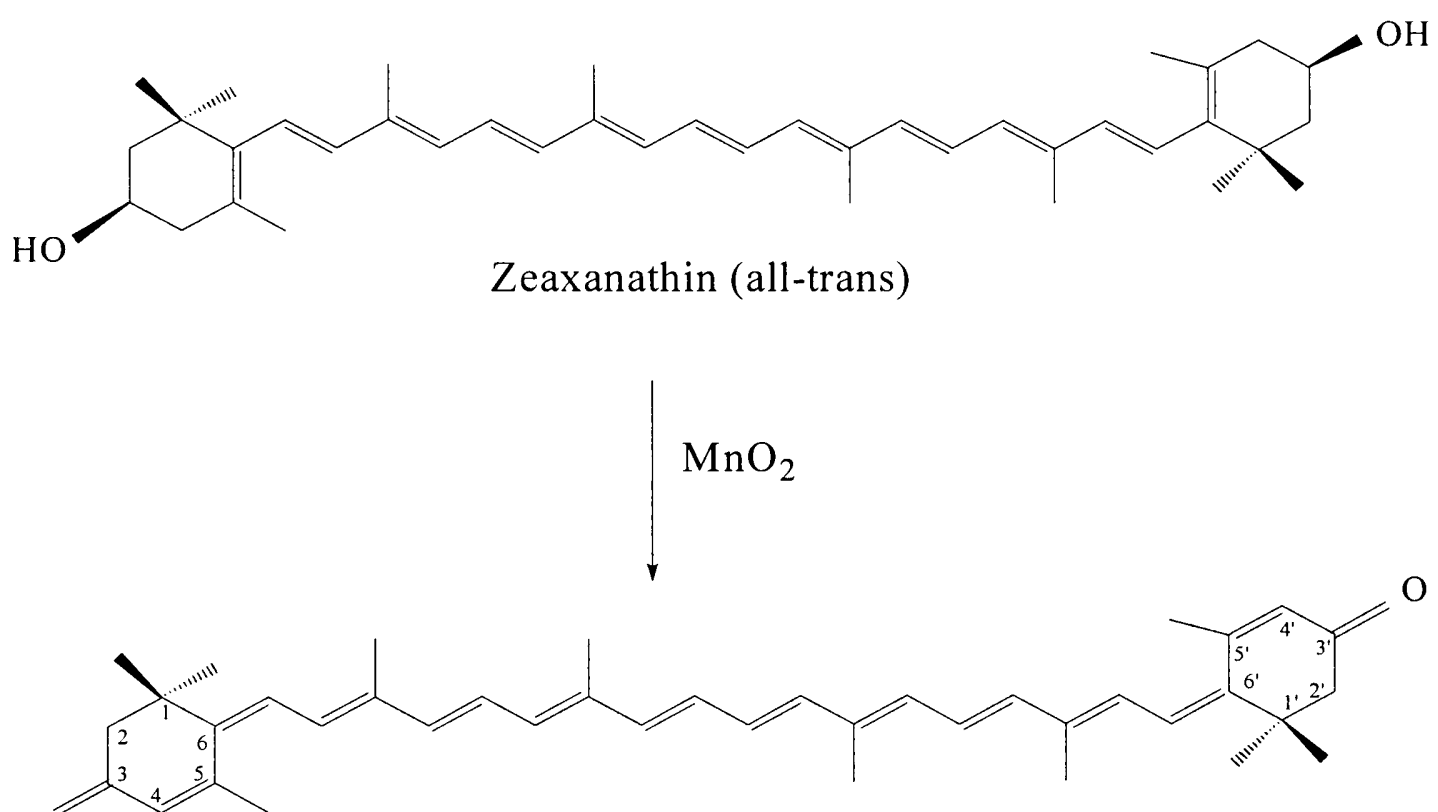

Rhodoxanthin $\left(6 \mathrm{E}, 6^{\prime} \mathrm{E}\right)$<smiles>CCCCC(C)C=CC=C(C)C=CC=C(C)C=CC=CC(C)=CC=CC(C)=CC=C1C(C)=CC(=O)CC1(C)C</smiles>

Rhodoxanthin $\left(6 \mathrm{Z}, 6^{\prime} \mathrm{Z}\right)$

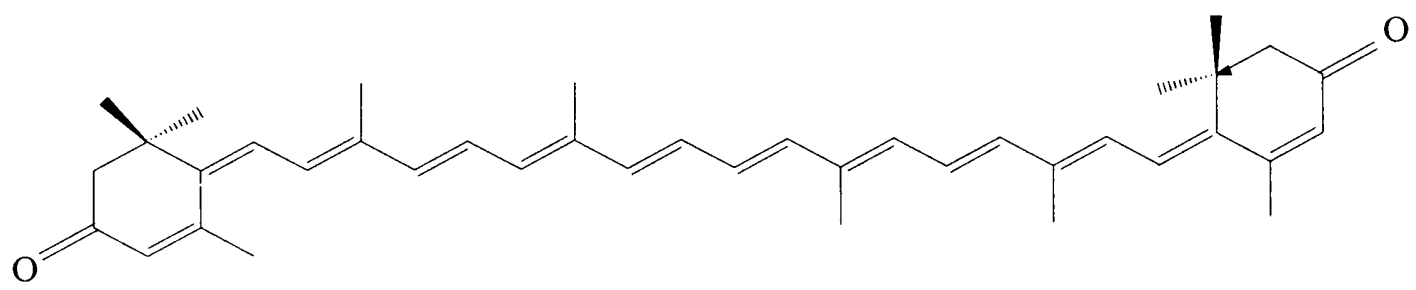

Rhodoxanthin $\left(6 \mathrm{E}, 6^{\prime} \mathrm{Z}\right)$

Figure 2.16 Oxidation reaction of zeaxanthin and the structures of all-trans rhodoxanthin and its 6,6'-di-cis, 6-cis isomers. 
From the UV/Vis spectrum, $\lambda_{\max }$ for rhodoxanthin is found to be $490 \mathrm{~nm}$. This value is longer than the $452 \mathrm{~nm} \lambda_{\max }$ of zeaxanthin. This bathochromic shift is consistent with increasing conjugation in the system. Another important feature can also be seen in the spectrum. Rhodoxanthin has a broad spectrum without the fine structure of zeaxanthin, which has a characteristic three-band carotenoid spectrum. The difference between the two spectra is due to the presence of the two carbonyl groups conjugated with the polyene chain. The presence of conjugated carbonyl groups causes a large bathochromic shift of the spectrum. The overall bathochromic shift is about $40 \mathrm{~nm}$ relative to zeaxanthin and is consistent with the increase in the number of double bonds in the polyene chain.

Since there are three isomers of rhodoxanthin, it is very difficult to assign the location of each proton in the ${ }^{1} \mathrm{H}-\mathrm{NMR}$ spectrum. Among the three structures of rhodoxanthin, see Figure 2.16, the all-trans and the 6,6'-di-cis rhodoxanthin are symmetric, therefore, they have half as many peaks in the ${ }^{1} \mathrm{H}-\mathrm{NMR}$ spectrum that of the asymmetric 6-cis rhodoxanthin. ${ }^{42}$

The peaks around 1.0 to $2.5 \mathrm{ppm}$ were assigned to the protons on the saturated methyl carbons $\left[\mathrm{C}\left(2,2^{\prime}\right), \mathrm{C}\left(16,16^{\prime}\right), \mathrm{C}\left(17,7^{\prime}\right), \mathrm{C}\left(18,18^{\prime}\right), \mathrm{C}\left(19,19^{\prime}\right), \mathrm{C}\left(20,20^{\prime}\right)\right]$. Those around $6 \mathrm{ppm}$ were attributed to the olefinic protons on the double carbon bonds $\left[\mathrm{C}\left(4,4^{\prime}\right)\right.$, $\left.\mathrm{C}\left(7,7^{\prime}\right), \mathrm{C}\left(8,8^{\prime}\right), \mathrm{C}\left(10,10^{\prime}\right), \mathrm{C}\left(11,11^{\prime}\right), \mathrm{C}\left(12,12^{\prime}\right), \mathrm{C}\left(14,14^{\prime}\right), \mathrm{C}\left(15,15^{\prime}\right)\right]$. The peak at 7.28 ppm is due to the solvent $\left(\mathrm{CDCl}_{3}\right) .{ }^{38} \mathrm{~A}$ broad peak around $1.7 \mathrm{ppm}$ might be caused by residual $\mathrm{H}_{2} \mathrm{O}$ in the solvent. There are 2 hydrogens attached on the $\mathrm{C} 2$ and a hydrogen attached to the $\mathrm{C} 4$ on the end-rings. The ratio of their integrations is identified to 2:1 (a:c). The data are consistent with those reported in the literature. ${ }^{37}$ 
While infrared spectroscopy does not provide information about the structure of a molecule, it was helpful in confirming the presence of the carbonyl groups. The frequency of an isolated carbonyl in the IR spectrum is typically observed at about 1720 $\mathrm{cm}^{-1}$. The $1660 \mathrm{~cm}^{-1} \mathrm{CO}$ frequency in our samples is consistent with the assignment as an $\alpha, \beta$-unsaturated carbonyl.

\subsection{The intermediate carotene dione}

This reduction product of rhodoxanthin, compound 1 , is unstable, and only small amounts of this compound could be isolated because they rapidly oxidize back to rhodoxanthin. Thus, it proved very challenging to obtain the spectra needed to adequately characterize this species.

Figure 2.17 are possible structures of the intermediate product formed by the reduction of rhodoxanthin. Although this intermediate has been previously described as compound 1, see Figure 2.17, its structure has remained unproven. Compound 2 is another candidate for the structure of this product. The reason is that carbonyl compounds with an $\beta, \gamma$ double bond often readily tautomerize to produce the more stable $\alpha, \beta$ unsaturated carbonyl system. It would not be surprising if compound 1, when formed, would readily transform into compound 2 . The end-groups of compound 2 are the $\varepsilon$ ionone rings in which the carbonyl at $\mathrm{C} 3$ is conjugated to the ring double bond. Oxolutein, a related keto-cartenoid, has an identical $\varepsilon$-ionone ring containing a conjugated carbonyl at C3. It has been previously studied in our lab. The NMR spectra of oxo-lutein can be seen in Figure 2.24. ${ }^{1} \mathrm{H}$-NMR spectrum of the $\varepsilon$-ring is distinctly different from that of the $\beta$-ring system. 


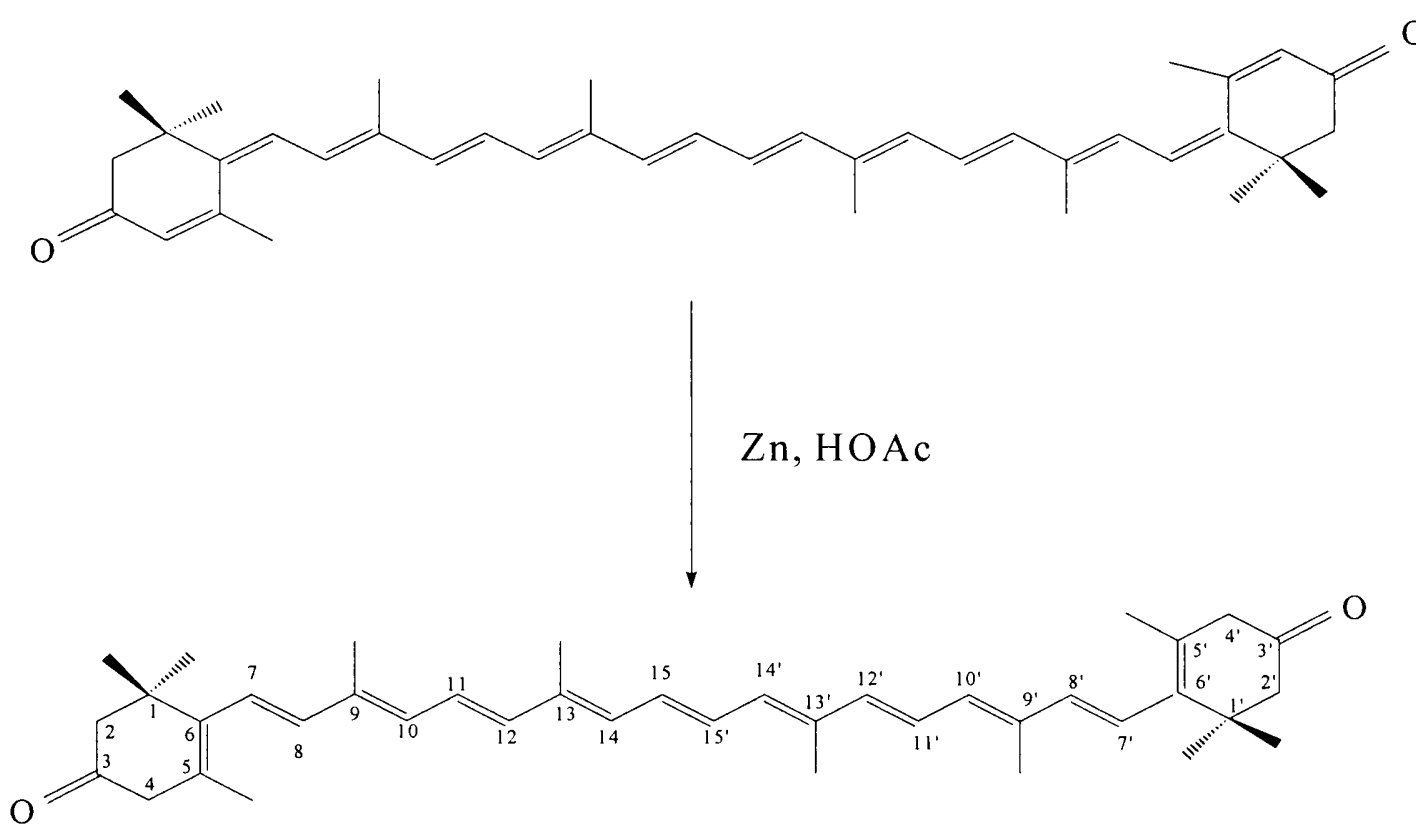

Compound 1

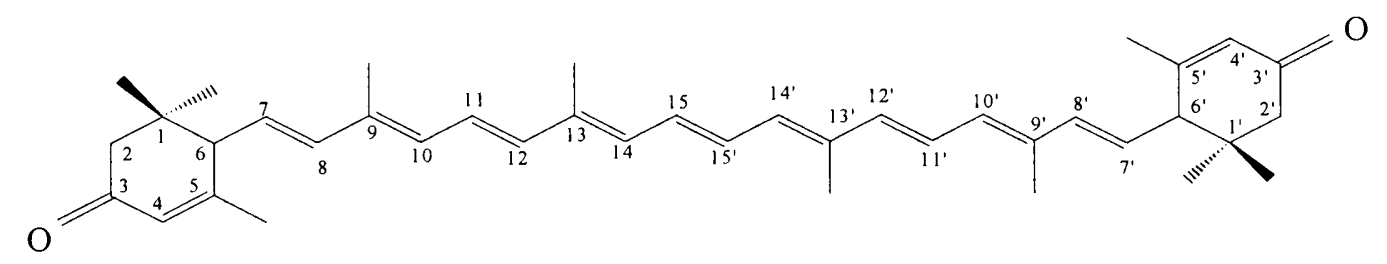

Compound 2

Figure 2.17 The possible candidates for the reduction product formed by the reaction of rhodoxanthin with $\mathrm{Zn} / \mathrm{HOAc}$

\subsubsection{Results}

\subsubsection{HPLC analysis}

Compound 1 (produced by $\mathrm{Zn} / \mathrm{HOAc}$ reduction of rhodoxanthin) was collected and purified by HPLC (System 2). The retention time was determined by HPLC (system 1). The elution time of compound 1 on this system was determined to be 8.30 minutes. 
The reason being the smaller column used in this experiment gives more consistent and reproducible results than system 1 . The chromatogram can be seen in Figure 2.18 and Figure 2.19 .

The reversed-phase chromatogram of the intermediate product of rhodoxanthin reduction and other by-products

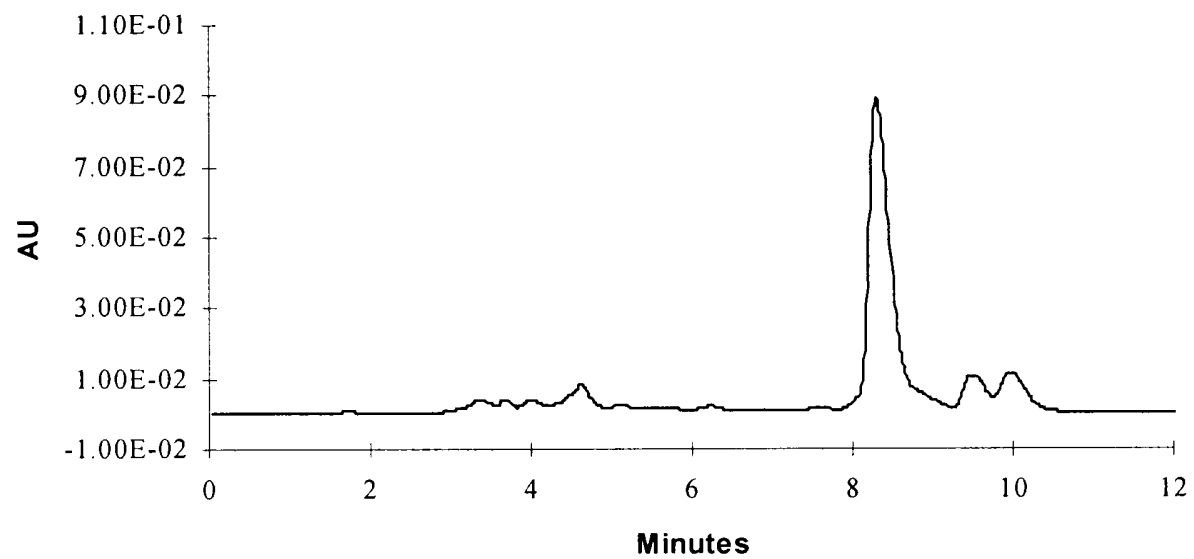

Figure 2.18 HPLC of product mixture formed by reduction of rhodoxanthin with $\mathrm{Zn} / \mathrm{HOAc}$

The reversed-phase chromatogram of purified product from the reduction of rhodoxanthin

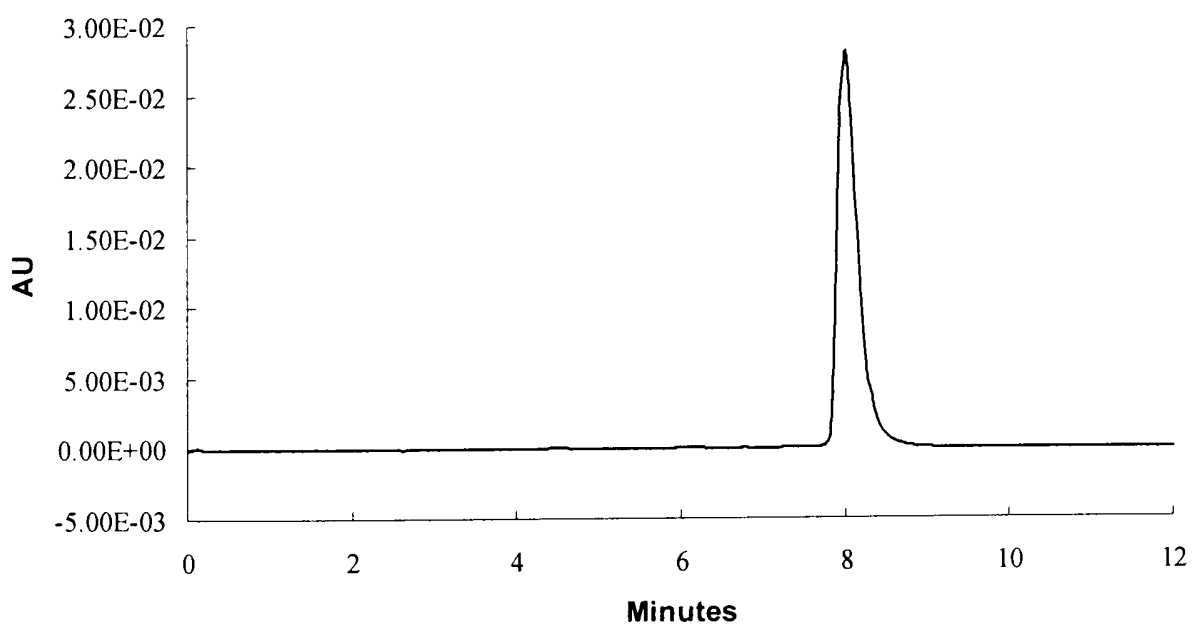

Figure 2.19 Purified compound 1 from reduction of rhodoxanthin with $\mathrm{Zn} / \mathrm{HOAc}$ (system II) 


\subsubsection{UV/Vis analysis}

UV/Visible spectrum of compound 1 has three absorption bands. Band II, $\lambda_{\max }$ in $\mathrm{EtOH}$ was at $450 \mathrm{~nm}$.

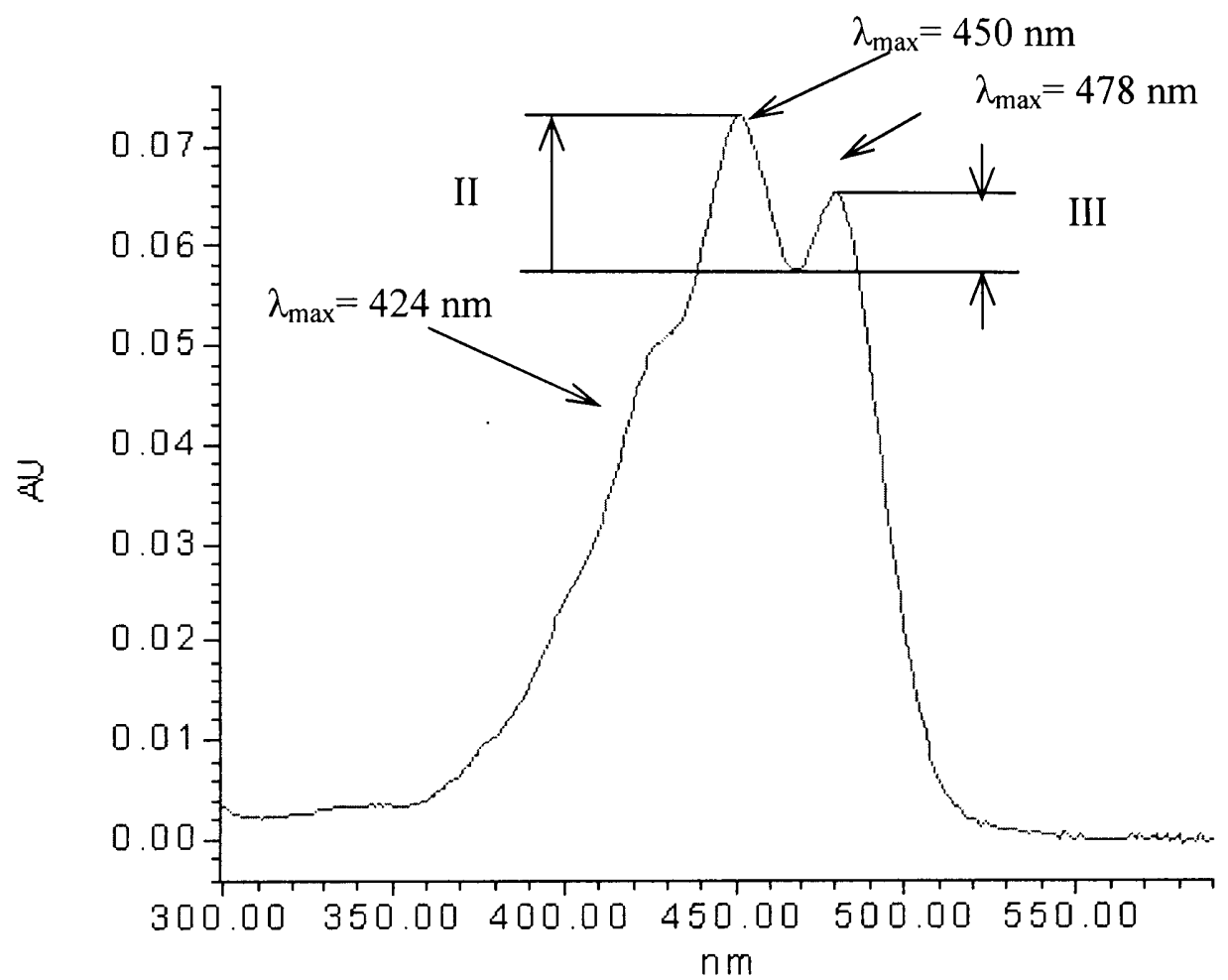

Figure $2.20 \mathrm{UV} /$ Visible spectrum of compound $1 . \lambda_{\max }=450 \mathrm{~nm}$. III $/ \mathrm{II}=50 \%$

\subsubsection{MS analysis}

MS analysis of carotenoids was done using APCI positive ion method. The Figure 2.21 shows base peak at $565 \mathrm{~m} / \mathrm{z}$.

\subsubsection{NMR analysis}

NMR, see Figure 2.22, for compound 1 has a large number of peaks. In the following table, some of the data from the unknown compound (the intermediate product formed by the reduction of rhodoxanthin) are assigned proton NMR spectra. These assignments enable us to identify the type of the ionone ring. 


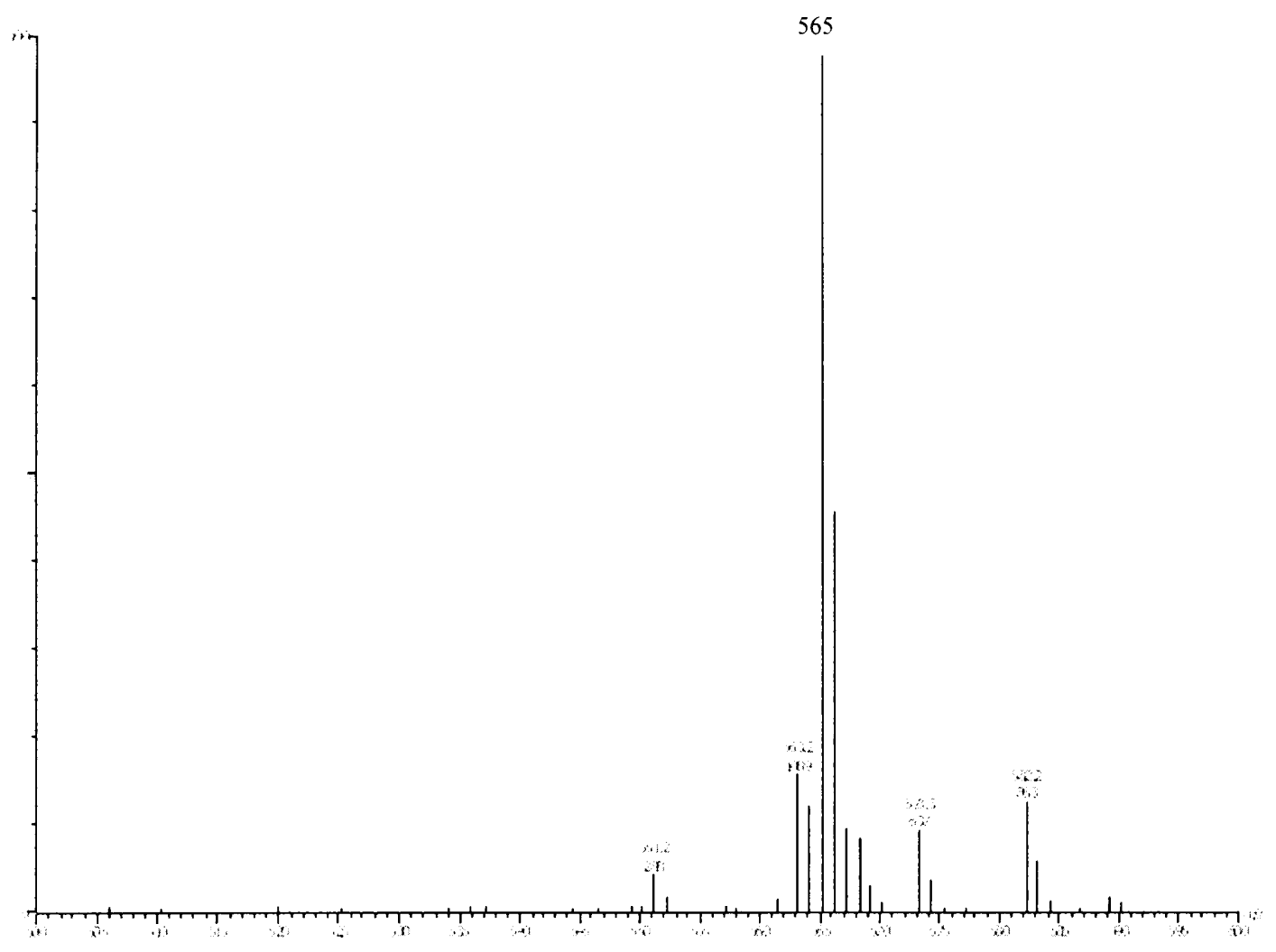

Figure 2.21 The $\mathrm{APCI}^{+}$Mass Spectrum of the reduction of rhodoxanthin

Table 2.3 Experimental ${ }^{1} \mathrm{H}-\mathrm{NMR}$ data of intermediate product formed by reduction of rhodoxanthin

\begin{tabular}{ccc}
\hline $\begin{array}{c}\text { Proton } \delta \text { ppm } \\
\text { ring) }\end{array}$ & $\begin{array}{c}\text { Chemical Shift }(\beta- \\
\text { ring) }\end{array}$ & Integration \\
\hline a. $\mathrm{H}-\mathrm{C}(1)$ & 1.084 & 3 \\
b. $\mathrm{H}-\mathrm{C}(2)$ & 2.415 & 1 \\
c. $\mathrm{H}-\mathrm{C}(4)$ & 2.895 & 1 \\
d. $\mathrm{H}-\mathrm{C}(6)$ & $\mathrm{N} / \mathrm{A}$ & N/A \\
\hline
\end{tabular}

$a, b, c, d$ refer to the position of hydrogens on the spectrum (see Figure 2.22) 


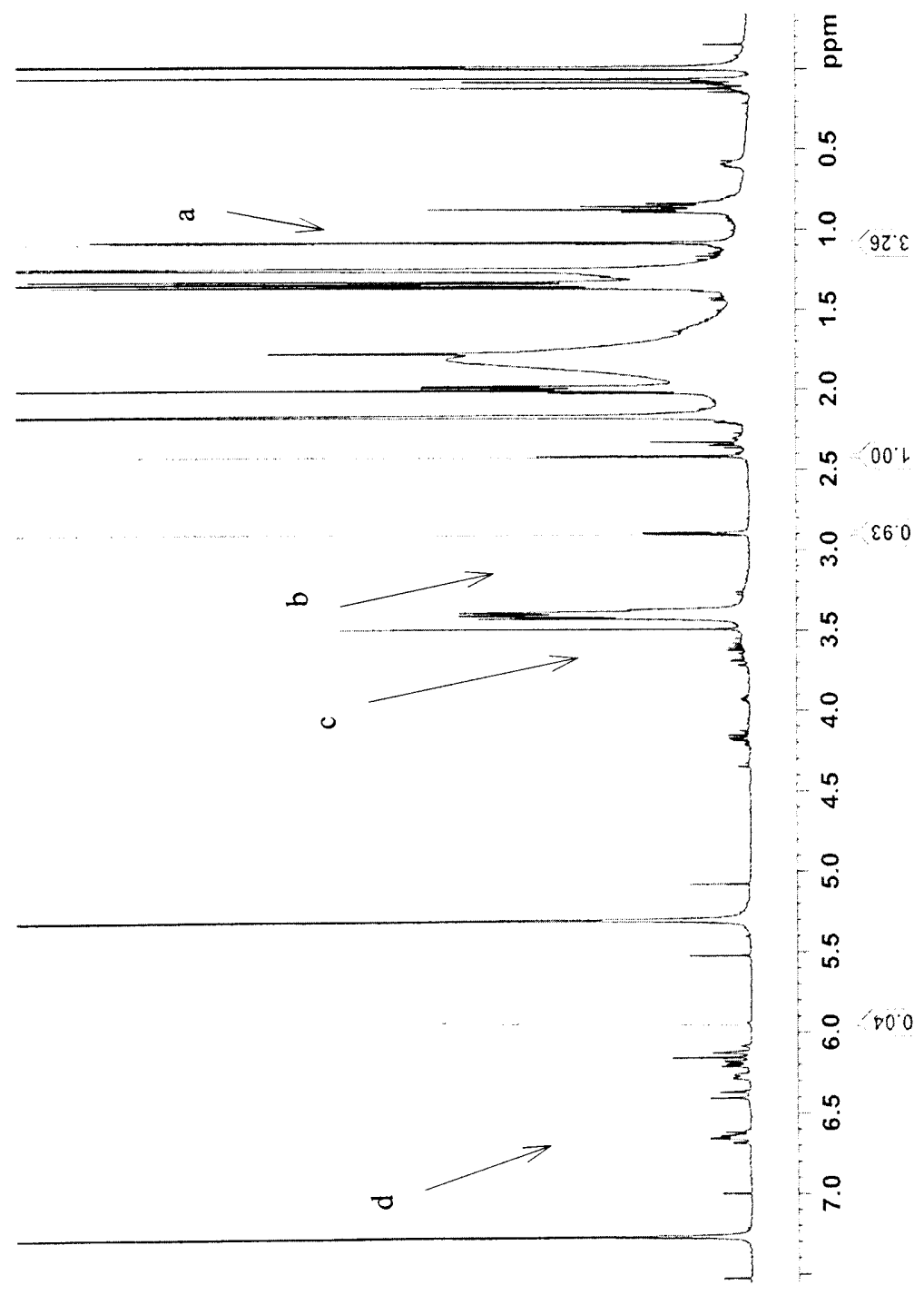

Figure $2.22{ }^{1} \mathrm{H}-\mathrm{NMR}$ of compound 1 obtained in $\mathrm{CDCl}_{3}, 400 \mathrm{MHz}$ 


\subsubsection{IR analysis}

Infrared spectroscopy was helpful in confirming the presence of the carbonyl functional groups in the compound. As it can be observed in Figure 2.23, the presence of a carbonyl is confirmed by a sharp, strong band at $1720 \mathrm{~cm}^{-1}$.

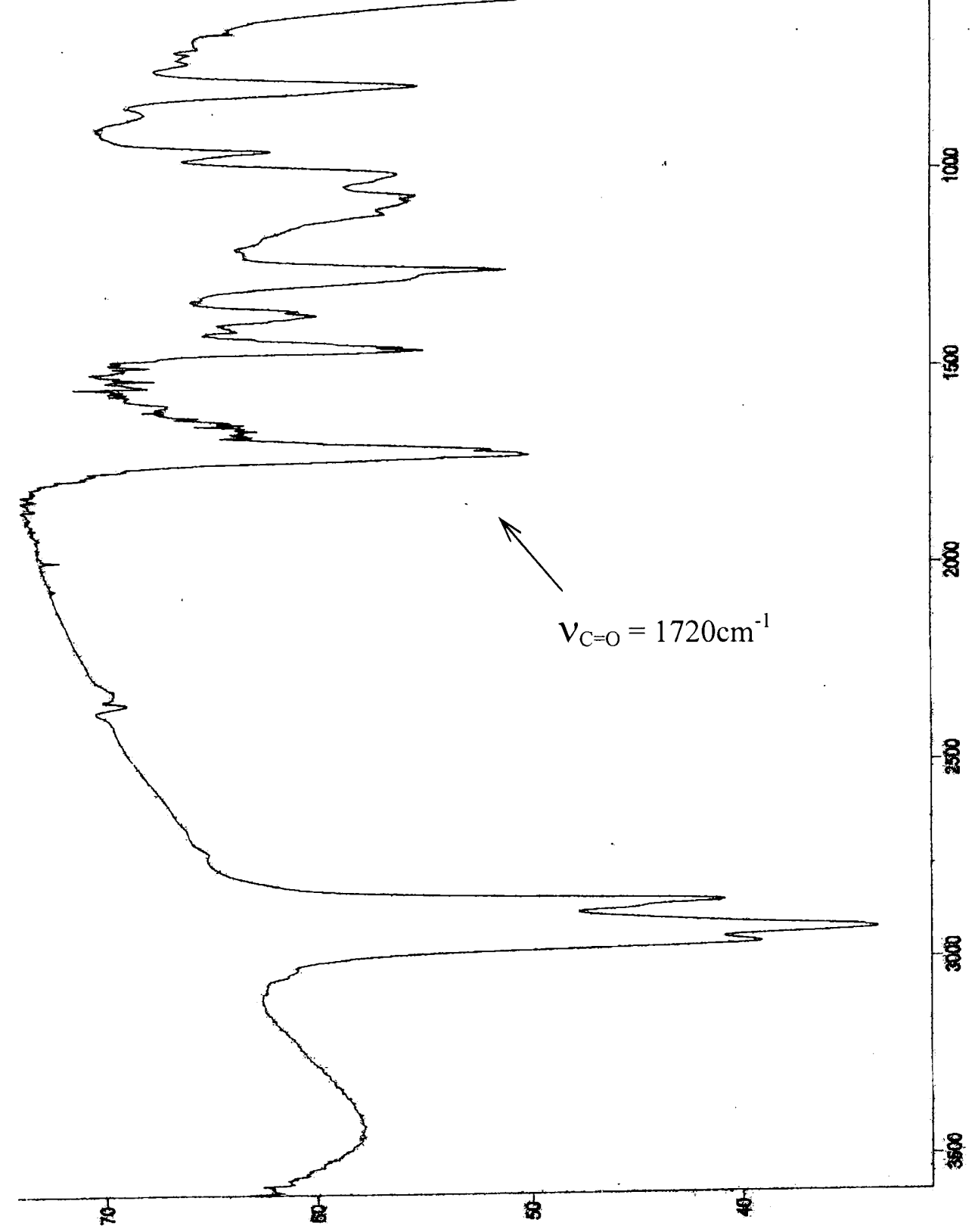

Figure 2.23 IR of the compound 1 
As mentioned previously, oxo-lutein, which processes an $\varepsilon$-ring, has been extensively studied in our lab. We can compare the spectrum of $\varepsilon$-ring of oxo-lutein with the spectrum of compound 1. The spectrum of oxo-lutein is shown in Figure 2.24. The chemical shifts and integrations are listed in following table.

Table 2.4 Experimental ${ }^{1} \mathrm{H}-\mathrm{NMR}$ data and literature data of oxo-lutein

\begin{tabular}{c|c|c|c|c}
\hline \multirow{2}{*}{ Proton $\delta(\mathrm{ppm})$} & \multicolumn{2}{|c}{ Exprimental } & \multicolumn{3}{c}{ Literature $^{37}$ at $400 \mathrm{MHz}$} \\
\cline { 2 - 5 } & chemical shift & integration & chemical shift & integration \\
\hline a H-C(2) & 1.94 & 2 & $2.10 / 2.38$ & 2 \\
b H-C(4) & 5.84 & 1 & 5.91 & 1 \\
c H-C(6) & 2.62 & 1 & 2.61 & 1 \\
\hline
\end{tabular}

$\mathrm{a}, \mathrm{b}$, and $\mathrm{c}$ refer to the positions of hydrogens on the spectrum, see Figure 2.24

\subsubsection{Discussion}

$\mathrm{UV} / \mathrm{Vis}$ shows the wavelength maximum (band II) of the intermediate product (compound 1) formed from the reduction of rhodoxanthin is observed at $450 \mathrm{~nm}$. Bands I and III, at either side of the main absorption band are observed at $424 \mathrm{~nm}$ and $478 \mathrm{~nm}$, respectively. $\lambda_{\max }$ is nearly that identical to be observed for zeaxanthin. A useful feature of carotenoid spectra is the III/II ratio. The ratio of the vibrational bands (III/II) for compound 1 is $50 \%$. This value proves that the end-groups in the molecule are not $2 \varepsilon$ rings. Another important feature of the spectrum should be emphasized, like zeaxanthin, compound 1 has 3 bands and therefore the carbonyls are not conjugated with the polyene chain. The $\lambda_{\max }$ of compound 1 was observed at $450 \mathrm{~nm}$ as opposed to the single broad band observed for rhodoxanthin of $490 \mathrm{~nm}$. This hypsochromic shift is consistent with a loss in conjugation in the system. The overall hypsochromic shift of about $40 \mathrm{~nm}$ compared to rhodoxanthin indicates that three bonds have been lost in the conjugated system. 


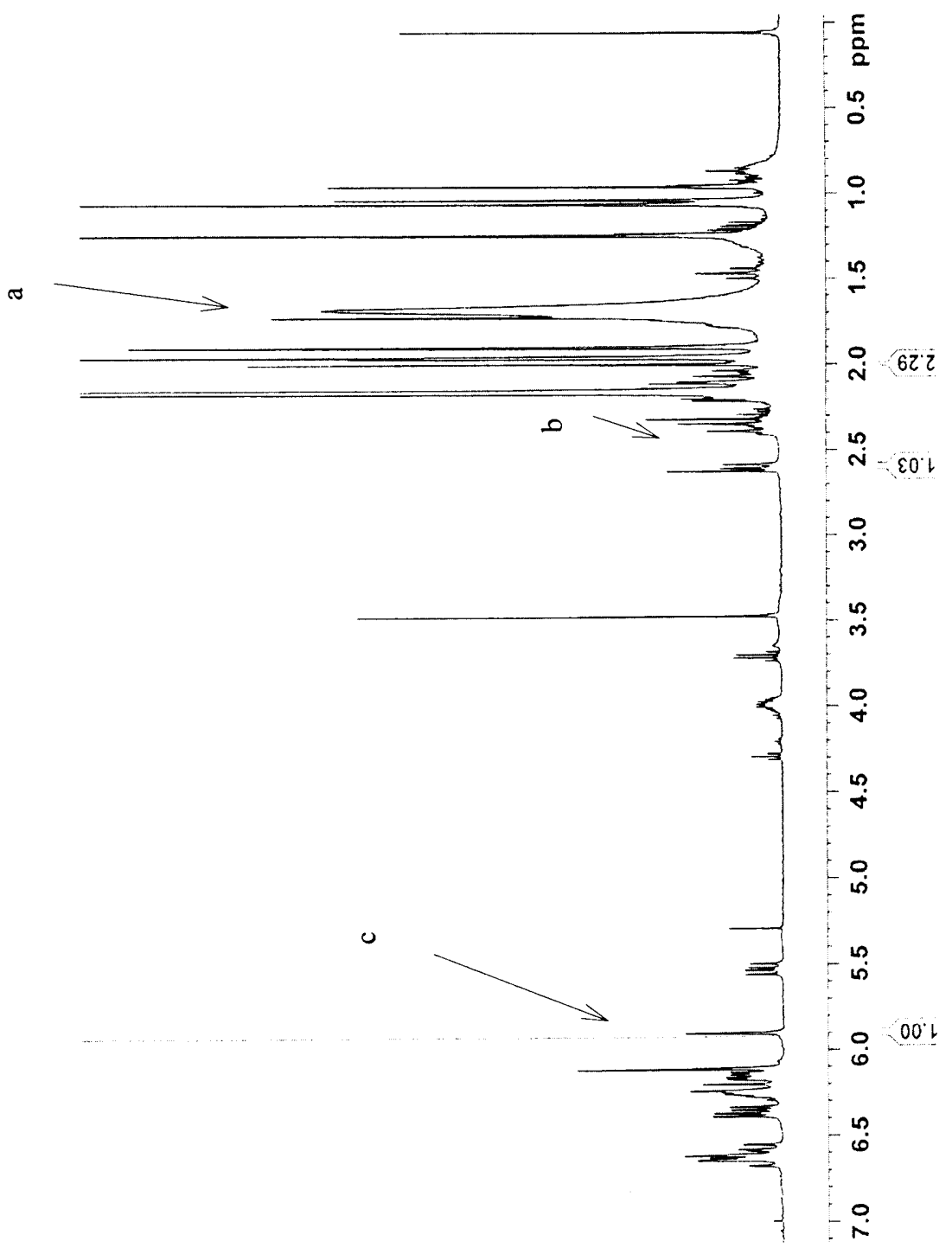

Figure $2.24{ }^{1} \mathrm{H}-\mathrm{NMR}$ of oxo-lutein ( $\varepsilon$-ring) obtained in $\mathrm{CDCl}_{3}, 400 \mathrm{MHz}$ 
The mass spectrum shows a quasimolecular ion at $[\mathrm{M}+\mathrm{H}]^{+}=565 \mathrm{~m} / \mathrm{z}$. This peak corresponds to the molecular weight of the final product plus the addition of a proton. The mass is consistent with the proposed structure, Figure 2.17

NMR peaks between 1.0 to $2.5 \mathrm{ppm}$ were assigned to the protons on saturated methyl carbons [C(2,2'), $\left.\mathrm{C}\left(4,4^{\prime}\right), \mathrm{C}\left(16,16^{\prime}\right), \mathrm{C}\left(17,17^{\prime}\right), \mathrm{C}\left(18,18^{\prime}\right), \mathrm{C}\left(19,19^{\prime}\right), \mathrm{C}\left(20,20^{\prime}\right)\right]$. Those around $6 \mathrm{ppm}$ are attributed to the olefinic protons on the double carbon bonds $\left[\mathrm{C}\left(7,7^{\prime}\right), \mathrm{C}\left(8,8^{\prime}\right), \mathrm{C}\left(10,10^{\prime}\right), \mathrm{C}\left(11,11^{\prime}\right), \mathrm{C}\left(12,12^{\prime}\right), \mathrm{C}\left(14,14^{\prime}\right), \mathrm{C}\left(15,15^{\prime}\right)\right]$. There is no literature NMR data for this compound. The peak at $7.28 \mathrm{ppm}$ was caused by the residual proton in the solvent $\left(\mathrm{CDCl}_{3}\right)$ and this value is identical to the data in the literature $(\delta=7.26 \mathrm{ppm}) .{ }^{38} \mathrm{~A}$ broad peak around $1.8 \mathrm{ppm}$ was caused by residual $\mathrm{H}_{2} \mathrm{O}$ in the solvent or saturated fatty residue in the sample.

Because identification of a carotenoid is primarily dependent on assignment of the structure of the end-group rings the assignment of the NMR peaks of the ionone ring $\mathrm{H}$ atoms is very important. The intermediate formed by the reduction of rhodoxanthin is very unstable, so the limited amount of sample can be obtained to elucidate the structure. Since only ${ }^{1} \mathrm{H}-\mathrm{NMR}$ spectrum can be obtained, it is challenging to fully elucidate the structure. The only unambiguous way to distinguish between the different end-groups is to compare the difference between proton resonances in the end-rings. As seen in Figure 2.25 , the difference between $\beta$-ring and $\varepsilon$-ring is the position of carbon-carbon bond. From the structure, it is clear that $\mathrm{H}_{(\mathrm{d})}$ is present in the $\varepsilon$-ring, while $\mathrm{H}_{(\mathrm{d})}$ is absent in the $\beta$ ring. There is only one $\mathrm{H}_{(\mathrm{c})}$ in the $\varepsilon$-ring, while two $\mathrm{H}_{(\mathrm{c}) \mathrm{S}}$ are present in the $\beta$-ring. Therefore, $\mathrm{H}_{(\mathrm{d})}$ peak should be absent on the spectrum of compound 2. The integration of $\mathrm{H}_{(\mathrm{a})}: \mathrm{H}_{(\mathrm{c})}$ or $\mathrm{H}_{(\mathrm{b})}: \mathrm{H}_{(\mathrm{c})}$ in the $\beta$-ring is $3: 1$, while $\mathrm{H}_{(\mathrm{a})}: \mathrm{H}_{(\mathrm{c})}$ or $\mathrm{H}_{(\mathrm{b})}: \mathrm{H}_{(\mathrm{c})}$ is $6: 1$ in the $\varepsilon$-ring. $\mathrm{H}_{(\mathrm{d})}$ 
is a critical hydrogen in the structure. The spectrum of oxo-lutein (Figure 2.24) shows a singlet peak $\sim 2.6 \mathrm{ppm}$, while no peaks near $2.6 \mathrm{ppm}$ are present in the spectrum of the intermediate formed from the reduction of rhodoxanthin. This is consistent with a $\beta$-ring assigenment. Another critical hydrogen in the structure is $\mathrm{H}_{(\mathrm{c}) \text {. }}$ Because the $\mathrm{H}_{(\mathrm{c})}$ is attached to the $\mathrm{sp}^{2}$ carbon center in the $\varepsilon$-ring, the $\mathrm{H}_{(\mathrm{c})}$ resonance is downfield at $\sim 5.9 \mathrm{ppm}$, while in the $\beta$-ring, since $\mathrm{H}_{(\mathrm{c})}$ is attached to the $\mathrm{sp}^{3}$ carbon center, the $\mathrm{H}_{(\mathrm{c})}$ resonance is upfield at $\sim 2.8 \mathrm{ppm}$. The resonance of $\sim 5.9 \mathrm{ppm}$ should be absent on the $\beta$-ring spectrum. Even if some peaks are downfield at $\sim 5.9 \mathrm{ppm}$ on the $\beta$-ring spectrum, they might be from olefinic protons on the double carbon bonds. A minor peak at $5.9 \mathrm{ppm}$ is present in the spectrum of compound 1. However, the integration of the peak at $5.9 \mathrm{ppm}, 2.4 \mathrm{ppm}\left[\mathrm{H}_{(\mathrm{c})}\right]$, and $1.1 \mathrm{ppm}\left[\mathrm{H}_{(\mathrm{a})}\right]$ are $0.02,0.31$, and 1 , respectively. Table 2.5 presents a comparison of resonances for the intermediate obtained by reduction of rhodoxanthin and those of the $\varepsilon$ ring in oxo-lutein. The ratio of integrations between $5.9 \mathrm{ppm}$ and $2.4 \mathrm{ppm}\left[\mathrm{H}_{(\mathrm{c})}\right]$ is $1: 15$, and $5.9 \mathrm{ppm}$ and $1.1 \mathrm{ppm}\left[\mathrm{H}_{(\mathrm{a})}\right]$ is 1:50. Thus, on the $\beta$-ring spectrum, we conclude that the peak of $5.9 \mathrm{ppm}$ is from the impurity in the reduction of rhodoxanthin.
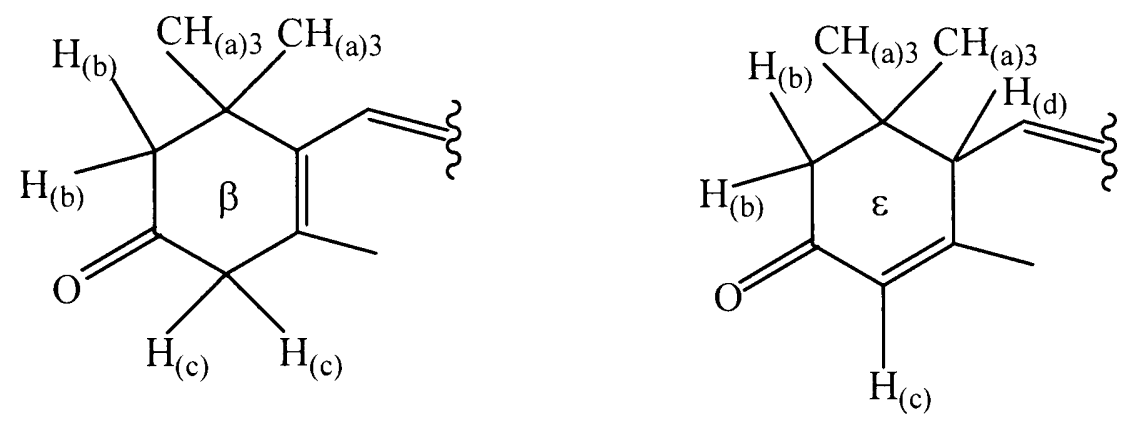

Figure 2.25 The chemical structure of $\beta$-ring and $\varepsilon$-ring 
TABLE 2.5 Chemical shifts, integration, and assignments of different hydrogens in the intermediate product formed by reduction of rhodoxanthin

\begin{tabular}{ccccc}
\hline \multirow{2}{*}{ Proton Sppm } & \multicolumn{2}{c}{ Chemical Shift } & \multicolumn{2}{c}{ Integration } \\
\cline { 2 - 5 } & $\beta$ & $\varepsilon$ & $\beta$ & $\varepsilon$ \\
\hline a. H-C $(1)$ & 1.084 & 1.1 & 3 & 6 \\
b. H-C $(2)$ & 2.415 & 1.936 & 1 & 2 \\
c. H-C $(4)$ & 2.895 & 5.84 & 1 & 1 \\
d. H-C $(6)$ & N/A & 2.62 & N/A & 1 \\
\hline
\end{tabular}

\section{Conclusion}

Compound 1 was prepared by synthesis from all-trans zeaxanthin by in vitro oxidation with $\mathrm{MnO}_{2}$, followed reduction with $\mathrm{Zn} / \mathrm{HOAc}$ in $\mathrm{CH}_{2} \mathrm{Cl}_{2}$. Preparative TLC and preparative reversed-phase HPLC were used to purify rhodoxanthin and the compound 1 , respectively. Compound 1 was collected for further identification. HPLC retention time, IR, and MS information demonstrate compound 1 is a diketone having the formula $\mathrm{C}_{40} \mathrm{H}_{52} \mathrm{O}_{2}$. IR spectrum of compound 1 shows a strong absorption at $1720 \mathrm{~cm}^{-1}$ consistent with presence of the isolated carbonyl. $\mathrm{APCI}^{+} \mathrm{MS}$ spectrometry shows a base peak at $565 \mathrm{~m} / \mathrm{z}$ and demonstrates that the molecular weight of compound 1 is 564 . UV/Visible spectrum of the compound 1 shows $\lambda_{\max }=450 \mathrm{~nm}$, and III $/ \mathrm{II}=50 \%$. Study of the ${ }^{1} \mathrm{H}-\mathrm{NMR}$ was carried out in order to characterize the ionone rings. By comparison of chemical shifts and integrations of ionone ring protons in compound 1 to those compounds such as, oxo-lutein (Figure 2.26), the end-groups of compound 1 were demonstrated to have NMR spectra consistent with the $\beta$-ring but not an $\varepsilon$-ring. We conclude that the structure of compound 1 is elucidated to be $\beta, \beta$-carotene-3,3'- dione. 


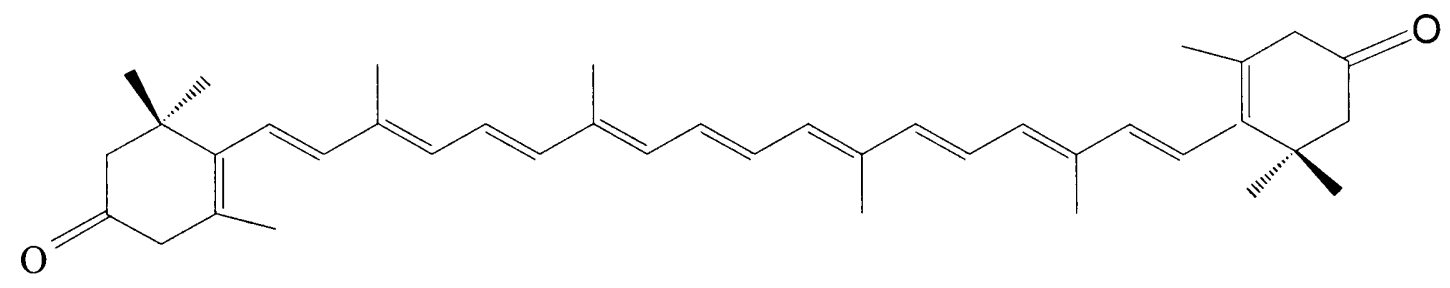

Figure 2.26 The elucidated structure of compound 1 


\section{CHAPTER III MEASUREMENT OF THE CAROTENOIDS STEREOISOMERS IN THE NON-HUMAN \\ PRIMATE RETINA, NEONATAL RETINA AS A FUNCTION OF AGE}

\section{Overview:}

Zeaxanthin and lutein are the two main components of macular pigment in the inner macula. ${ }^{21}$ Lutein and zeaxanthin are yellow pigments and are widespread in nature. Zeaxanthin, $\beta, \beta$-carotene-3,3'-diol, see Figure 3.1 , is a common component in human serum. Although it is not the most abundant carotenoid in serum, it is a main component of macular pigment in the inner macula where the concentration of zeaxanthin is about twice that of lutein. ${ }^{22}$ Lutein is also a common micronutrient, and it is also one of the most abundant carotenoids found in the human body. The structure of lutein, $\beta, \varepsilon-$ carotene-3,3'-diol, is shown in Figure 3.2. Both lutein and zeaxanthin act as antioxidants in biological systems. ${ }^{43,44,45}$<smiles>CC1=C(/C=C/C(C)=C/C=C/C(C)=C/C=C/C=C(C)/C=C/C=C(C)/C=C/C2=C(C)[C@H](O)CC2(C)C)C(C)(C)C[C@H](O)C1</smiles>

A

$\mathrm{HO}$<smiles>CC1=C[C@H](O)CC(C)(C)C1/C=C/C(C)=C/C=C/C(C)=C/C=C/C=C(C)/C=C/C=C(C)/C=C/C1=C(C)C[C@@H](C)CC1(C)C</smiles>

B

Figure 3.1 The chemical structure of zeaxanthin, A, ( $\beta, \beta$-carotene-3,3'-diol) and lutein, $B,(\beta, \varepsilon$-carotene-3,3'-diol) are shown above. 
The macula is the anatomical region of the retina that is responsible for central vision. The macular pigment has a protective function for shielding the central retina from excess blut-light. ${ }^{26}$ The neutral retina is composed of several functionally and structurally distinct layers overlaying and supporting the cone and rod photoreceptors. It is in the inner layers of the retina, the so-called Henle fibers, consisting of the neural axons in which the largest amount of macular pigment is found. ${ }^{26}$ Macular lutein is believed to function as a blue light filter by absorbing a significant portion of blue light that reaches the retina. ${ }^{23}$ In the average person the macular carotenoids can reduce the blue light intensity reaching photoreceptors by about 40 percent. ${ }^{22}$ Blue light can cause the formation of singlet oxygen, triplet excited state species, and free radicals. Lutein and zeaxanthin may act as active quenchers of singlet oxygen, and excited state triplets. They can react with and deactivate radical species preventing chain propagation. ${ }^{45}$ These actions all appear to be functions of carotenoids of the macular pigment.

Age-related macular degeneration (AMD) is one of the eye diseases which disrupt the normal functioning of the macula. It occurs in about $20 \%$ of people over the age of $65^{22,25}$ As the population ages, there is an accompanying need to identify strategies that will prevent or delay the onset of AMD. Such strategies must reduce the prevalence of visual impairment and blindness among the elderly. Increasing macular levels of lutein and zeaxanthin may play an important part of these strategies. ${ }^{24}$

Zeaxanthin (Z, including RRZ, RSZ, and SSZ) exists naturally in 3 distinct stereoisomeric forms, R,R-zeaxanthin (RRZ), S,S-zeaxanthin (SSZ), and R,S-zeaxanthin (RSZ), see Figure 3.2. RRZ is the most common form of zeaxanthin and is the only 
stereoisomer produced in higher plants. The other two isomers are only occasionally found and generally are the result of metabolism in animals. ${ }^{46}$<smiles>CC1=C(/C=C/C(C)=C/C=C/C(C)=C/C=C/C=C(C)/C=C/C=C(C)/C=C/C2=C(C)[C@H](O)CC2(C)C)C(C)(C)C[C@H](O)C1</smiles>

$\left(3 \mathrm{R}, 3^{\prime} \mathrm{R}\right)-\beta, \beta$-carotene-3,3'-diol

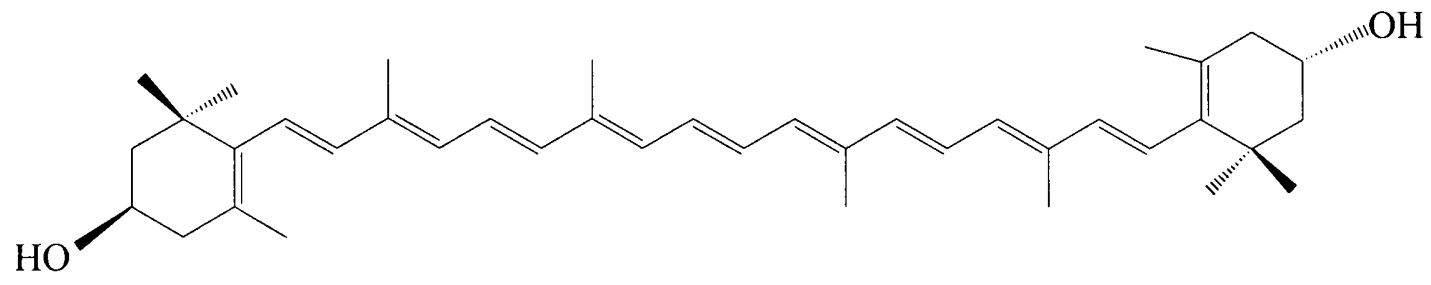

(3R,3'S)- $\beta . \beta$-carotene-3,3'-diol

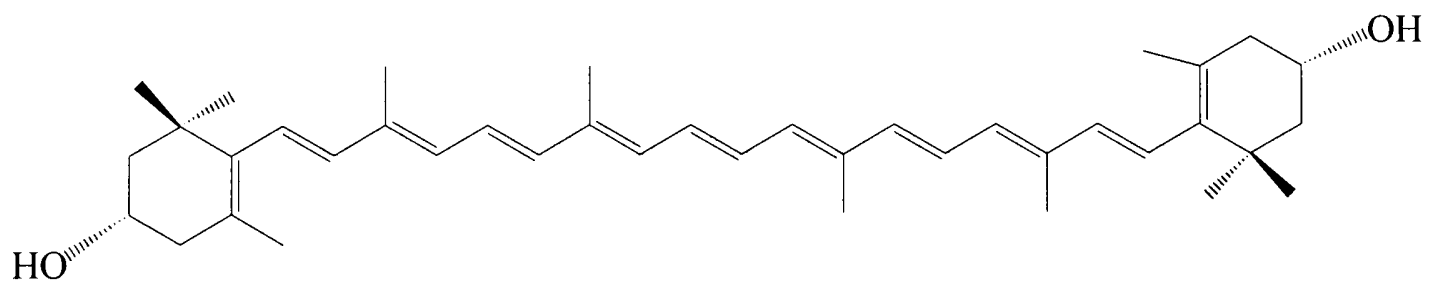

(3S, 3'S)- $\beta, \beta$-carotene-3,3'-diol

Figure 3.2 The three stereoisomers of zeaxanthin $3 R, 3^{\prime} R-\beta, \beta$-carotene-3,3' -diol (3R,3'Rzeaxanthin), 3S,3'S- $\beta, \beta$-carotene-3,3'-diol (3S,3'S-zeaxanthin), and 3R,3'S- $\beta$, $\beta$-carotene3,3'-diol (3R,3'S-zeaxanthin).

Based on previous work, the distribution of zeaxanthin and lutein throughout the human retina and the change in lutein and zeaxanthin in human retina with age has been investigated by Bone and Landrum. ${ }^{21}$ Also, Johnson and co-workers have demonstrated that lutein is the precursor of RSZ, a major component of macular pigment. ${ }^{32}$ 
Our study, prompted by earlier results, is an investigation of the carotenoid distribution in any single retina from 32 non-human primates in order to determine if there is a relationship between the amounts of the carotenoids found in the retina and age in the earliest stages of development.

\section{Experimental Section}

2.1 Reagents and materials

HPLC grade methanol, acetonitrile, hexane, isopropanol, and ethanol were purchased from Fisher. Primate retinas were obtained from the Oregon National Primate Research Center in accordance with institutional IACUC requirements.

\subsection{Apparatus}

Reversed-phase HPLC system 1, is a Waters 2690 separation module coupled with a Waters 486 tunable absorbance UV/Visible detector and Water 996 photodiode array detector. Reversed-phase HPLC system 2, is an LDC Analytical ConstaMeric 3200 solvent delivery system equipped with a $500 \mu \mathrm{l}$ injection loop and coupled with a Thermo Finnigan Spectra system UV1000.

\subsection{Procedures}

All retina samples were analyzed on a reversed-phase column (Phenomenex, Ultracarb $3 \mu \mathrm{m}$ ODS, $150 \mathrm{~mm} \times 4.6 \mathrm{~mm}$ ) HPLC and a normal-phase, chiral column (Chiralpak AD-H, Derivatized amylose, $250 \mathrm{~mm} \times 4.6 \mathrm{~mm}$ ) HPLC. Zeaxanthin and lutein in the retinas were separated by reversed-phase HPLC, and then, the purified zeaxanthin was analyzed on the normal-phase chiral column. An internal standard, mono-propyl lutein (MPrL), was used to quantify carotenoids. The concentrations of zeaxanthin and lutein were determined by comparison to the peak area of the internal standard. 


\subsection{Retina extraction}

The retinas of primate eyes were cut into three sections, an inner ring $(0-2 \mathrm{~mm})$, a medial ring (2-4 mm), and an outer ring (4-8 mm), see Figure 3.3. For analysis a section of retina was transferred into a glass tissue homogenizer containing $10 \mu 1$ mono-propyl lutein (see internal standard section) and $2 \mathrm{ml}$ of acetone. The concentration of the internal standard was $24 \mathrm{ng}$ per $10 \mu \mathrm{l}$. The homogenized mixture was filtered through a $0.22 \mu \mathrm{m}$ nylon-mesh syringe filter and evaporated under a stream of pure nitrogen in a glass vial. The yellow carotenoids were dissolved in acetone and a whitish residue deposited on the wall of the vial. This vial was rinsed with cool acetone. The yellow solution was evaporated under nitrogen. All of these procedures were performed carefully under conditions of a dim light. The extracted carotenoid sample was dissolved in $8 \mu \mathrm{l}$ of ethanol for HPLC analysis, or the dried extracted carotenoid sample was stored in the dark $-80^{\circ} \mathrm{C}$ prior to HPLC analysis. To minimize experimental errors, all injections are handled by manual injection.

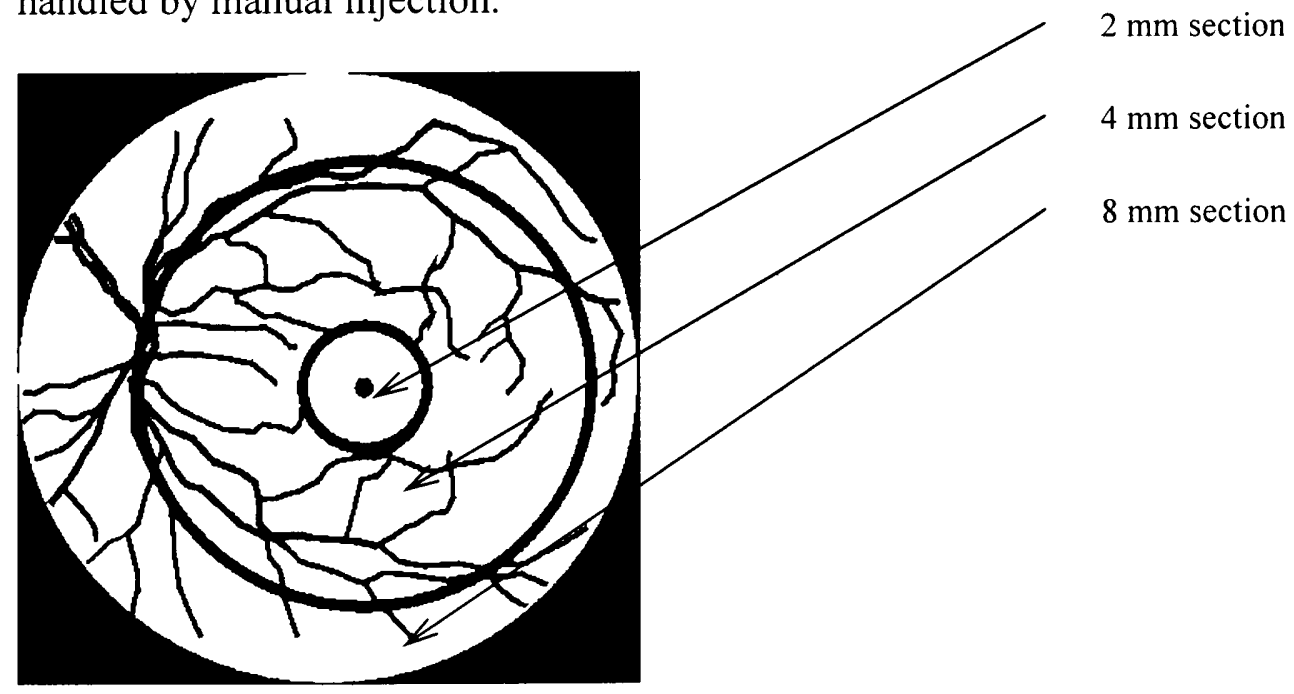

Figure 3.3 A view of a retina showing the sectioning. The retina was sectioned using punches that were 2,4 , and $8 \mathrm{~mm}$ in diameter 
2.5 Preparation of the Internal Standard, 3-hydroxy-3'-propoxy- $\beta, \varepsilon$-carotene, MPrL

The internal standard was chosen because of its chemical similarity to that of the analyte. It was shown that lutein and zeaxanthin and the internal standard have same percent recovery in the process of extraction and behave similarly on the HPLC column differing only in retention time. Both assumptions have been proven in a previous study in our group. ${ }^{36}$ Mono-propyl lutein was chosen as an internal standard for quantitative analysis of extracted carotenoids from retina in this experiment. ${ }^{35}$ The structure of MPrL is shown in Figure 3.4.

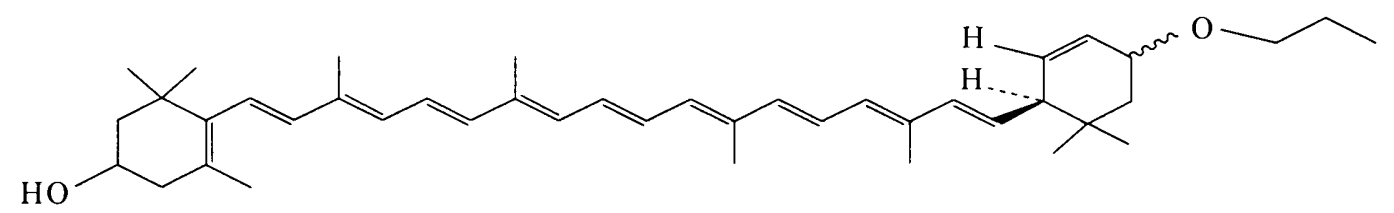

Figure 3.4 The chemical structure of monopropyl lutein, 3-hydroxy-3'-propoxy- $\beta, \varepsilon$ carotene.

Monopropyl lutein was synthesized as follows:

An acidified propanol solution was prepared by adding $10 \mathrm{ml}$ concentrated $\mathrm{HCl}$ to $90 \mathrm{ml} \mathrm{1-propanol.} \mathrm{About} 3 \mathrm{mg}$ of dry lutein was dissolved in $10 \mathrm{ml} \mathrm{1-propanol.} \mathrm{The}$ acidified alcohol solution containing the lutein was stirred at $22^{\circ} \mathrm{C}$ for at least 30 min to ensure that the reaction reached completion. About $50 \mathrm{ml}$ of saturated $\mathrm{NaHCO}_{3}$ solution was transferred to the mixture to quench the reaction. The carotenoids were extracted with 3 equal portions of $\mathrm{CH}_{2} \mathrm{Cl}_{2}$. The $\mathrm{CH}_{2} \mathrm{Cl}_{2}$ aliquots were combined and evaporated by a rotary evaporator. The resulting carotenoid reaction mixture containing MPrL was dissolved in acetone and purified by a reversed-phase HPLC system 2 (LDC/Milton Roy solvent delivery system) which is coupled to a UV-Visible detector set at $447 \mathrm{~nm}$. A manual injector with a $500 \mu$ injection loop was installed in this HPLC system. The 
column used was a Phenomenex Ultracarb ODS $3 \mu \mathrm{l}(250 \times 21.20 \mathrm{~mm})$. The flow rate was $5 \mathrm{ml} / \mathrm{min}$. The mobile phase used was $85 \%$ acetontrile, $15 \%$ methanol, with $0.1 \%$ $(\mathrm{V}: \mathrm{V})$ of triethylamine added. The MPrL peak was collected at a retention time of $40 \mathrm{~min}$ and concentrated by rotary evaporator and dried under a stream of nitrogen gas. The purified MPrL was redissolved in ethanol. The concentration of MPrL was determined from the absorption of the resulting solution at a wavelength of $447 \mathrm{~nm}$. The absorption coefficient of MPrL is identical to that of lutein $\varepsilon=1.5 \times 10^{-5} \mathrm{M}^{-1} \mathrm{~cm}^{-1}$.

2.6 Preparation of zeaxanthin racemic mixtures

In order to measure the zeaxanthin stereoisomer composition in the tissue, we prepared standards of all three zeaxanthin stereoisomers. The two steps of this procedure are described in Chapter II. The last step was carried-out as follows: $\beta, \beta$-Carotene-3,3'dione was redissolved in methylene chloride. Treatment of the methylene chloride solution with sodium borohydride resulted in no color changes. The resulting product contains a statistical mixture of the three zeaxanthin stereoisomers which were characterized by UV spectrum and HPLC retention time. The retention time of the racemic zeaxanthin stereoisomers is $6.3 \mathrm{~min}$ on reserved-phase HPLC and is consistent with an authentic zeaxanthin standard. The racemic mixture of three zeaxanthin stereoisomers was resolved by chiral normal-phase HPLC, as illustrated in Figure 3.5. In Figure 3.5 the fourth peak is lutein. From Figure 3.5, it is seen that the second eluting peak is as twice size as the first and third peaks, so, based on the statistical distribution, the second peak of zeaxanthin isomers is identified as (3R,3'S)-zeaxanthin (RSZ). The R,R-zeaxanthin stereoisomer was identified as the third peak in the chromatogram with a retention time of at about $17.3 \mathrm{~min}$ by co-injection with an authentic standard (3R,3'R)- 
zeaxanthin (RRZ). It is concluded that the first peak was SSZ. The retention times of SSZ and RSZ were $13.8 \mathrm{~min}$ and $15.9 \mathrm{~min}$, respectively on chiral column. The zeaxanthin racemic mixtures were used as a standard to identify zeaxanthin stereoisomers isolated from retinal tissue.

The chiral normal-phase chromatogram of zeaxanthin racemic mixture

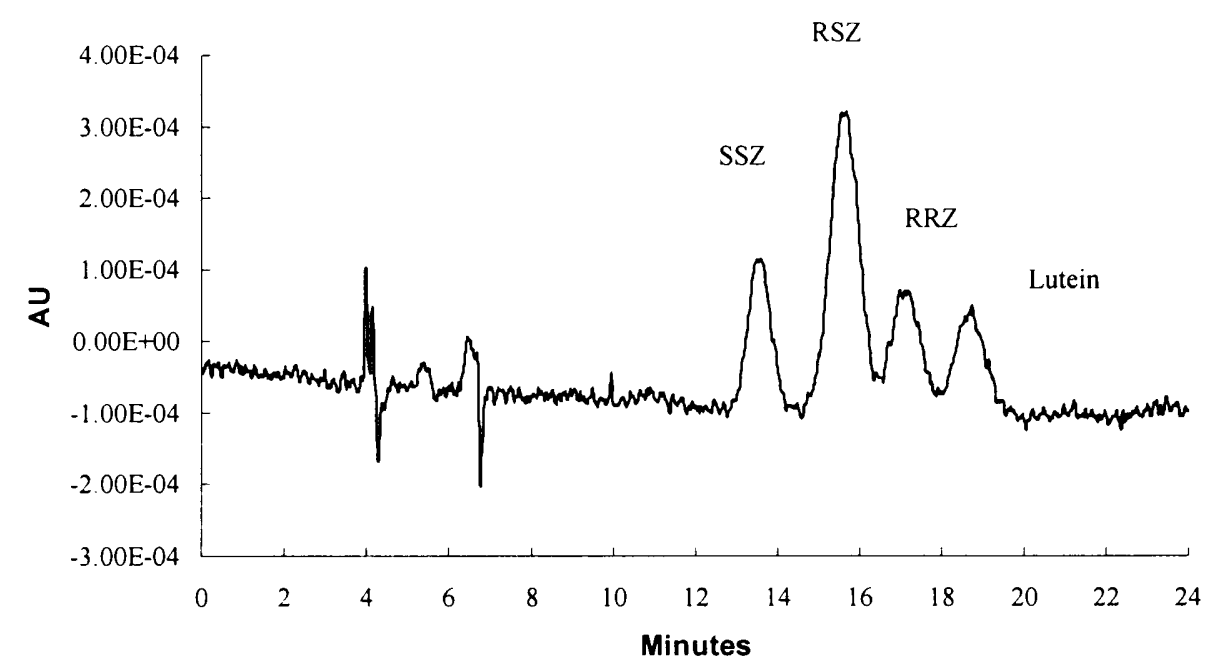

Figure 3.5 The chromatogram showing the separation of a sample which also contained a small amount of lutein

2.7 Reversed-phase HPLC conditions

Analysis of all extracted carotenoids from retina samples were conducted on reversed-phase HPLC system (LDC/Milton Roy solvent delivery system) which was coupled to an UV-Visible detector set at $450 \mathrm{~nm}$. The column used was a $150 \times 4.6 \mathrm{~mm}$ C18 column packed with $3 \mu \mathrm{m}$ Ultracarb ODS (Phenomenex) and was protected with a C18 Phenomenex guard cartridge. Separation was achieved with a mobile phase of $85 \%$ acetonitrile and $15 \%$ methanol, with $0.1 \%(\mathrm{~V} / \mathrm{V})$ of triethylamine added to inhibit degradation of carotenoids during elution. The flow rate was $1.0 \mathrm{ml} / \mathrm{min}$. 
Analysis of all zeaxanthin collected from retina samples were conducted on a Waters 2690 separation module HPLC with a Waters 486 UV tunable detector set at 450 $\mathrm{nm}$ and photodiode array detector set from $300 \mathrm{~nm}$ to $600 \mathrm{~nm}$. The data was stored and processed using the Millenium ${ }^{\mathrm{TM}}$ software. The column used was a $250 \times 4.6 \mathrm{~mm} \mathrm{C18}$ column.

In order to achieve the best resolution of the zeaxanthin stereoisomers, a very specific composition of mobile phase was needed. Based on Johnson's work ${ }^{32}$, we conducted a investigation to optimize the solvent conditions needed to separate the zeaxanthin stereoisomers. It was determined that a composition of the mobile phase containing $90 \%$ hexane and $10 \%$ isopropanol, always with $0.1 \%(\mathrm{~V} / \mathrm{V})$ of triethylamine added to inhibit degradation of carotenoids during elution result in the separation of the zeaxanthin stereoisomers. The flow rate used for all separations was $0.8 \mathrm{~min} / \mathrm{ml}$. The solvent composition was varied from $90 \%$ hexane to $94 \%$ hexane and the resolution of the stereoisomers was determined using the following equation: ${ }^{47}$

$$
\mathrm{R}=\frac{2\left[\left(\mathrm{t}_{\mathrm{R}}\right)_{\mathrm{B}}-\left(\mathrm{t}_{\mathrm{R}}\right)_{\mathrm{A}}\right]}{\mathrm{w}_{\mathrm{A}}+\mathrm{w}_{\mathrm{B}}}
$$

Where $\left(t_{R}\right)_{A}$ and $\left(t_{R}\right)_{B}$ are retention time of each peak, and $w_{A}$ and $w_{B}$ are width of each peak, Figure 3.6. 


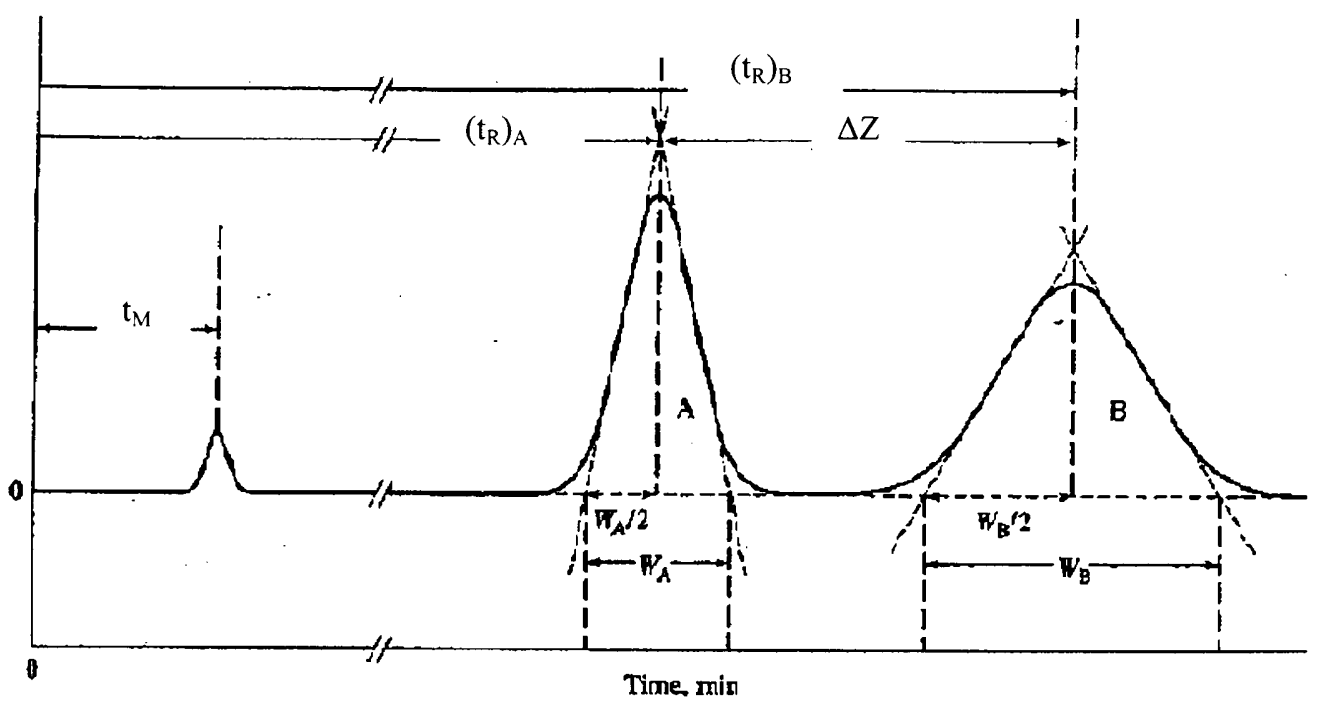

Figure 3.6 Calculation of the resolution of a peaks in the chiral column chromatography ${ }^{47}$

TABLE 3.1 Resolution of zeaxanthin stereoisomers as a function of solvent composition

\begin{tabular}{ccccc}
\hline $\begin{array}{c}\text { Composition of } \\
\text { mobile phase }\end{array}$ & $\begin{array}{c}\text { Resolution } \\
\text { of SSZ \& } \\
\text { RSZ }\end{array}$ & $\begin{array}{c}\text { Resolution } \\
\text { of RSZ \& } \\
\text { RRZ }\end{array}$ & $\begin{array}{c}\text { Resolution } \\
\text { of RRZ \& L }\end{array}$ & $\begin{array}{c}\text { Elution } \\
\text { time (min) }\end{array}$ \\
\hline $90 \% \mathrm{H}^{*}$ and $10 \% \mathrm{I}^{* *}$ & 1.9 & 1.33 & 2.47 & 12.45 \\
$91 \% \mathrm{H}^{*}$ and $9 \% \mathrm{I}^{* *}$ & 2.01 & 1.58 & 2.56 & 14.78 \\
$92 \% \mathrm{H}^{*}$ and $8 \% \mathrm{I}^{* *}$ & 2.51 & 1.9 & 2.92 & 17.31 \\
$93 \% \mathrm{H}^{*}$ and $7 \% \mathrm{I}^{* *}$ & 2.27 & 1.75 & 2.08 & 21.73 \\
$94 \% \mathrm{H}^{*}$ and $6 \% \mathrm{I}^{* *}$ & 2.7 & 2.51 & 2.42 & 28.69 \\
\hline
\end{tabular}

Note: ${ }^{*} \mathrm{H}$ : Hexane; ${ }^{* *} \mathrm{I}$ : Isopropanol; ${ }^{* * *}$ Mobile phase is always under the isocratic composition with $0.1 \%(\mathrm{~V} / \mathrm{V})$ of triethylamine to prevent the degradation of carotenoids during elution; Temperature range of $22^{\circ} \mathrm{C}-25^{\circ} \mathrm{C}$.

The optimized solvent composition to separate zeaxanthin stereoisomers was determined to be $92 \%$ hexane and $8 \%$ isopropanol with $0.1 \%(\mathrm{~V} / \mathrm{V})$ of triethylamine with a flow rated of $0.8 \mathrm{ml} / \mathrm{min}$. This composition of mobile phase gives a good resolution of zeaxanthin stereoisomers while keeping the elution time within acceptable limits. 


\subsection{Statistical Analysis}

A linear regression analysis was used to test for the association between age and the amount of lutein, meso-zeaxanthin, and zeaxanthin. $\mathrm{F}$ tests were used to determine the mean xanthophyll concentration in different sections of neonate and adult primate retinas.

Independent $t$ tests were used to determine the effects that age and distribution had on carotenoid concentration. Results were considered statistically significant at $\mathrm{P}<$ 0.05. The Statistical Package for the Social Science (SSPS), version 14.0 was used for all the statistical analyses in this study.

\section{Result and Discussion}

The amounts of the carotenoids extracted from retina tissue samples are reported in nanograms. The calculation is based on Beer's law.

$$
A=\varepsilon b c
$$

Where A is absorption, $\varepsilon$ is molar extinction coefficient, $\mathrm{b}$ is the pathlength of the cell, and $\mathrm{C}$ is the concentration of the analyte. The extinction coefficient of the internal standard and lutein are identical at all wavelengths because of the shared chromophore. The wavelength of detection was selected so that the extinction coefficient of zeaxanthin was also identical within precision of experimental error. Therefore, we can determine the amount of carotenoid present in our samples using equation 3.1

$$
\mathrm{M}_{\mathrm{A}}=\frac{\mathrm{A}_{\mathrm{A}} \times \mathrm{M}_{\mathrm{MPrL}}}{\mathrm{A}_{\mathrm{MPrL}}}
$$

$\mathrm{M}_{\mathrm{A}}$ is the amount of the carotenoid. $\mathrm{M}_{\mathrm{MPrL}}$ is the amount of the internal standard, MPrL. $A_{A}$ is the peak area of the carotenoid obtained from the chromatogram. $A_{M P r L}$ is the peak area of the internal standard, MPrL. 
The masses of zeaxanthin and lutein in each sample were determined from their peak areas relative to that of the internal standard, the mass of which was known. As stated above, the internal standard, lutein and zeaxanthin all have the same absorption coefficient at the wavelength of analysis.

The reversed-phase chromatogram of a retina extract is shown in Figure 3.7, and reveals three dominant peaks, in addition to the internal standard (IS). All of these are carotenoids with absorption maxima at $450 \mathrm{~nm}$. The most prominent 2 peaks (labeled Peak 2 and Peak 3) have retention times identical to lutein and zeaxanthin, as shown by the standards run in Figure 3.6 Peak 1 in Figure 3.7 is much more prominent on analyses of the retina than of the xanthophylls and attributed to retinal, 15-apo- $\beta$-carotenal, that was extracted from the retina. ${ }^{50}$ Satellite peaks 4 and 5 are oxo-lutein and zeaxanthin cis isomer, respectively. After the elution of the internal standard, no significant peaks were detected.

The reversed phase chromatogram of the neonate primate retina

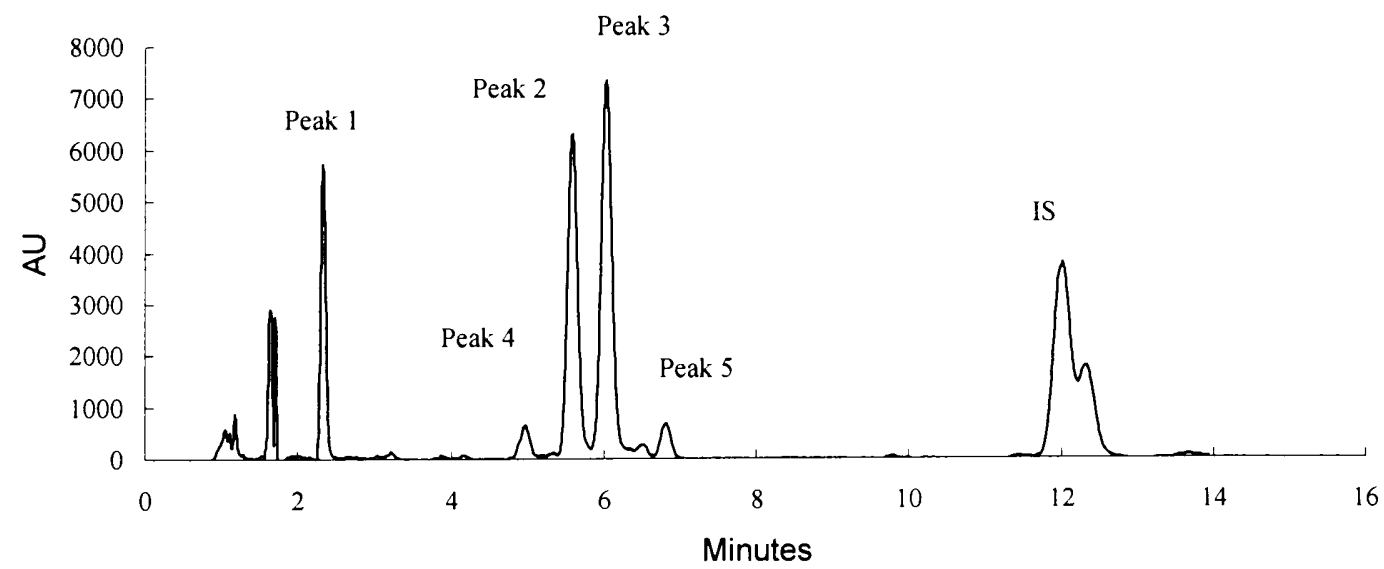

Figure 3.7 An example chromatogram showing the carotenoids from a primate retina using a reversed-phase chromatography. Peak 1, retinal (Vitamin A); Peak 2, lutein; Peak 3, zeaxanthin; Peak 4, oxo-lutein; Peak 5, cis isomer; IS, internal standard, mono-propyl lutein and its internal standard. ${ }^{50}$ 


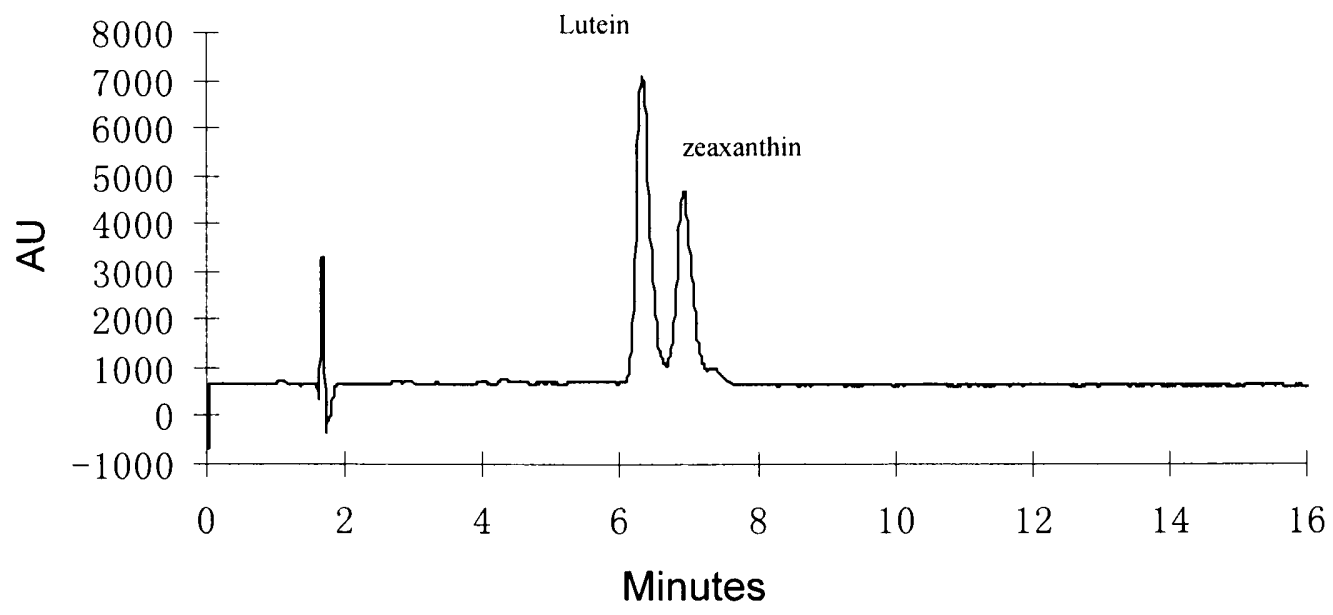

Figure 3.8 Lutein and zeaxanthin standards in reversed-phase chromatogram $(150 \mathrm{~mm} \times 4.6 \mathrm{~mm})$

The chiral normal-phase chromatogram of the macular zeaxanthin after collection from the reversed-phases separation is shown in Figure 3.8. This chromatogram reveals three dominant peaks, in addition to lutein. The first three peaks have been identified as SSZ, RSZ, and RRZ by comparison of chromatogram of zeaxanthin racemic mixture as previously described.

S,S-zeaxanthin was not observed in all retina samples but was clearly present in a few. S,S-zeaxanthin was found in detectable quantities in both neonate and adult retinas but when detectable amounts of SSZ were observed it was always present as a relatively small proportion of the total zeaxanthin.

During our studies, the zeaxanthin collected during reversed-phase chromatography from the inner, medial, and outer regions for the individual sample were subsequently run on a chiral, normal-phase column to provide a measure of the 
zeaxanthin stereoisomer composition. Table 3.2 shows the detailed data of carotenoids content present in the pooled sample.

A The chiral normal-phase chromatogram of neonate retina

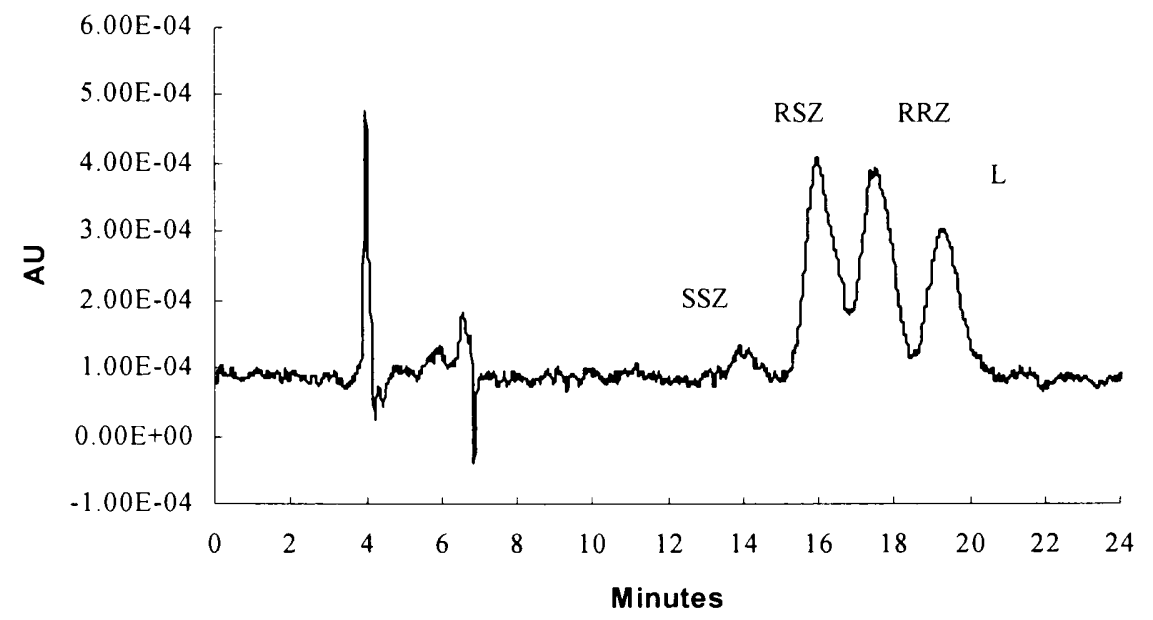

B The chiral normal-phase chromatogram of adult retina

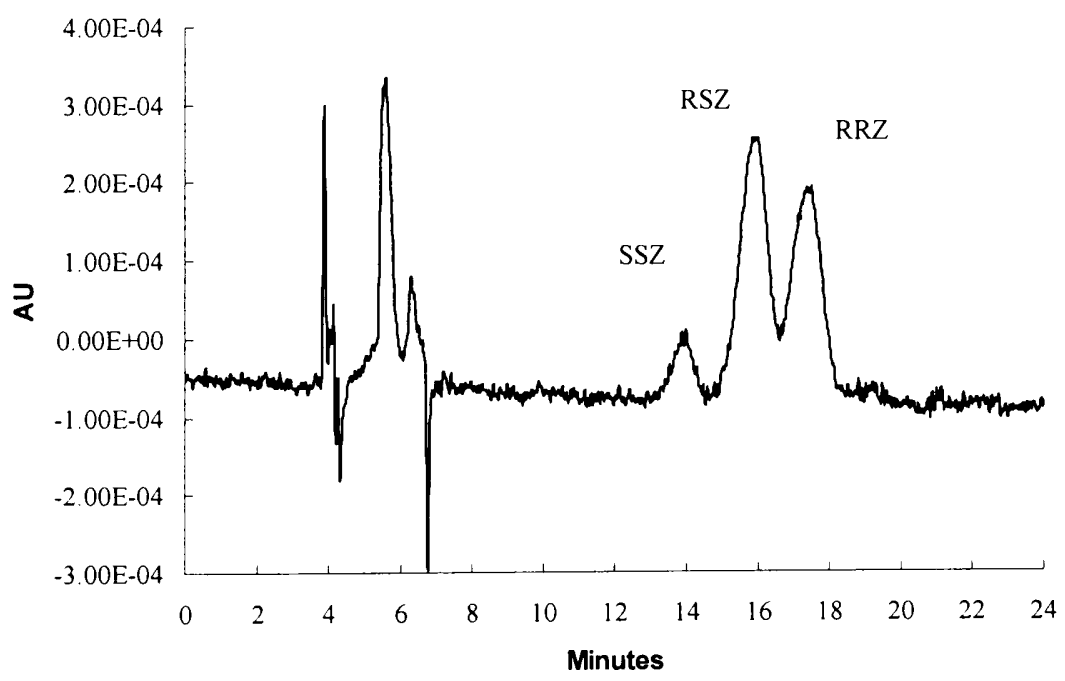

Figure 3.9 HPLC chromatograms, obtained with a chiral normal-phase column, of macular zeaxanthin A) from analysis of single neonate retina, and B) from analysis of a single adult primate retina. In order of elution, the peaks are (3S,3'S)-zeaxanthin (SSZ), meso-zeaxanthin (RSZ), zeaxanthin (RRZ), and lutein (L). 
During our studies, the zeaxanthin collected during reversed-phase chromatography from the inner, medial, and outer regions for the individual sample were subsequently run on a chiral, normal-phase column to provide a measure of the zeaxanthin stereoisomer composition. Table 3.2 shows the detailed data of carotenoids content present in the pooled sample.

For each eye that was analyzed individually, the total mass of total zeaxanthin stereoisomers, $\mathrm{Z}_{\mathrm{T}}$, in inner, medial, or outer tissue samples was determined from the reversed-phase chromatogram by comparison to the internal standard. A similar calculation gave the mass of L. (A linear relationship between peak area and the mass of $\mathrm{L}, \mathrm{Z}_{\mathrm{T}}$ and standard was determined by independent measurements). Using the relative peak areas obtained from the chiral normal-phase chromatograms, it was possible to confirm the mass of $Z_{T}$ among the zeaxanthin stereoisomers.

For adult retinas, samples are only analyzed by reversed-phase HPLC. In $2 \mathrm{~mm}$ punches, the concentration of $\mathrm{L}$ ranged from $8.001-18.848 \mathrm{ng} / \mathrm{mm}^{2}$, and $\mathrm{Z}$ is ranged from 24.432-92.098 ng/mm². In $4 \mathrm{~mm}$ punches, the concentration of $\mathrm{L}$ ranged from 5.806$19.867 \mathrm{ng} / \mathrm{mm}^{2}$ and $\mathrm{Z}$ ranged from $8.728-22.345 \mathrm{ng} / \mathrm{mm}^{2}$. In $8 \mathrm{~mm}$ punches, the concentration of $\mathrm{L}$ ranged from $6.210-11.869 \mathrm{ng} / \mathrm{mm}^{2}$ and $\mathrm{Z}$ ranged from 4.076-11.869 $\mathrm{ng} / \mathrm{mm}^{2}$.

For fetus and neonate retinas, samples are analyzed by both reversed-phase and normal-phase chiral HPLC. In $2 \mathrm{~mm}$ punches, the concentration of L ranged from 0.037$2.462 \mathrm{ng} / \mathrm{mm}^{2}$, RRZ ranged from $0-1.357 \mathrm{ng} / \mathrm{mm}^{2}$, and RSZ ranged from $0.021-2.024$ $\mathrm{ng} / \mathrm{mm}^{2}$. SSZ is present in only 4 samples ranged from $0.01-0.25 \mathrm{ng} / \mathrm{mm}^{2}$. In $4 \mathrm{~mm}$ punches, the concentration of $\mathrm{L}$ ranged from $0.027-0.641 \mathrm{ng} / \mathrm{mm}^{2}, \mathrm{RRZ}$ ranged from 
$0-0.251 \mathrm{ng} / \mathrm{mm}^{2}$, and RSZ ranged from $0-0.256 \mathrm{ng} / \mathrm{mm}^{2}$. SSZ is only present in 2 samples $\left(0.009 \mathrm{ng} / \mathrm{mm}^{2}\right)$. In $8 \mathrm{~mm}$ punches, the concentration of $\mathrm{L}$ ranged from 0.003-0.242 $\mathrm{ng} / \mathrm{mm}^{2}, \mathrm{RRZ}$ ranged from $0.006-0.109 \mathrm{ng} / \mathrm{mm}^{2}$, and RSZ ranged from $0-0.021 \mathrm{ng} / \mathrm{mm}^{2}$. SSZ is only present in 1 sample $\left(0.009 \mathrm{ng} / \mathrm{mm}^{2}\right)$.

3.1 Individual Retinal Distribution:

For a single neonate retina, chromatograms of extracts from the central disk ('inner') and two concentric annuli of tissue ('medial' and 'outer') consistently displayed the trend, previously observed, ${ }^{48,49}$ of an increasing lutein $(\mathrm{L})$ : zeaxanthin $\left(\mathrm{Z}_{\mathrm{T}}\right)$ ratio with increasing distance from the fovea. This is apparent from the sample chromatograms, the result of analysis of different sections obtained from a single eye, shown in Figure 3.10. For the inner, medial, and outer regions, the average $\mathrm{Z}_{\mathrm{T}}: \mathrm{L}$ ratios obtained using individuals eyes were $0.84 \pm 0.10,0.67 \pm 0.06,0.49 \pm 0.18$, respectively.

Figure 3.10 shows the comparison of the HPLC chromatogram from the three sections of a neonate retina. With increasing eccentricity, there is a clear change in the proportions and amounts of the two xanthopylls, lutein and zeaxanthin. In Figure 3.10A $\mathrm{Z}_{\mathrm{T}}$ is present in greater amounts than lutein whereas in $3.10 \mathrm{~B} \mathrm{~L}$ and $\mathrm{Z}_{\mathrm{T}}$ are approximately equal in abundance and in 3.10C lutein in the dominant carotenoid. 


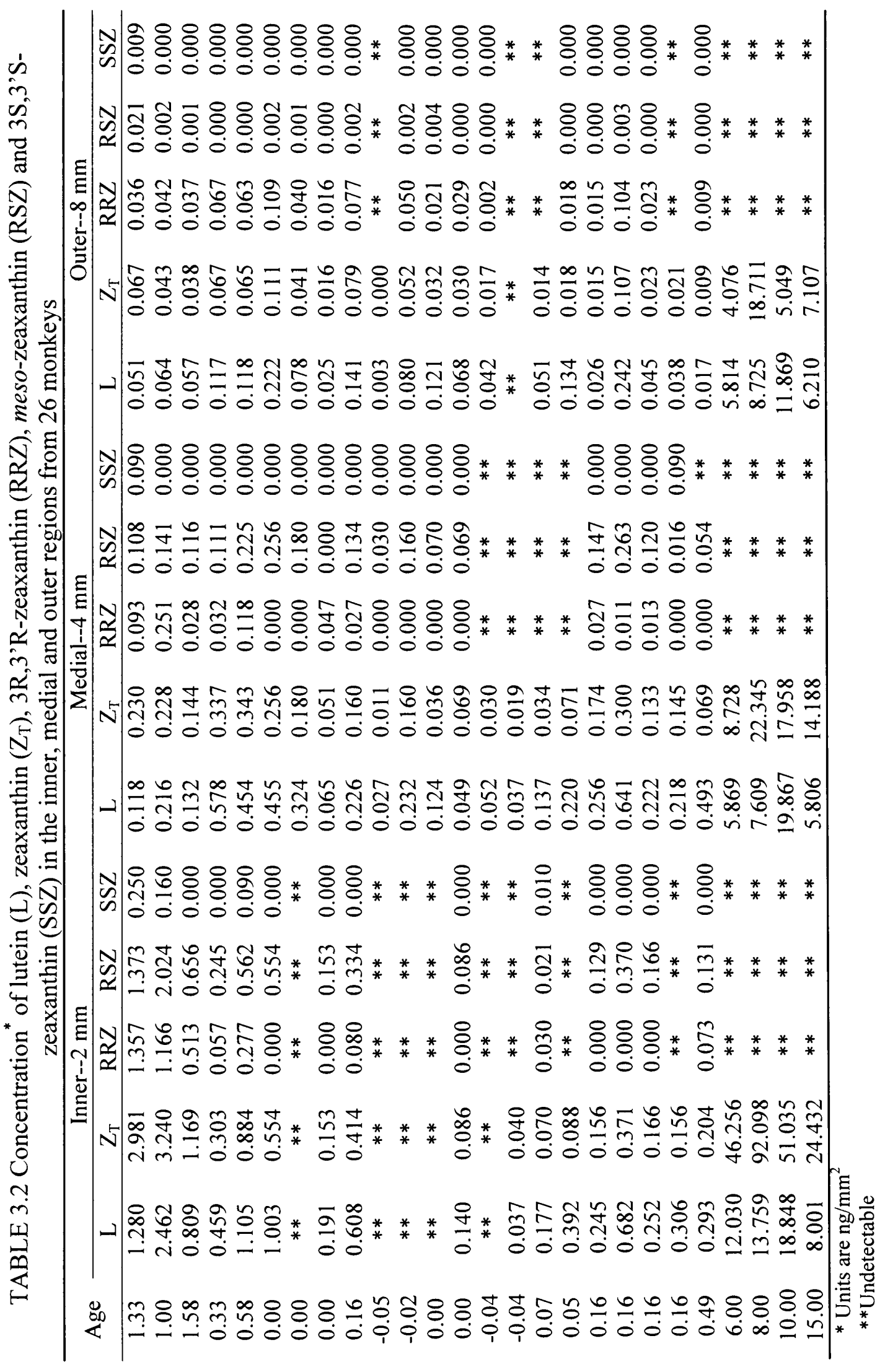


A e reversed-phase chormatogram of $2 \mathrm{~mm}$ punch in the neonate retina

MPrL (IS)

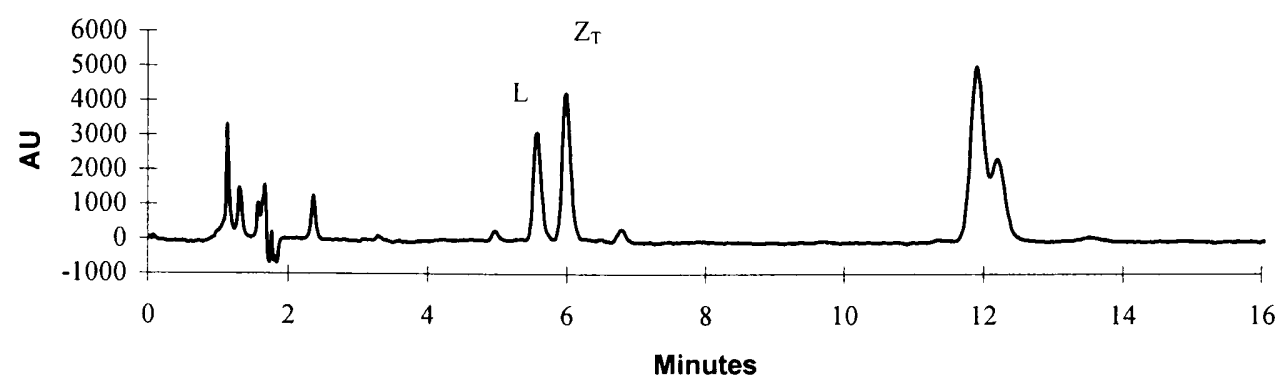

$\mathbf{B}^{\text {The reversed-phase chromatogram of } 4 \mathrm{~mm} \text { punch in neonate retina }}$

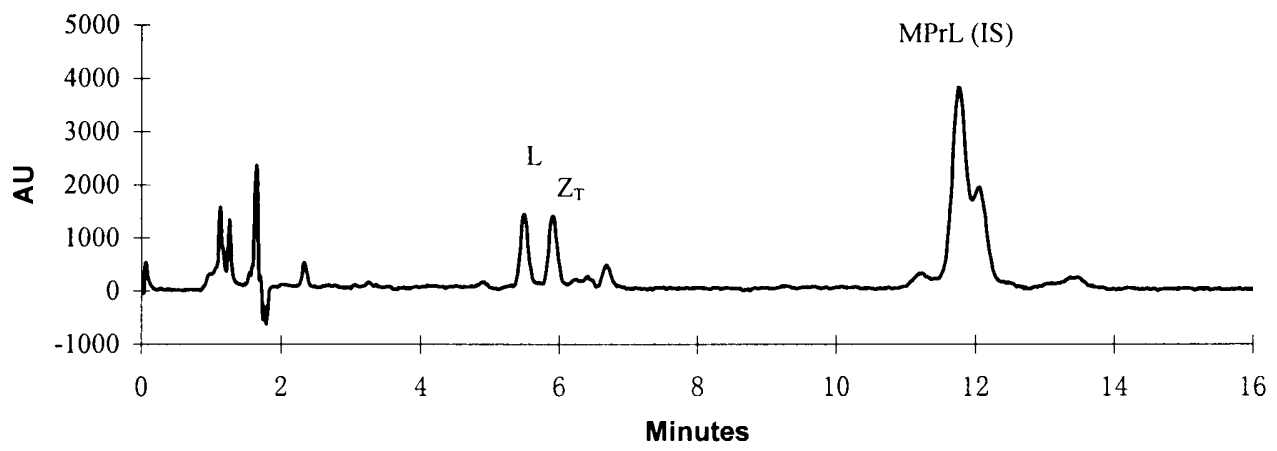

C The reversed-phase chromatogram of $8 \mathrm{~mm}$ punch in neonate retina

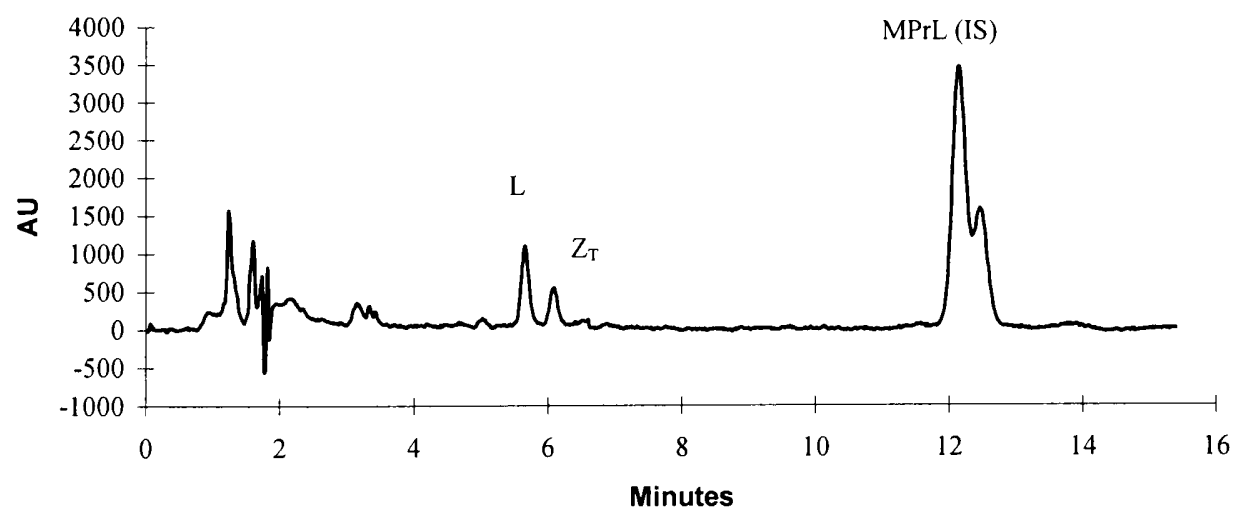

Figure 3.10 HPLC chromatograms obtained with a reversed-phase column of carotenoids. These were obtained from the three different regions of a single primate retina. In order of elution, the carotenoids are lutein $(\mathrm{L})$, zeaxanthin $\left(\mathrm{Z}_{\mathrm{T}}\right)$, and internal standard (IS) 
A The chiral normal-phase chromatogram of $2 \mathrm{~mm}$ punch of neonate

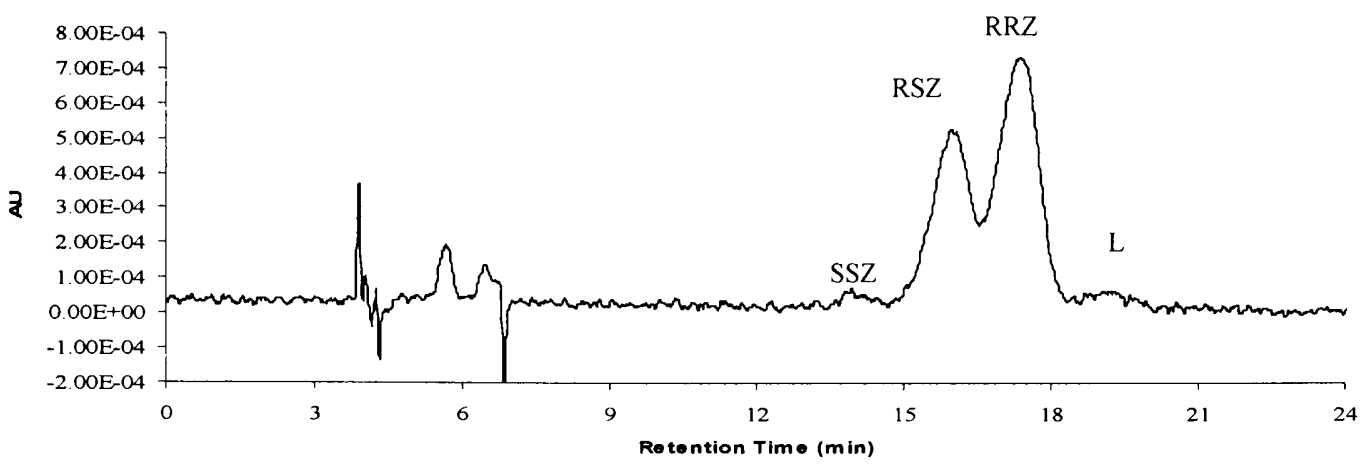

B The chiral normal-phase chromatogram of $4 \mathrm{~mm}$ punch of neonate

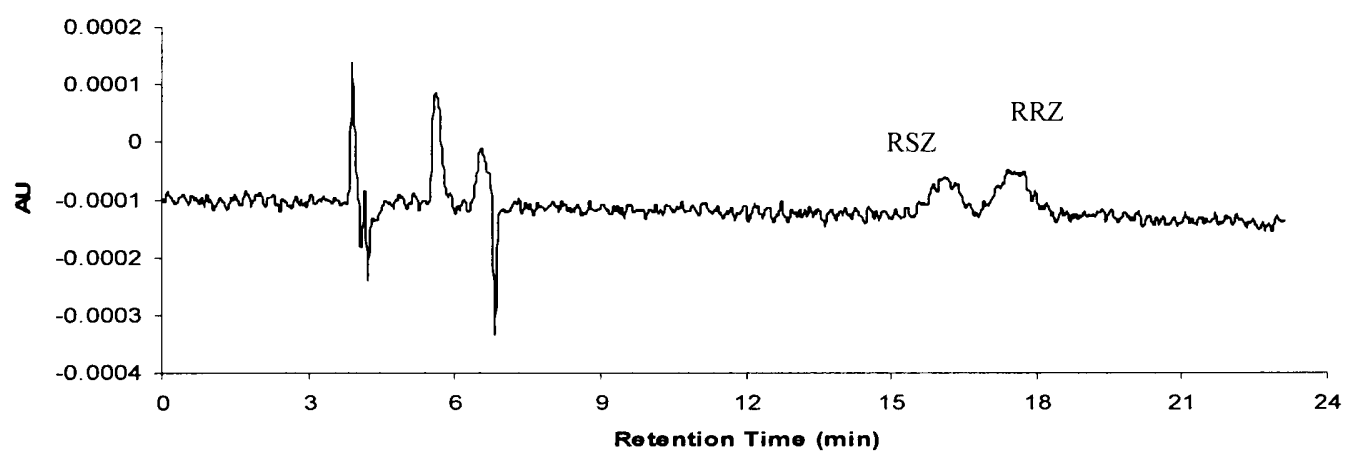

C The chiral normal-phase chromatogram of $8 \mathrm{~mm}$ punch of neonate retinas

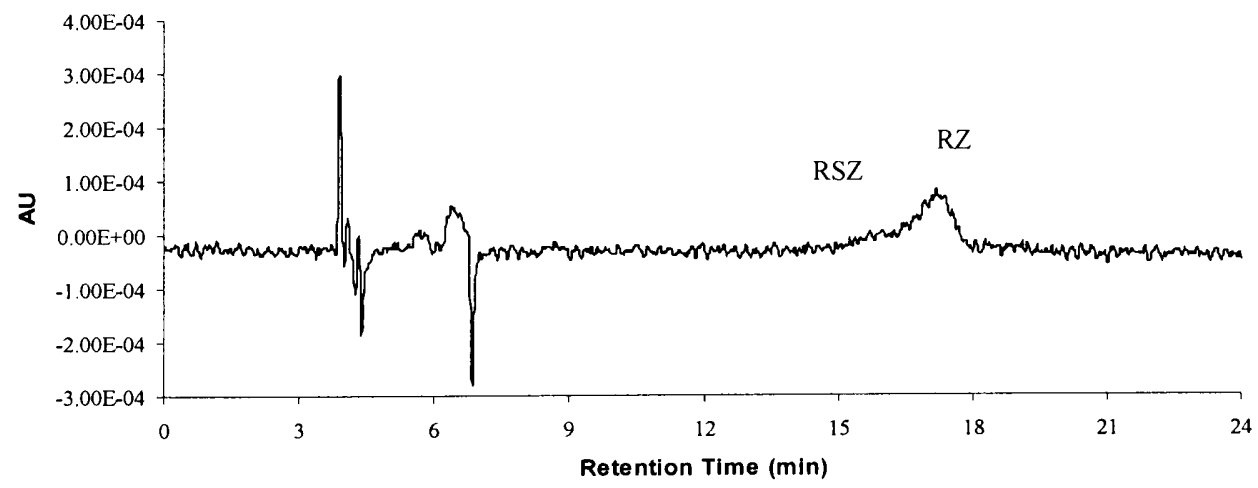

Figure 3.11 HPLC chromatograms obtained with a chiral, normal-phase column of macular zeaxanthin. These were obtained from the three different regions of a single primate retina, A) inner, B) medial, and C) outer retinal sections. In order of elution, the compounds are meso-zeaxanthin (RSZ), R,R-zeaxanthin (RRZ), and lutein (L). In (C) the small peak did not elute at the characteristic retention time and the amount typically detected was much less than in the other sections 
The zeaxanthin collected during reversed-phase chromatography from the inner, medial, and outer regions for the pooled samples subsequently yielded the chiral column chromatograms, shown in Figure 3.11. Figure 3.11A demonstrates the presence of RSZ and RRZ in the inner $2 \mathrm{~mm}$ retina sections, and both of them were found to be present in comparable quantities. In the $4 \mathrm{~mm}$ retina sections, $\mathrm{RSZ}$ and $\mathrm{RRZ}$ were found to present in much lower amounts than in $2 \mathrm{~mm}$ retina sections. Observation of detectable amounts of RSZ in $8 \mathrm{~mm}$ section was rare, see Figure 3.11C. By comparing the retention times of RRZ in Figure 3.11C, A, B, and C chromatograms, we can see that the retention times can vary by minutes. This is because of the sensitivity of the retention time on the chiral column to different temperatures in the lab from day to day. Standard samples were run on each day to provide reference retention times. In Figure 3.11 A, lutein is observed in the chromatograms because collection of the zeaxanthin peak from the reversed-phase column was started prior to the completed elution of lutein.

Table 3.3.1, Table 3.3.2, and Table 3.3.3 list the masses of $L, Z_{T}$, RRZ, RSZ, SSZ for distribution studies for neonate retinas. These results will be discussed individually as part of the discussion of the effect of age on carotenoid levels (see below). For neonate primate retinas, the average $\mathrm{RSZ}: \mathrm{Z}_{\mathrm{T}}$ ratios of inner, medial, and outer regions obtained using individuals eyes were $0.49 \pm 0.15,0.26 \pm 0.13,0.04 \pm 0.12$ respectively, see Table 3.3.1 and 3.3.2. The average RSZ:L ratios of inner, medial, and outer regions for individuals were $0.24 \pm 0.07,0.20 \pm 0.12,0.05 \pm 0.04$, respectively, see Table 3.3.1 and 3.3.2. In computing such averages, here and elsewhere, left and right eye data for a primate, where available, were averaged. The amounts of the different carotenoids present in the 
inner, medial, and outer regions in moles $/ \mathrm{mm}^{2}$ are shown in the Table 3.2.1, 3.3.2, and 3.3.3.

TABLE 3.3.1 Mean $( \pm \mathrm{SD})$ carotenoid concentrations in retina sections, on $2 \mathrm{~mm}$ and $4 \mathrm{~mm}$

\begin{tabular}{cccc}
\hline Carotenoids & $2 \mathrm{~mm}$ punches & $4 \mathrm{~mm}$ punches & P-value \\
\hline Lutein $(\mathrm{L}), \mathrm{ng} / \mathrm{mm} 2$ & $0.64 \pm 0.13$ & $0.24 \pm 0.03$ & $<0.001$ \\
Total zeaxanthin $\left(\mathrm{Z}_{\mathrm{T}}\right), \mathrm{ng} / \mathrm{mm} 2$ & $0.66 \pm 0.19$ & $0.15 \pm 0.02$ & $<0.001$ \\
$\mathrm{Z}_{\mathrm{T}} / \mathrm{L}$ & $0.84 \pm 0.10$ & $0.67 \pm 0.06$ & 0.049 \\
Xanthophylls, ng/mm2 & $0.50 \pm 0.07$ & $0.39 \pm 0.05$ & $\mathrm{NS}$ \\
Meso-zeaxanthin (RSZ), & $0.29 \pm 0.11$ & $0.04 \pm 0.02$ & $<0.001$ \\
ng/mm2 & & & \\
R,R-zeaxanthin (RRZ), & $0.53 \pm 0.14$ & $0.14 \pm 0.02$ & $<0.001$ \\
ng/mm2 & $0.49 \pm 0.15$ & $0.26 \pm 0.13$ & $\mathrm{NS}$ \\
Z/RRZ & $0.24 \pm 0.07$ & $0.20 \pm 0.12$ & $\mathrm{NS}$ \\
Z/L & 17 & 22 & $\mathrm{~N} \backslash \mathrm{A}$ \\
$\mathrm{N}$ &
\end{tabular}

P-value tests the statistical difference between carotenoid concentrations at $2 \mathrm{~mm}$ punch and $4 \mathrm{~mm}$ punch retinas

NS $=$ Not significant

Results were considered significant if $\mathrm{P}<0.05$

$\mathrm{N}=$ Total number of samples

TABLE 3.3.2 Mean $( \pm \mathrm{SD})$ carotenoid concentrations in retina sections, $4 \mathrm{~mm}$ and $8 \mathrm{~mm}$

\begin{tabular}{cccc}
\hline Carotenoids & $4 \mathrm{~mm}$ punches & $8 \mathrm{~mm}$ punches & P-value \\
\hline Lutein $(\mathrm{L}), \mathrm{ng} / \mathrm{mm}^{2}$ & $0.24 \pm 0.03$ & $0.08 \pm 0.01$ & $<0.001$ \\
Total zeaxanthin $\left(\mathrm{Z}_{\mathrm{T}}\right), \mathrm{ng} / \mathrm{mm}^{2}$ & $0.15 \pm 0.02$ & $0.04 \pm 0.01$ & $<0.001$ \\
$\mathrm{Z}_{\mathrm{T}} / \mathrm{L}$ & $0.67 \pm 0.06$ & $0.49 \pm 0.18$ & 0.026 \\
Xanthophylls, $\mathrm{ng} / \mathrm{mm}^{2}$ & $0.39 \pm 0.05$ & $0.12 \pm 0.02$ & $<0.001$ \\
Meso-zeaxanthin (RSZ), ng/mm $\mathrm{mm}^{2}$ & $0.04 \pm 0.02$ & $0.002 \pm 0.003$ & 0.002 \\
R,R-zeaxanthin (RRZ), ng/mm ${ }^{2}$ & $0.14 \pm 0.02$ & $0.05 \pm 0.01$ & 0.001 \\
RSZ/RRZ & $0.26 \pm 0.13$ & $0.04 \pm 0.12$ & 0.12 \\
RSZ/L & $0.20 \pm 0.12$ & $0.05 \pm 0.04$ & $\mathrm{NS}$ \\
$\mathrm{N}$ & 22 & 20 & $\mathrm{~N} / \mathrm{A}$ \\
\hline
\end{tabular}

P-value tests the statistical difference between carotenoid concentrations at $4 \mathrm{~mm}$ punch and $8 \mathrm{~mm}$ punch retinas

NS $=$ Not significant

Results were considered significant if $\mathrm{P}<0.05$

$\mathrm{N}=$ Total number of samples 
TABLE 3.3.3 Mean $( \pm \mathrm{SD})$ carotenoid concentrations in retina sections on $2 \mathrm{~mm}$ and $8 \mathrm{~mm}$

\begin{tabular}{|c|c|c|c|}
\hline Carotenoids & $2 \mathrm{~mm}$ punches & $8 \mathrm{~mm}$ punches & P-value \\
\hline Lutein $(\mathrm{L}), \mathrm{ng} / \mathrm{mm}^{2}$ & $0.64 \pm 0.13$ & $0.08 \pm 0.01$ & $<0.001$ \\
\hline Total zeaxanthin $\left(\mathrm{Z}_{\mathrm{T}}\right), \mathrm{ng} / \mathrm{mm}^{2}$ & $0.66 \pm 0.19$ & $0.04 \pm 0.01$ & $<0.001$ \\
\hline $\mathrm{Z}_{\mathrm{T}} / \mathrm{L}$ & $0.84 \pm 0.10$ & $0.49 \pm 0.18$ & $<0.001$ \\
\hline Xanthophylls, $\mathrm{ng} / \mathrm{mm}^{2}$ & $0.50 \pm 0.07$ & $0.12 \pm 0.02$ & 0.001 \\
\hline $\begin{array}{l}\text { Meso-zeaxanthin (RSZ), } \\
\mathrm{ng} / \mathrm{mm}^{2}\end{array}$ & $0.29 \pm 0.11$ & $0.002 \pm 0.003$ & $<0.001$ \\
\hline $\begin{array}{l}\mathrm{R}, \mathrm{R} \text {-zeaxanthin } \\
\mathrm{ng} / \mathrm{mm}^{2}\end{array}$ & $0.53 \pm 0.14$ & $0.05 \pm 0.01$ & $<0.001$ \\
\hline RSZ/RRZ & $0.49 \pm 0.15$ & $0.04 \pm 0.12$ & $<0.001$ \\
\hline $\mathrm{RSZ} / \mathrm{L}$ & $0.24 \pm 0.07$ & $0.05 \pm 0.04$ & 0.013 \\
\hline $\mathrm{N}$ & 17 & 20 & $\mathrm{~N} / \mathrm{A}$ \\
\hline
\end{tabular}

P-value tests the statistical difference between carotenoid concentrations at $2 \mathrm{~mm}$ punch and $8 \mathrm{~mm}$ punch retinas

$\mathrm{NS}=$ Not significant

Results were considered significant if $\mathrm{P}<0.05$

$\mathrm{N}=$ Total number of samples

The means of the carotenoid concentration in the retina were compared for inner, medial, and outer punches. Table 3.3.1 compares the mean L, RSZ, and RRZ in $2 \mathrm{~mm}$ and $4 \mathrm{~mm}$ punches. Table 3.3 .2 compares the mean for each carotenoid in $4 \mathrm{~mm}$ and $8 \mathrm{~mm}$ punches. Table 3.3 .3 compares the mean for each carotenoid in $2 \mathrm{~mm}$ and $8 \mathrm{~mm}$ punches. Most of the differences observed between the $2 \mathrm{~mm}, 4 \mathrm{~mm}$, and $8 \mathrm{~mm}$ punches were statistically significant. Lutein is consistently present in greatest amounts in the central $2 \mathrm{~mm}$ of the retina $(\mathrm{P}<0.001)$ for these neonate retinas. Similarly $\mathrm{Z}_{\mathrm{T}}$ is also present is greater quantities in the central $2 \mathrm{~mm}(\mathrm{P}<0.001)$ than in the 4 or $8 \mathrm{~mm}$ tissue sections. A statistical comparison of the $(\mathrm{RRZ}+\mathrm{RSZ}) / \mathrm{L}$ ratio of the $2 \mathrm{~mm}$ and $4 \mathrm{~mm}$ sections shows that there is a significant change between the 2 sections, and the comparison of the (RRZ+RSZ)/L ratio of the $4 \mathrm{~mm}$ and $8 \mathrm{~mm}$ sections also shows that 
there is a significant change between. The two stereoisomers of zeaxanthin are always present in greatest amounts in the central $2 \mathrm{~mm}$ region.

Apart from minor carotenoid metabolites identified as oxo-lutein and carotenoid cis isomers, ${ }^{50}$ zeaxanthin and lutein are the only known carotenoids observed in the retinal tissues. There is a recent report that small amounts of 3'-methoxyzeaxanthin are observed in human retinas. ${ }^{51}$ These results show that carotenoids are selectively accumulated in central portion of a retina. The ratio of $\mathrm{RSZ} / \mathrm{L}$ and $\mathrm{Z}_{\mathrm{T}} / \mathrm{L}$ increased with increasing distance from fovea of the retina. This trend is illustrated graphically in Figure 3.12. The result is essentially consistent with Johnson's reports that $L$ is the precursor of $\mathrm{RSZ}$ and it occurs in $2 \mathrm{~mm}$ retina sections. ${ }^{32}$

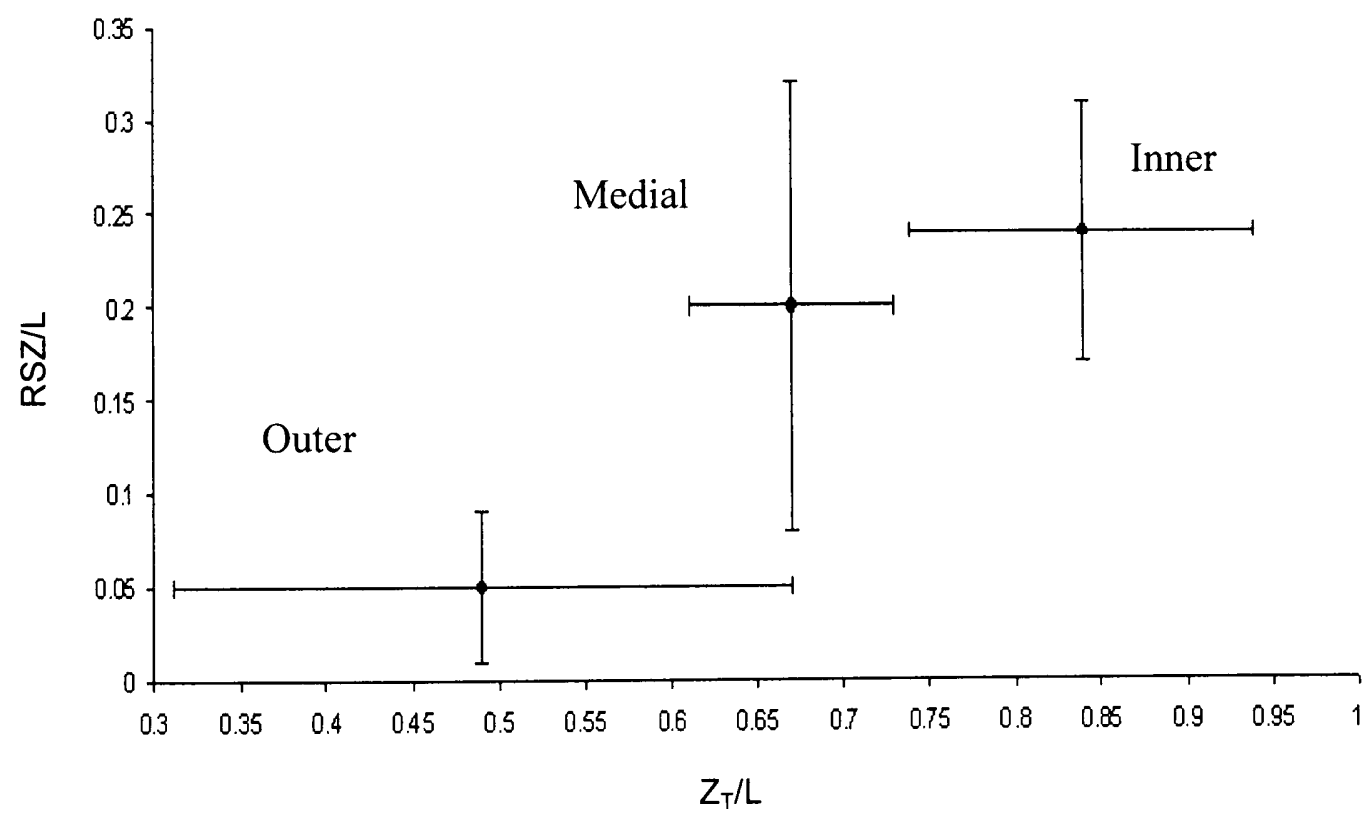

Figure 3.12 The ratio of meso-zeaxanthin to lutein (vertical) and $\mathrm{Z}_{\mathrm{T}}$ to lutein (horizontal) for different sections of retina tissue. 


\subsection{Age Effects}

In this study, 21 retinas form new born monkeys, fetus to 7 months in age, 3 young monkeys from 12 months to 19 months, and 8 adult monkeys from 6 years old to 15 years old were analyzed. For approximately $80 \%$ of the monkeys the results were obtained for both eyes and the average value was recorded. For the remainder, reliable data were obtained only for one eye.

Based on previous work, carotenoids are known to selectively accumulate in the central portion of a retina. ${ }^{21}$ In this study, the relationship between age and amount of each carotenoid in this study was limited to $2 \mathrm{~mm}$ punches of retinas. From Figure 3.13, the amounts of lutein, see Figure 3.13A, RSZ Figure 3.13B, RRZ, see Figure 3.13C in $2 \mathrm{~mm}$ punches increased significantly with age. All of these increase as the age increases. From Figure 3.14, the ratios of RSZ/L and $\mathrm{Z}_{\mathrm{T}} / \mathrm{L}$ in $2 \mathrm{~mm}$ punches were all found to vary significantly with age. Meanwhile, the ratio of RSZ/L, see Figure 3.14A for animals younger than 7 months was consistently less than 0.3 , average value $0.01 \pm 0.11$ for younger animals and $0.06 \pm 0.31$ for older animals. And $\mathrm{Z}_{\mathrm{T}} / \mathrm{L}$, see Figure $3.14 \mathrm{~B}$ for animals younger than 7 months was consistently less than 1.00 , average value $0.64 \pm 0.08$ for younger animals and $1.70 \pm 0.42$ for older animals. 
A

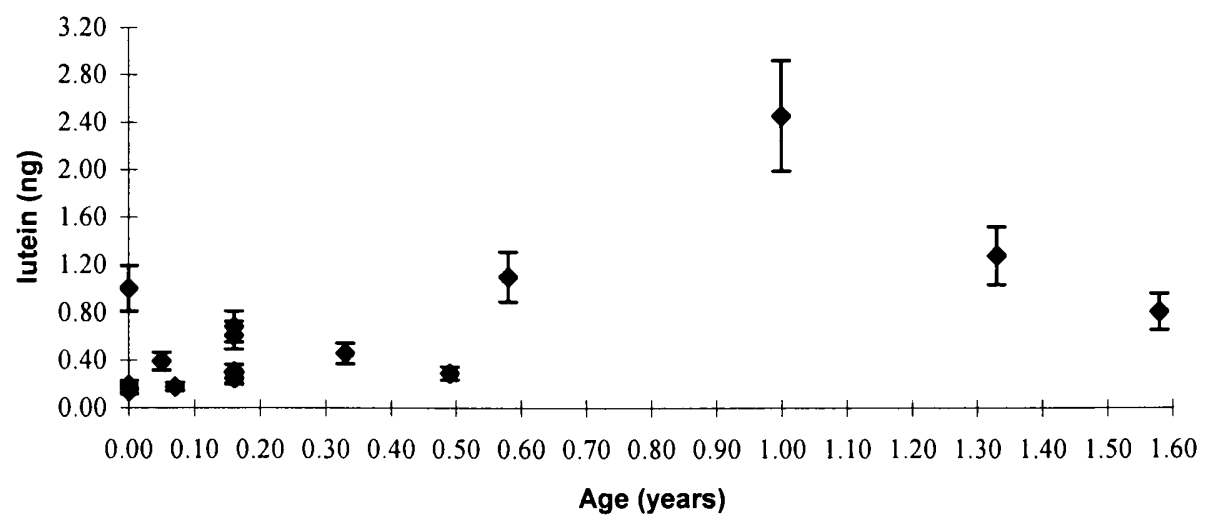

B

RSZ v.s. Age $(P=0.001)$

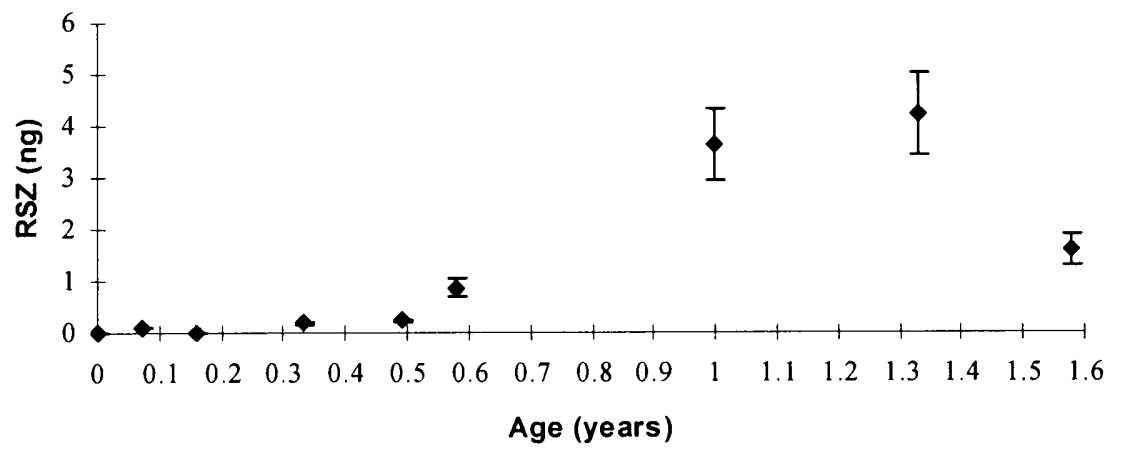

C RRZ v.s. Age $(P=0.012)$

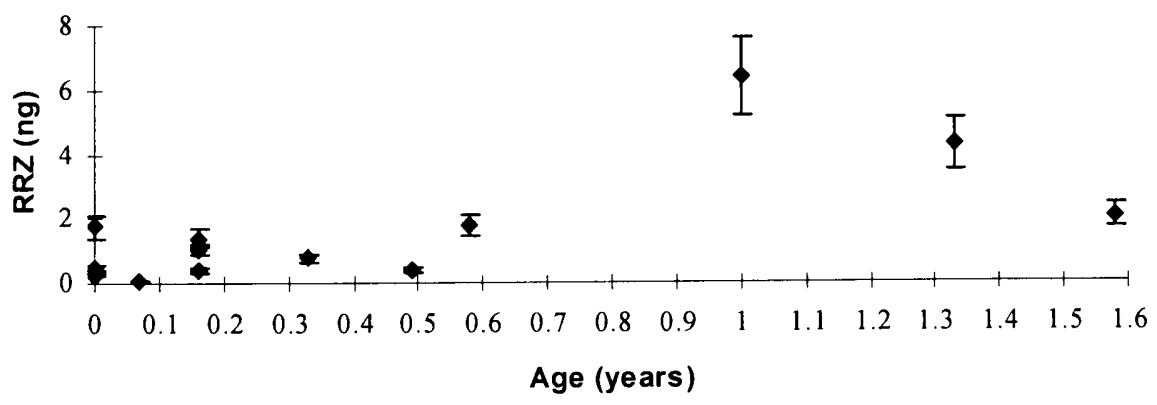

Figure 3.13 Effect of age on the amounts of for L, RSZ, and RRZ in neonate primate retinas 


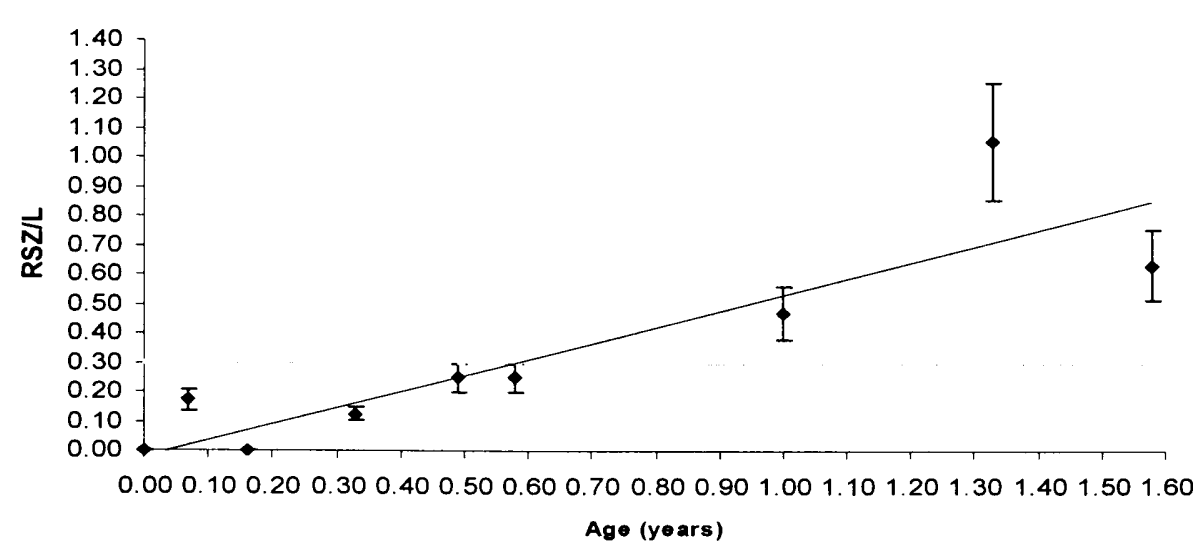

B $\quad Z_{\mathrm{T} / \text { L v.s. Age }(P<0.001)}$

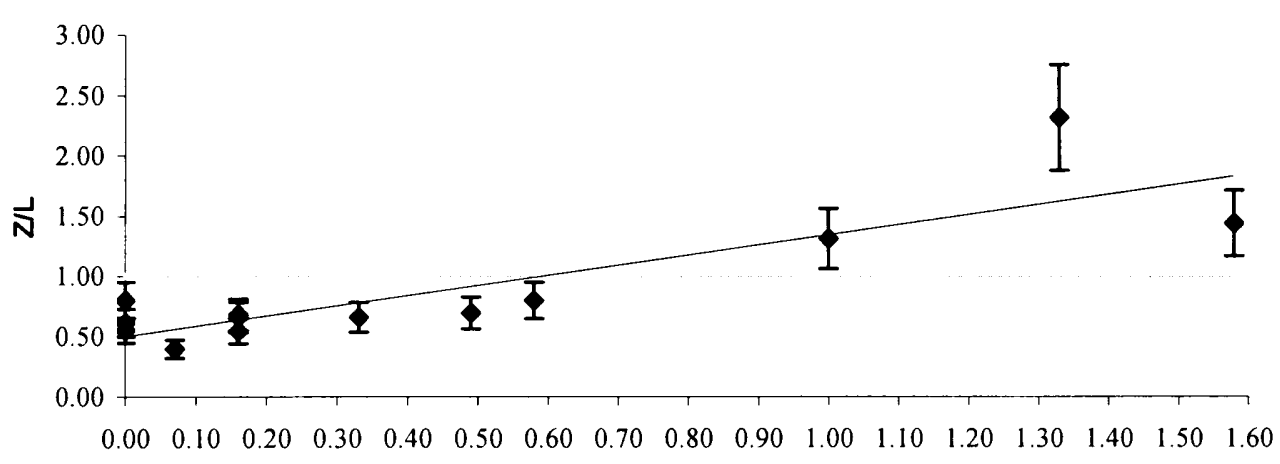

Age (years)

Figure 3.14 Effect of age on the $\mathrm{Z}_{\mathrm{T}} / \mathrm{L}$, and $\mathrm{RSZ} / \mathrm{L}$ ratio in neonate retinas

The combined masses of xanthophylls (zeaxanthin and lutein) in the whole retinas were insignificantly different between new born and adult monkeys, as illustrated in Figure 3.15. However, the $\mathrm{Z}_{\mathrm{T}} / \mathrm{L}$ ratio showed a significant variation $(\mathrm{P}=0.000)$ between new born and adult monkeys. This can be seen in Figure 3.16, where the average result and associated standard deviations are plotted for new born and adult monkeys. For the new born monkeys, the dominant pigment was consistently lutein, while the dominant pigment was zeaxanthin in retinas of adult monkey. A value of 1.0 is the boundary of 
between $\mathrm{Z}_{\mathrm{T}} / \mathrm{L}$ ratio of new born and adult monkeys. This can be seen in TABLE 3.4. The results obtained from new-born monkeys, where the average zeaxanthin: lutein ratio was $0.60 \pm 0.08$ is compared with a value of $2.05 \pm 0.44$ for adult monkeys.

\section{Xanthophylls}

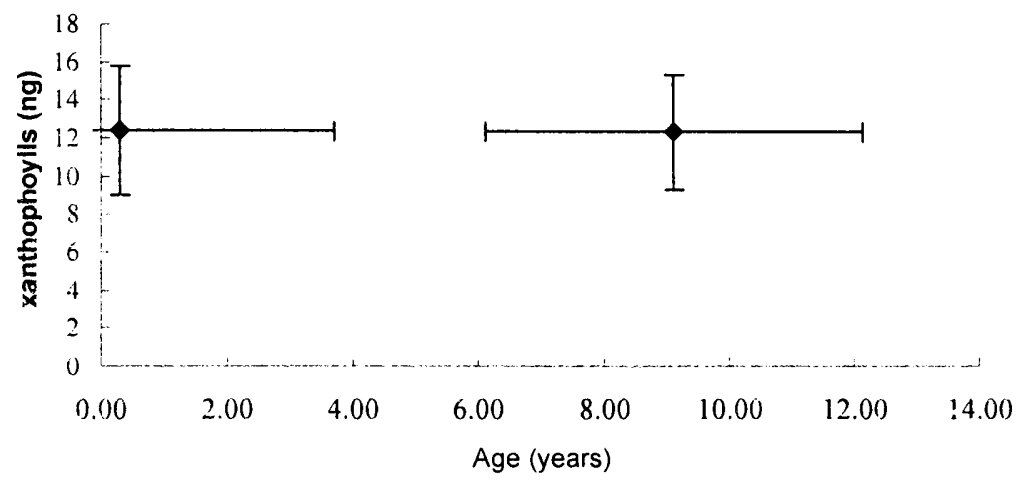

Figure 3.15 Effect of age on the total mass of xanthophylls in new born and adult primate retinas

\section{$\mathbf{Z}_{\mathrm{T} / \mathrm{L}}$}

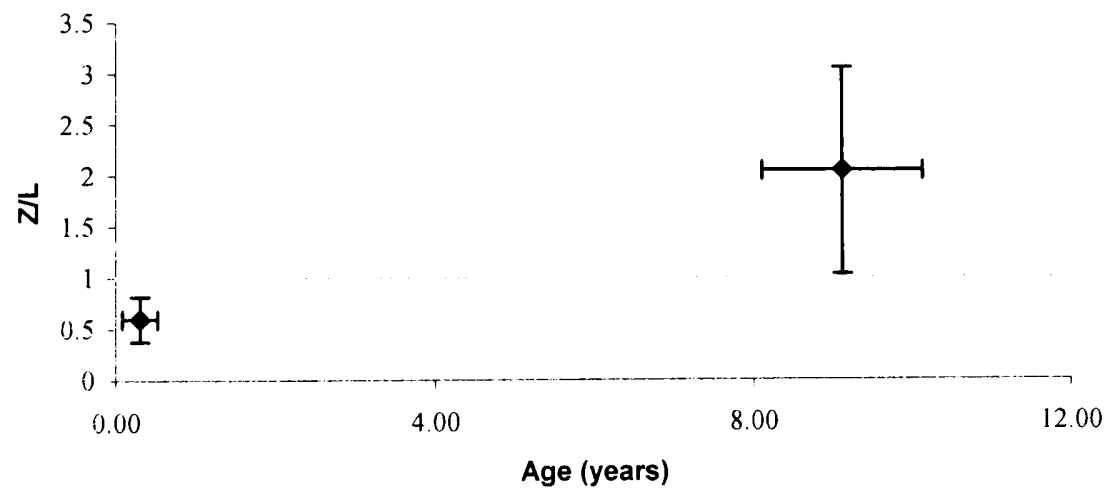

Figure 3.16 Effect of age on the total mass of the $\mathrm{Z}_{\mathrm{T}} /$ lutein ratio between new born and adult primate retinas 
TABLE 3.4 Mean ( \pm SD) between carotenoid concentrations at new born and adult retinas

\begin{tabular}{cccc}
\hline Carotenoids & $\begin{array}{c}\text { New born } \\
\text { monkeys }\end{array}$ & $\begin{array}{c}\text { Adult } \\
\text { monkeys }\end{array}$ & P-value \\
\hline Lutein $(\mathrm{L}), \mathrm{ng} / \mathrm{mm}^{2}$ & $7.65 \pm 1.28$ & $4.53 \pm 0.65$ & 0.003 \\
Zeaxanthin $\left(\mathrm{Z}_{\mathrm{T}}\right), \mathrm{ng} / \mathrm{mm}^{2}$ & $4.74 \pm 0.98$ & $7.84 \pm 3.86$ & $\mathrm{NS}$ \\
Xanthophylls, ng/mm & $12.39 \pm 2.15$ & $12.37 \pm 1.38$ & $\mathrm{NS}$ \\
$\mathrm{Z}_{\mathrm{T}} / \mathrm{L}$ & $0.64 \pm 0.08$ & $2.05 \pm 0.44$ & $<0.001$ \\
\hline
\end{tabular}

$\mathrm{P}$-value tests the statistical difference between carotenoid concentrations at new born and adult monkey retinas

NS $=$ Not significant

Results were considered significant if $\mathrm{P}<0.05$

\section{Conclusion}

Both neonate and adult primate retinas were investigated in this study. For adult primate eyes, generally, the amount of carotenoid observed were low compared to those found in human, ${ }^{21}$ averaging $12.4 \pm 3.0 \mathrm{ng}$ of total carotenoid. This is essentially consistent with results reported by Handelman et. al. ${ }^{31}$ in which they measured an average value of $12.4 \pm 5.7 \mathrm{ng}$ for the retinal carotenoid content. In our study, we have found the average of total $Z_{\mathrm{T}}$ to lutein ratio is $2.0 \pm 1.0$ as compared to $1.4 \pm 0.5 \mathrm{ng}$ observed by Handelman et. al. ${ }^{31}$ For neonate retinas, the average of zeaxanthin to lutein ratio is $0.6 \pm 0.2$ which is lower than that found by both Handelman et. al. and the adult macaque retina study reported here. ${ }^{31}$ This result is consistent with the prediction of Bone and Landrum ${ }^{21}$ and the observation of Johnson et. al. ${ }^{32}$ that lutein is the precursor of meso-zeaxanthin (RSZ); we expect that meso-zeaxanthin (RSZ) must be present in lower amounts in young animals since it is a metabolic product.

For single retinas, the amount and distribution of lutein and zeaxanthin stereoisomers in neonate primate eyes was studied. The results show that the amounts of lutein, meso-zeaxanthin, and R,R-zeaxanthin in $2 \mathrm{~mm}$ punches are significantly greater 
than in $4 \mathrm{~mm}$ annuli $(\mathrm{P}<0.0001)$, and the amounts in $4 \mathrm{~mm}$ annuli are significantly greater than in $8 \mathrm{~mm}$ annuli $(\mathrm{P}<0.002)$. The ratios of $\mathrm{Z}_{\mathrm{T}} / \mathrm{L}$ and $\mathrm{RSZ} / \mathrm{L}$ dramatically dropped as the annuli increased. For the age study, the amounts of L, RSZ, and RRZ in $2 \mathrm{~mm}$ punches were all found to vary significantly with age $(\mathrm{P}<0.003)$. The ratios of $\mathrm{RSZ} / \mathrm{L}$ and $\mathrm{Z}_{\mathrm{T}} / \mathrm{L}$ in $2 \mathrm{~mm}$ punches increased significantly with age $(\mathrm{P}<0.001)$. A t-test, was employed in comparing carotenoids and their ratios between new born (fetus-7months old) primate retinas and adult (6yrs-10yrs old) primate retinas. The results show that the ratio of $Z_{\mathrm{T}} / \mathrm{L}$ in adult primate retinas was significantly greater than the ratio in the new born primate retinas, see Figure 3.16 .

These data are the first to define in detail the developmental course of macular pigment in the non-human primate retina. The increase in the RSZ/L ratio with age is consistent with a pathway in which $\mathrm{L}$ is converted to RSZ. RSZ was not detected in the retinas of macaques younger than 25 days, indicating that retinal conversion of $\mathrm{L}$ to RSZ begins soon after birth and increases in efficiency with the development of the retina. The decrease in the RSZ/L ratio with eccentrically indicates that the conversion primarily occurs in central portion. SSZ was present in both neonate and adult retinas, but only a few samples; the presence of SSZ is evidence that the physiology of carotenoids in the primate retina involves complex transformations about which we have little knowledge. 


\section{Chapter IV CONCLUSIONS}

\section{Identification of $\beta, \beta$-carotene-3,3'-dione}

It has been hypothesized that $\beta, \beta$-carotene-3,3'-dione is a metabolite of zeaxanthin in biological systems. $\beta, \beta$-carotene-3,3'-dione is also a suggested intermediate product formed during the 2 step reduction of rhodoxanthin to produce the zeaxanthin stereoisomers. In vitro oxidation of zeaxanthin with $\mathrm{MnO}_{2}$ in acetone produces three components. They have identified as all-trans rhodoxanthin and its two cis-isomers. All of these are reduced by $\mathrm{Zn} / \mathrm{HOAc}$ in $\mathrm{CHCl}_{2}$ to produce an intermediate product that has been suggested to be $\beta, \beta$-carotene-3,3'-dione.$^{52}$ This compound is fairly reactive and only limited amounts of it can be obtained in sufficiently pure form to enable spectroscopic studies needed to confirm the structure. In our study we have attempted to provide a complete characterization of the structure of this intermediate product. In this effort, we

have used both analytical and spectroscopic methods including, IR, UV/Vis, MS, ${ }^{1} \mathrm{H}$ NMR, and HPLC to characterize its structure.

In summary, we have been able to demonstrate that the reduction of rhodoxanthin produces a product whose spectroscopic properties are completely consistent with an assignment as $\beta, \beta$-carotene-3,3'-dione. The data obtained rule out the presence of the tautomer, $\varepsilon, \varepsilon$-carotene-3,3'-dione. $\quad \beta, \beta$-carotene-3,3'-dione was found to rapidly react with atmospheric oxygen, even at low temperatures $\left(4^{\circ} \mathrm{C}\right)$ to revert to rhodoxanthin. The reactivity of this diketone in vitro makes its detection as a metabolite unlikely and its tendency to oxidize to form rhodoxanthin, which is not observed, further supports the conclusion that $\beta, \beta$-carotene-3,3'-dione is not formed from zeaxanthin in vivo. The in 
vivo metabolic products formed from zeaxanthin remain incompletely understood but this work has shown that the probability that hydroxyl group oxidation to form a diketone is unlikely.

These results are significant because they demonstrate that oxidation of the hydroxyl groups of zeaxanthin to produce $\beta, \beta$-carotene-3,3'-dione, while an apparently reasonable chemical outcome, is not consistent with the chemistry of this molecule or the absence of rhodoxanthin in human serum as a secondary metabolite. The characterization of $\beta, \beta$-carotene-3,3'-dione increments our understanding of the carotenoids and their chemistry. This thesis presents the first definitive study of this molecule and its spectroscopic properties.

\section{Changes in Carotenoid Stereoisomers in the Non-Human Primate Retina with}

\section{Age}

The presence of high concentrations of carotenoids in the central retina of adult humans and primates has been a topic of interest for researchers in the field of vision for some time. Very little work has been carried out on the carotenoid content of the retina in the young eye and there is virtually nothing known about the developmental steps that lead to the deposition of the carotenoid mixtures observed in older individuals. It is well known that meso-zeaxanthin is found only in the retina and is metabolite of lutein and some early research showed that the retinas of the very young humans have lower levels of pigment overall and that the ratio of zeaxanthin to lutein in these subjects was lower than in the adult. In this study we have had the opportunity to study neonatal retinas from macaque monkeys and to analyze amounts of carotenoids found in these tissues. 
We have applied the use of chiral column HPLC to the analysis of retinal sections of neonatal macaque retinas providing the first data on the developmental changes that characterize the macular pigment in non-human primates. Our results obtained from the study of 32 retinas demonstrates that the neonate retina is indeed deficient in mesozeaxanthin as compared to adult retinas and that the proportion of this carotenoid increases with age reaching an adult ratio during the first year of life. These data lend further evidence of the meso-zeaxanthin is a metabolic product formed from lutein in the retina. The steady increase in the proportion of meso-zeaxanthin present in the neonate with increasing age is consistent with an enzymatic mechanism that becomes functional shortly after birth as the retina matures. We have been unable to detect meso-zeaxanthin in the retina prior to one month following birth.

The stereisomer S,S-zeaxanthin was detectable in the retinas of a few young monkeys, but not consistently. The metabolic pathway by which this isomer could readily form is not understood. It is clear from these data that the pathway of S,Szeaxanthin formation must be distinctly different from that of meso-zeaxanthin. The formation of S,S-zeaxanthin requires a change in the absolute configuration in one stereocenter if the precursor molecule is lutein and would require a change in two if zeaxanthin is the precursor. A potential chemical pathway for the formation of S,Szeaxanthin would be the enzymatic reduction of $\beta, \beta$-carotene-3,3'-dione, however our work on this molecule suggests this is unlikely. The nature of the pathway by which S,Szeaxanthin forms in the retina remains a unresolved question.

Carotenoid metabolism in the retina changes during the first months of life as the retina itself undergoes developmental changes. Further study of the neonate retina and 
the compositional changes that characterize the macular pigment in this period would be helpful to extending our understanding functions of carotenoids in the eye. 


\section{List of References:}

1. Britton, G., Carotenoids Today and Chanllenges for the Future, in Carotenoids, G. Britton, S. Liaaen-Jensen, and H.Pfander, Editors. 1995. Birkhauser-Verlag: Basel.p. 13-26.

2. Britton, G., Structure and Properties of Carotenoids in Relation to Function. FASEB, 1995. Birkhauser-Verlag: Basel. 9: p. 1551-1558.

3. Britton, G., Structure and Properties of Carotenoids in Relation to Function. FASEB, 1995. 9: p. 1551-1558.

4. Ong, E.S. and Tee A.S.H., Natural Source of Carotenoids from Plants and oils. Meth. Enzymol, 1992. 213: p. 142-167.

5. Pfander, H. Carotenoids: an overview. Meth. Enzymol, 1992. 213: p. 3-13.

6. Michah, S., Introduction: Dietary and Serum Carotenoids Concentrations of Healthy Volunteers Consuming a Low dose Lutein Supplement. 2000: p. 1-2.

7. Britton, G., Overview of Carotenoid Biosynthesis, in Carotenoids, G. Britton, S. Liaaen-Jensen, and H. Pfander, Editors. 1998, Birkhauser-Verlag: Basel. p. 13147.

8. Khachik, F., Separation and quantitation of carotenoids in foods. Methods Enzymol, 1992. 213: p. 347-59.

9. Khachik, F., Separation and identification of carotenoids and their oxidation products in the extracts of human plasma. Anal Chem, 1992. 64(18): p. 2111-22.

10. Barua, H.C. and Furr, A.B., Extraction and Analysis by High Performance Liquid Chromatography of Carotenoids in Human Serum. Methods in Enzymology, 1992. 213: p. 273-281.

11. Weale, R., Spectral sensitivity curves and the absorption of light by the ocular media. Brit. J. Ophthalmol., 1953. 37: p. 148-57.

12. Goodwin, T.W., The biochemistry of the carotenoids. Chapman \& Hall, 1984. 224.

13. Khachik, F., Bernstein, P.S.and Garland, D.L. Identification of lutein and zeaxanthin oxidation products in human and monkey retinas. Invest Ophthalmol Vis Sci, 1997. 38(9): p. 1802-11. 
14. Andrews, A., Borch, G. and Liaaen-Jensen, S. Carotenoids of higher plants. 7. On the absolute configuration of lutein. Acta Chem. Scand. B, 1974. 28: p. 139-140.

15. Straub, O., Key to Carotenoids. 1987. 296

16. Cogdell, R.J., Carotenoids in Photosynthesis. Pure Appl. Chem, 1985. 57: p. 723728.

17. Koyama, and Yasushi, Configurations of Carotenoids in the Reaction Center and the Light-Harvesting Complex of Rhodospirillum rubrum. Natural Selection of Carotenoid Configurations by Pigment Protein Complexes. Phtochemistry and photobiology, 1990. 51: p. 119-128.

18. Scott, J.K., Thurnham, D.I., Hart, D.J., Bingham, S.A., The correlation between the intake of lutein, lycopene and $\beta$-carotene from vegetables and fruits and blood plasma concentrations in a group of women aged 50-65 years in the U.K. . Br. J. Nutr., 1996. 75: p. 409-418.

19. Khachik, F., Beecher, G.R., and Smith, J.C., Jr., Lutein, Lycopene, and Their Oxidative Metabolites in Chemoprevention of Cancer. Cell. Biochem. Supplement, 1995. 22: p. 236-246.

20. Khachik, F., Bernstein, P.S., and Garland, D.L., Identification of Lutein and Zeaxanthin Oxidation Products in Human and Monkey Retinas. Invest. Ophthalmol. Vis. Sci., 1997. 38: p. 1802-1810.

21. Khachik, F., Spangler, C.J., Smith, J.C., Identification, quantification, and relative concentrations of carotenoids and their metabolites in human milk and serum. Anal Chem, 1997. 69(10): p. 1873-81.

22. Bone, R.A., Landrum, J. T, Analysis of the Macular Pigment by HPLC: Retinal Distribution and Age Study. Invest. Ophthalmol. Vis. Sci., 1988. 29: p. 843-849.

23. Landrum, J.T., Bone, R.A. and Kilburn, M.D. The Macular Pigment: a possible role in protection from age-related macular degeneration, in Adv. in Pharmacology, H. Sies, Editor. 1997, Academic Press: San Diego. p. 537-556.

24. Schalch, W., Dayhaw-Barker, P. and Barker, F.M. The carotenoids of the human retina. Nutritional and Environmental Influences on the Eye, ed. A. Taylor. 1999, Boca Raton: CRC. 215-250.

25. Landrum, J.T., Bone, R. A., A One Year Study of the Macular Pigment: The Effect of 140 Days of a Lutein Supplement. Exp. Eye Res., 1997. 65: p. 57-62. 
26. Landrum, J.T., Bone, R.A., Vidal, T., Menendez, E., and Kilburn, M., Macular pigment stereoisomers in individual eyes: A comparison between normals and those with age-related macular degeneration. . Invest. Ophthalmol. Vis. Sci, 1995. 19: p. 875-863.

27. Snodderly, D.M., Evidence for protection against age-related macular degeneration by carotenoids and antioxidant vitamins. Am. J. Clin. Nutr., 1995. 62: p. 1448-1461.

28. Seddon, J.M., Dietary Carotenoids, vitamins $A, C$, and $E$ and advanced agerelated macular degeneration. JAMA, 1994. 272: p. 1413-1420.

29. Bone, R.A., Landrum, J.T. and Tarsis, S.L. Preliminary Identification of the Human Macular Pigment. Vision Res., 1985. 25: p. 1531-1535.

30. Wang, W., Isolation and Identification of Zeaxanthin and Lutein from Human and Chicken Tissues, in Chemistry and Biochemistry. 1993, Florida International University: Miami. p. 9.

31. Bone, R.A., Landrum, J.T., Stereochemistry of the Human Macular Carotenoids. Invest. Ophthalmol. Vis. Sci., 1993. 34: p. 2033-2040.

32. Handelman, G.J., Biological control of primate macular pigment. Biochemical and densitometric studies. Invest Ophthalmol Vis Sci, 1991. 32(2): p. 257-67.

33. Johnson, E.J., Neuringer, M., Russell, R.M., Schalch, W., and Snodderly, M.D., Nutritional Manipulation of Primate Retinas, III: Effects of Lutein or Zeaxanthin Supplementation on Adipose Tissue and Retina of Xanthophyll-Free Monkeys. Invest Ophthalmol Vis Sci., 2005. 46: p. 692-702.

34. Entschel, R., Helv. Chim. Acta, 1959. 42: p. 466-472.

35. Britton, G. UV/Visible Spectroscopy., in Carotenoids, G.Britton, S.Liaaen-Jensen, and H.Pfander, Editors. 1995. p. 13-62.

36. Chi, J., Oxidation of Zeaxanthin by $\mathrm{MnO2}$, in Department of Chemistry and Biochemistry. 2001, Florida International University.

37. Moreno, C., The Reaction of Lutein with Mild Chemical Oxidants: Understanding Lutein Metabolism., in Chemistry and Biochemistry. 2001, Florida International University: Mimai. p. 30-31.

38. Britton, G. UV/Visible Spectroscopy, in Carotenois, G.Britton, S.Liaaen-Jensen, and H.Pfander, Editors. 1995. p. 142-260. 
39. Silverstein R.M. and Webster, F.X. Proton Magnetic Resonance Spectrometry, in Spectrometric Identification of Organic Compound, R.M.Silverstein and F.X.Webster, Editors. 1997. p. 214.

40. Williams, R.J.H., Britton, G. and Goodwin, T.W. Biochem, Biophys, Acta, 1966. 124: p. 200-203.

41. Britton, G. Chemistry and Biochemistry of Plant Pigment, in Biosynthesis of Carotenoids, T.W. Goodwin, Editor. 1976. p. 262-327.

42. Andrew, A.G., Absolute Configuration of Eschscholtzxanthin. Phytochemistry 1979. 18: p. 303-309.

43. Englert, G. and Vecchi, M., J. Chromatogr., 1982. 235: p. 197.

44. Foote, C.S., Chang, Y.C., and Denny, R.W., Chemistry of Singlet Oxygen. X. Carotenoid Quenching Parallels Biological Protection. J. Am. Chem. Soc., 1970. 92: p. 5216-5218.

45. Krinsky, N.I., Antioxidant Functions of Carotenoids. Free Radic. Biol. Med., 1989. 7: p. 617-635.

46. Palozza, P. and Krinsky, N.I., Antioxidant Effects of Carotenoids in Vivo and in Vitro: An Overview. Methods in Enzymology, 1992. 213: p. 403-420.

47. Chen, Y., A Study of Carotenoids Uptake in Human Subjects and Their Metabolites, in Chemistry and Biochemistry. 1999, Florida International University. p. 5-7.

48. Landrum, J.T., and Bone, R.A., A Preliminary Study of the Stereochemistry of Human Lens Zeaxanthin. Invest. Ophthalmol. Vis. Sci., 1997. 38: p. S1026.

49. Skoog, Holler, and Neiman, Principle of Instrumental Analysis. 5th ed

50. Handelman, G.J., and Snodderly, D.M., Carotenoids in the human macula and whole retina. Invest. Ophthalmol. Vis. Sci, 1988. 29: p. 850-855.

51. Bone, R.A., and Landrum, J.T., Distribution of Lutein and Zeaxanthin Stereoisomers in the Human Retina. Exp. Eye Res., 1997. 64: p. 211-218.

52. Bone, R.A. and Landrum, J.T. Meth. Enzymol, 1992. 213: p. 360.

53. Bhosale, P., Identification of 3-Methoxyzeaxanthin as a Novel,Age-Related Carotenoid Metabolite in the Human Macula. Invest Ophthalmology Vis. Sci., 2006. 
54. Widemer, E., Technische Verfahren zur Synthese von Carotinoiden und verwandten Verbindungen aus 6-Oxo-isophoron. VII. Synthese von Rhodoxanthin und (3 RS, 3' RS)-Zeaxanthin aus der C15-Ringkomponente. Helvetica Chimica Acta, 1982. 65: p. 958-967. 